Aus dem Institut für Klinische Pharmakologie

(Prof. Dr. med. J. Brockmöller)

der Medizinischen Fakultät der Universität Göttingen

\title{
Molekular-genetische Prädiktoren der Toxizität einer neo-adjuvanten Radiochemotherapie am Beispiel des Rektumkarzinoms
}

\author{
INAUGURAL - DISSERTATION \\ zur Erlangung des Doktorgrades \\ der Medizinischen Fakultät der \\ Georg-August-Universität zu Göttingen
}

vorgelegt von

Caroline Patricia Nadine Mergler aus Bad Soden i. Ts. 
Dekan:

Referent:

Ko-Referent:

Drittreferentin:
Prof. Dr. med. H. K. Kroemer

PD. Dr. M. Schirmer

Prof. Dr. T. Liersch

Prof. Dr. M. Schön

Datum der mündlichen Prüfung: 27.02.2019 
Hiermit erkläre ich, die Dissertation mit dem Titel

" Molekular-genetische Prädiktoren der Toxizität einer neo-adjuvanten Radiochemotherapie am Beispiel des Rektumkarzinoms" eigenständig angefertigt und keine anderen als die von mir angegebenen Quellen und Hilfsmittel verwendet zu haben.

Göttingen, den 


\section{Inhaltsverzeichnis}

II ABKÜRZUNGSVERZEICHNIS ......................................................................... iv

III TABELLENVERZEICHNIS ............................................................................. vii

IV ABBILDUNGSVERZEICHNIS ................................................................. viii

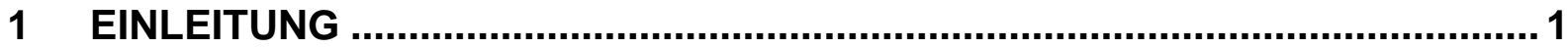

$1.1 \quad$ Rektumkarzinom .....................................................................................................................................................

$1.2 \quad$ Therapie des Rektumkarzinoms...............................................................................................................1

$1.3 \quad$ Toxizität der Radiochemotherapie .....................................................................................................................2

1.4 TGFB-Signalweg ...........................................................................................................................................2

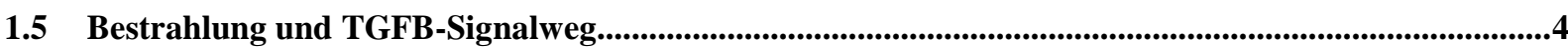

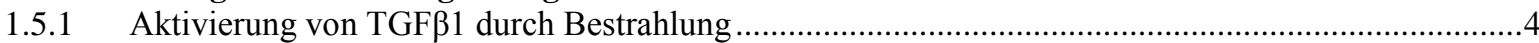

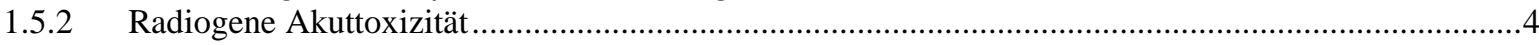

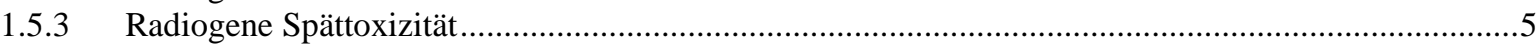

1.6 Radiotoxizität und genetische Variabilität im TGFB-Signalweg...................................................................5

1.7 Zellbiologische Prädiktoren der Radiotoxizität ......................................................................................................

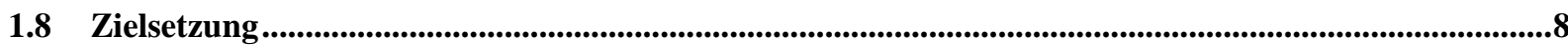

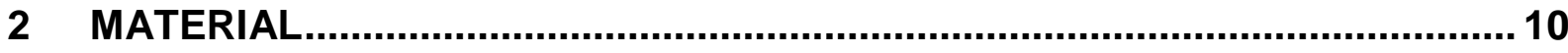

2.1 Geräte................................................................................................................................................................................10

2.2 Verbrauchsmaterialien...........................................................................................................................11

2.3 Chemikalien............................................................................................................................................12

2.4 Kits und Assays .............................................................................................................................................13

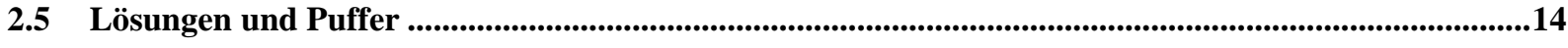

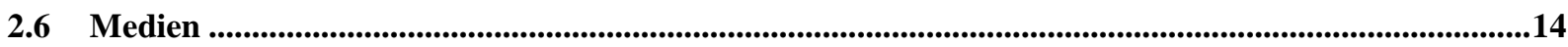

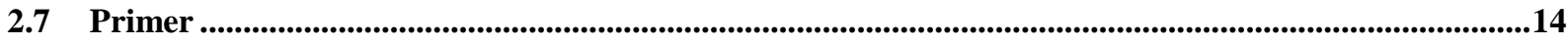

2.8 Software .........................................................................................................................................................................20

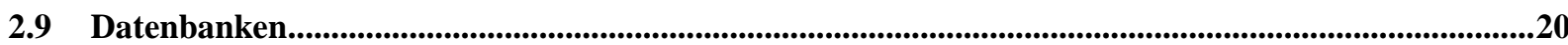




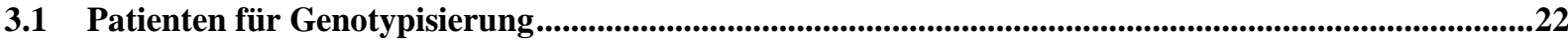

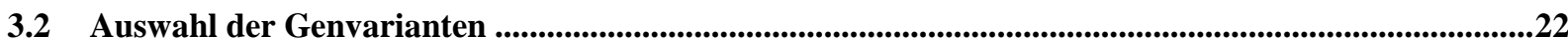

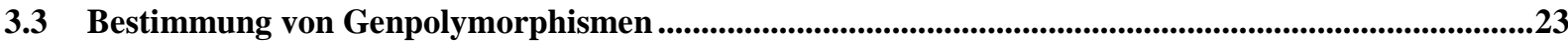

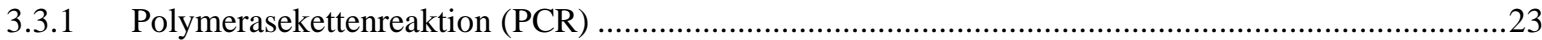

3.3.2 Bestimmung von Genotypen mittels Primerextentionsverfahren ..................................................24

3.3.3 Fragmentlängenanalyse einer 9-bp-Deletion im TGFBR1( $* 6 A)$.................................................27

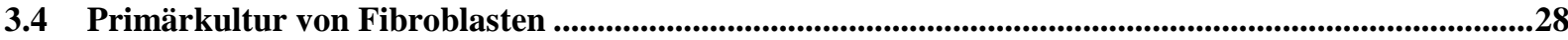

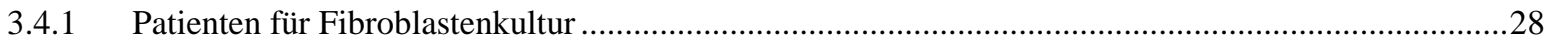

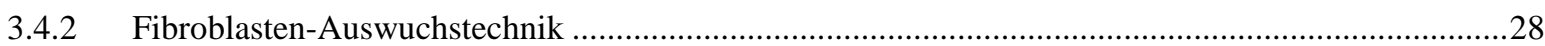

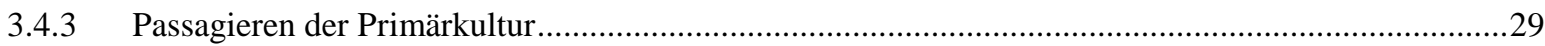

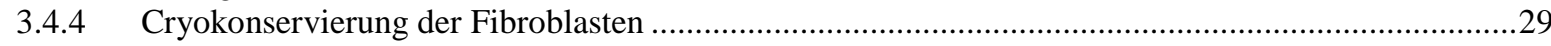

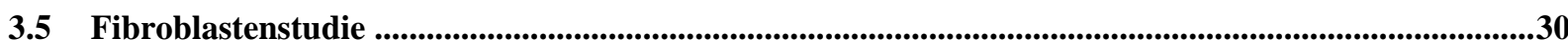

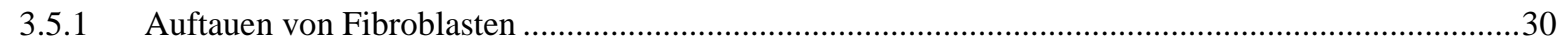

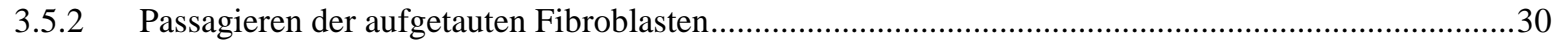

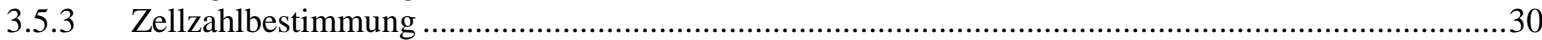

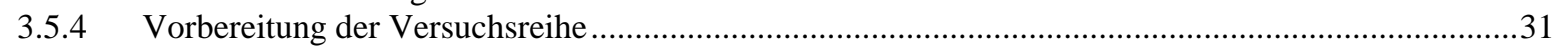

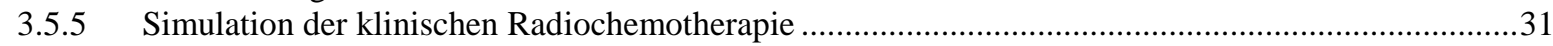

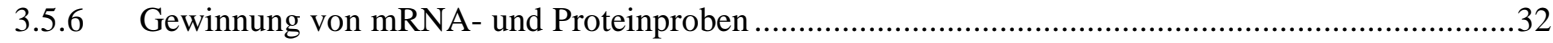

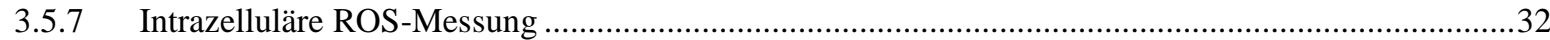

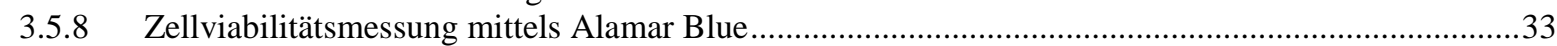

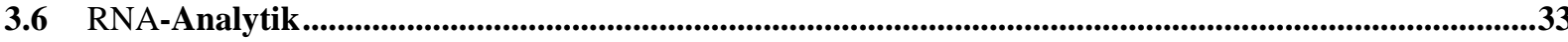

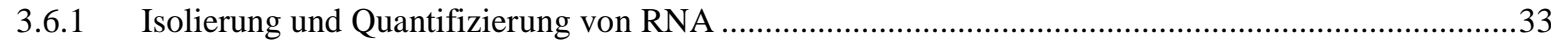

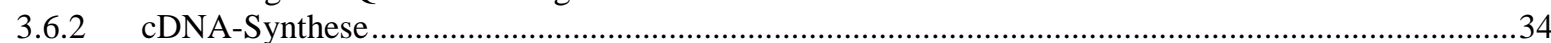

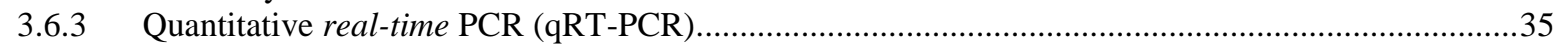

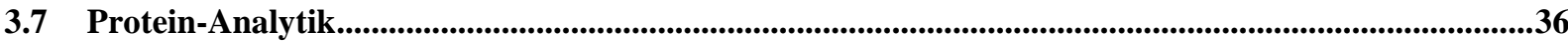

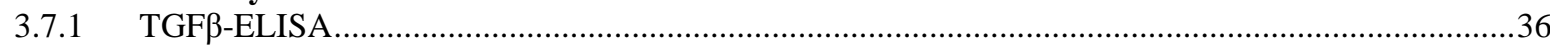

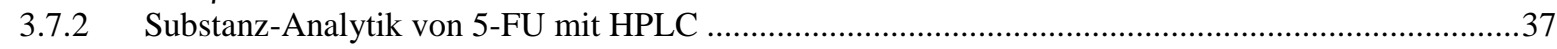

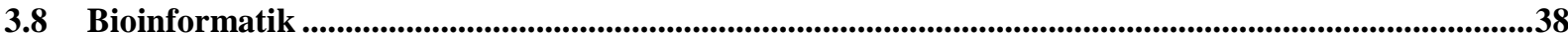

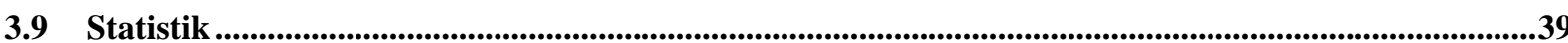

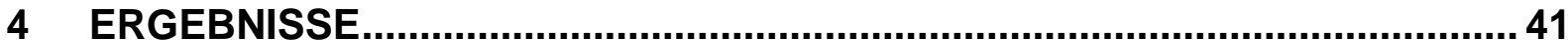

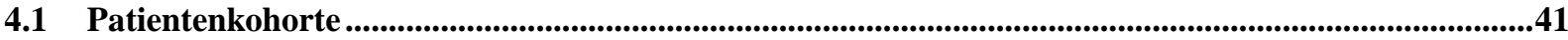

4.2 Häufigkeitsverteilung der Radiotoxizität...........................................................................................42

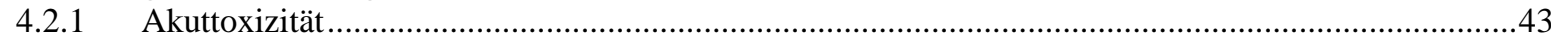

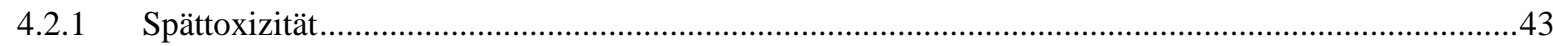

4.3 Testung vorbeschriebener genetischer Marker im TGF $\beta$-Signalweg in Bezug auf die beobachtete Radiotoxizität.

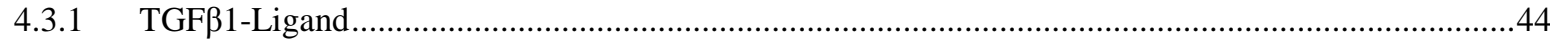

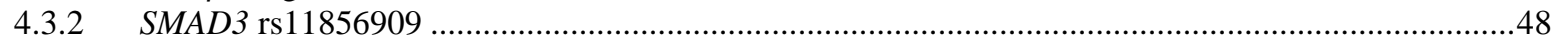

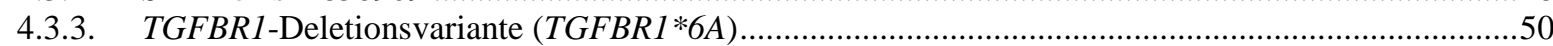

4.4 Umfassende Analyse der genetischen Variabilität im TGF $\beta$-Signalweg in Bezug auf die beobachtete

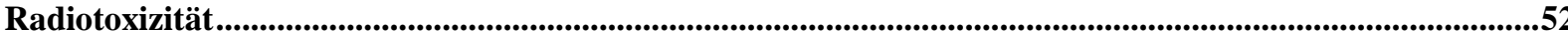

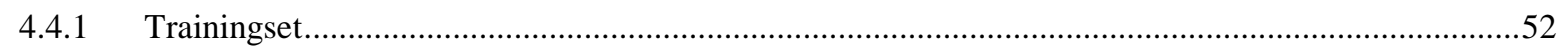

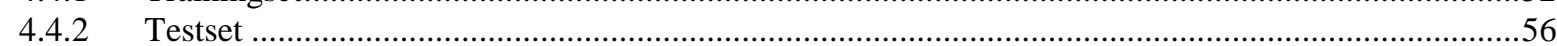

4.5 Kombinierte Betrachtung von TGF $\beta$-Signalweg-Polymorphismen in Bezug auf die beobachtete Radiotoxizität 
4.6 TGF $\beta$-Signalweg-Genexpression im Therapieverlauf .............................................................................60

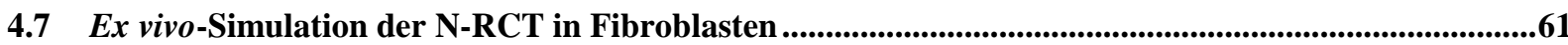

4.7.1 Expression von Kandidatengenen im Behandlungsverlauf ...................................................61

4.7.2 Gentranskription in Fibroblasten und klinische Toxizität .....................................................66

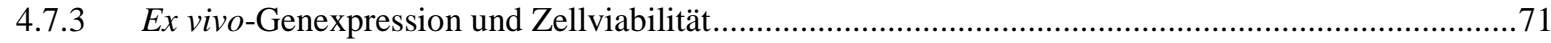

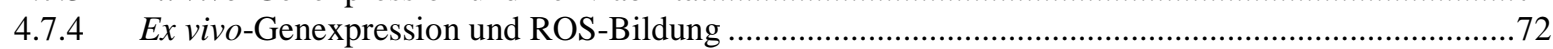

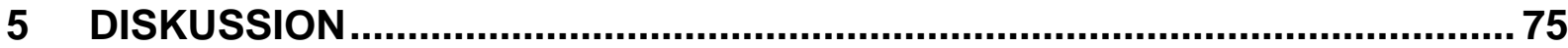

5.1 Arg25Pro-Polymorphismus in TGFß1 .......................................................................................................75

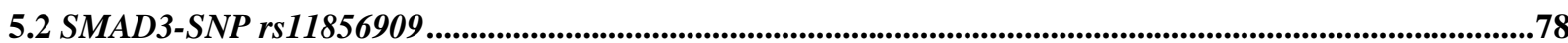

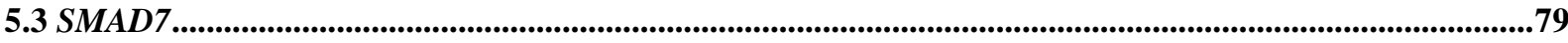

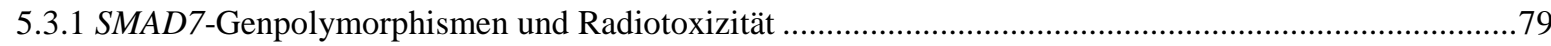

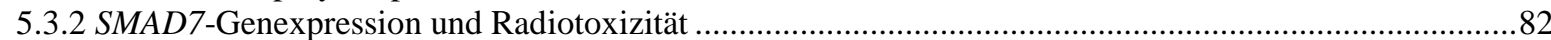

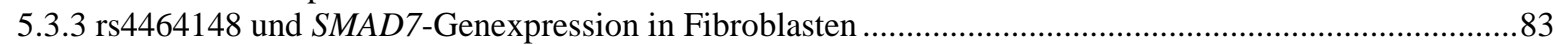

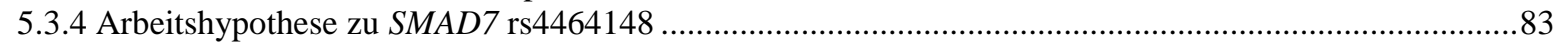

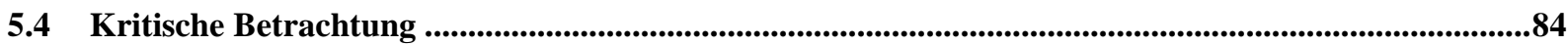

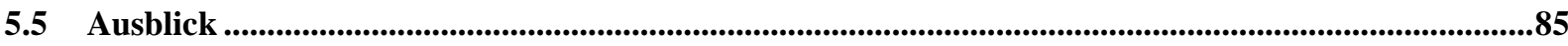

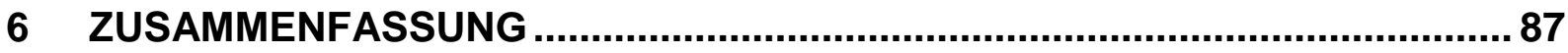

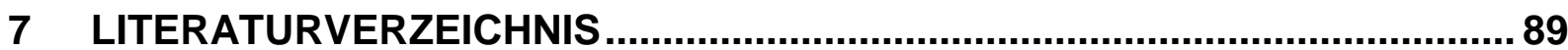




\section{Abkürzungsverzeichnis}

A

ALK

AOTkomb

AS

BMI

bp

bzw.

$\mathrm{C}$

cDNA

CEA

$\mathrm{CO}_{2}$

CTC

CTCAE

CTGF

$\mathrm{CU}$

DCFH-DA

$\mathrm{ddH}_{2} \mathrm{O}$

ddNTP

DMSO

DNA

dNTP

dsDNA

EDTA

ELISA

Exo

FAM

FCS

5-FU

G

g

GAPDH

Gy

$\mathrm{h}$
Adenin

Activin receptor-like kinase

Kombinierte Organtoxizität

Aminosäure

Body mass index

Basenpaare

beziehungsweise

Cytosin

komplementäre oder copy DNA

Carcinoembryonales Antigen

Kohlendioxid

Common Toxicity Criteria

Common Toxicity Criteria for Adverse Events

Connective tissue growth factor

Chlorouracil

Dichlorofluorescein-Diacetat

(doppelt destilliertes) Wasser

Didesoxynukleosidtriphosphat

Dimethylsulfoxid

Desoxyribonucleic Acid, Desoxyribonukleinsäure

Desoxynukleosidtriphosphat

doppelsträngige DNA

Ethylen Diamin Tetraacetic Acid

Enzyme Linked Immunosorbent Assay

Exonuklease

6-Carboxyfluorescein

Fetal Calf Serum, fetales Kälberserum

5-Fluorouracil

Guanin

Erdbeschleunigung $\left(9,81 \mathrm{~m} / \mathrm{s}^{2}\right)$

Glycerinaldehyd-3-Phosphat-Dehydrogenase

Gray

Stunde 


\begin{tabular}{|c|c|}
\hline $\mathrm{HCl}$ & Chlorwasserstoff \\
\hline HPRT1 & Hypoxanthin-Phosphoribosyltransferase-1 \\
\hline HPLC & high performance liquid chromatography \\
\hline HRP & Horseradish peroxidase \\
\hline $\mathrm{k}$ & Kilo \\
\hline $\mathrm{kbp}$ & Kilobasenpaare \\
\hline $\mathrm{kV}$ & Kilovolt \\
\hline LAP & latency-associated peptide \\
\hline LD & paarweises Kopplungsungleichgewicht \\
\hline LENT-SOMA & $\begin{array}{l}\text { Late Effects of Normal Tissue - Subjective, Objective, } \\
\text { Management, Analytic }\end{array}$ \\
\hline M & $\mathrm{mol} / \mathrm{l}$ \\
\hline $\mathrm{mA}$ & Milliampere \\
\hline$\mu l$ & Mikroliter \\
\hline $\min$ & Minute \\
\hline $\mathrm{mg} / \mathrm{ml}$ & Milligramm / Milliliter \\
\hline $\mathrm{NaCl}$ & Natriumchlorid \\
\hline $\mathrm{NaOH}$ & Natriumhydroxid \\
\hline NCBI & National Center for Biotechnology Information \\
\hline $\mathrm{ng} / \mathrm{nm}$ & Nanogramm / Nanometer \\
\hline NSAID & Nichtsteroidales Antiphlogistikum \\
\hline $\mathrm{N}-\mathrm{RCT}$ & Neoadjuvante Radiochemotherapie \\
\hline $\mathrm{p}$ & Signifikanzniveau \\
\hline PBS & Phosphate-Buffered Saline, Phosphat-gepufferte Salzlösung \\
\hline PCR / qRT-PCR & $\begin{array}{l}\text { Polymerase Chain Reaction, Polymerasekettenreaktion / } \\
\text { quantitative Echtzeit-PCR }\end{array}$ \\
\hline $\mathrm{pH}$ & pondus Hydrogenii \\
\hline$r / r^{2}$ & Korrelationskoeffizient / Bestimmtheitsmaß \\
\hline $\mathrm{RCT}$ & Radiochemotherapie \\
\hline RNA & Ribonukelinsäure \\
\hline mRNA & messenger Ribonucleic Acid, Boten-Ribonukleinsäure \\
\hline RNAse & Ribonuklease \\
\hline ROS & reactive oxygen species, reaktive Sauerstoffspezies \\
\hline rpm & rotations per minute, Umdrehungen pro Minute \\
\hline RT & Raumtemperatur \\
\hline
\end{tabular}


S

SAP

$S M A D$

SNP

$\mathrm{T}$

$\mathrm{TE}$

$T G F B$

TMB

Tris

$\mathrm{U}$

UICC

UTR

$\mathrm{v} / \mathrm{v}$

WHO
Sekunde

Shrimp alkalic phosphatase

mothers against decapentaplegic homolog

Single Nucleotide Polymorphism, Einzelnukleotid-

Polymorphismus

Thymin

Tris-EDTA-Puffer

Transforming growth factor beta

Tetramethylbenzidin

Tris-Hydroxymethyl-Aminomethan

Unit (Einheit für Enzymaktivität)

Union inteRNAtionale contre le cancer

untranslated region, nicht abgelesener Bereich auf der mRNA

volume per volume (Volumen pro Volumen)

World Health Organization

Bezeichnungen von Allelen bzw. Gennamen als Nukleinsäuren (DNA oder RNA) erscheinen im Text in kursiver, die entsprechenden Proteinprodukte in normaler Schrift. 


\section{Tabellenverzeichnis}

Tab. 1 Klassifikation der Tumorstadien nach UICC 1

Tab. 2 Für die Genotypisierung verwendete Primer ......................................................................... 185

Tab. 3 Primer für quantitative real-time PCR (qRT-PCR). ................................................................. 19

Tab. 4 Kandidatengene mit Anzahl untersuchter Genvarianten (SNPs) ..............................................22

Tab. 5 Pipettierschema der Multiplex-PCRmit Q-Solution bei Pool I,II,III sowie SMAD3 und ohne Q-

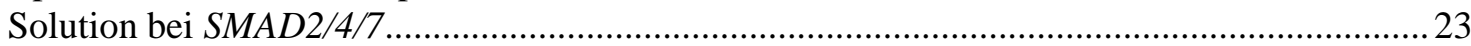

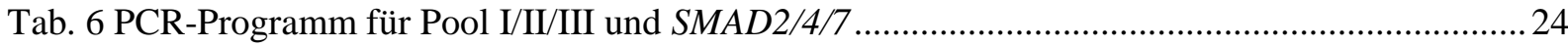

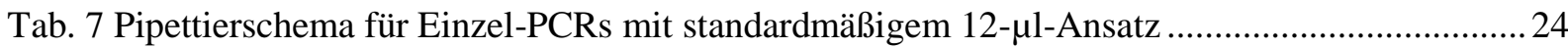

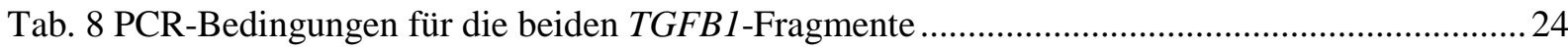

Tab. 9 Zusammensetzung des Verdaumixes zur Aufreinigung von PCR-Produkten ...........................25

Tab. 10 Reaktionsansatz für SNaPshot ${ }^{\mathrm{TM}}$-PCR (auf Eis pipettiert) ...................................................25

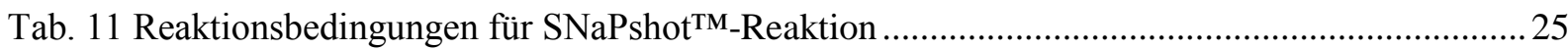

Tab. 12 Fluoreszenz-Markierungen der verwendeten ddNTPs für die SNaPshot ${ }^{\mathrm{TM}}$-Reaktion ..............26

Tab. 13 Pipettierschema für Einzel-PCR der TGFBRI-Deletionsvariante ……....................................28

Tab. 14 PCR-Programm zur Amplifikation des Sequenzbereichs der TGFBR1-Deletionsvariante .......28

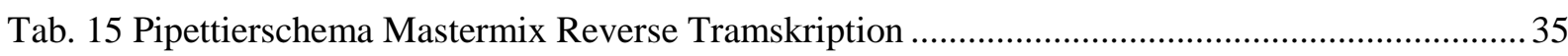

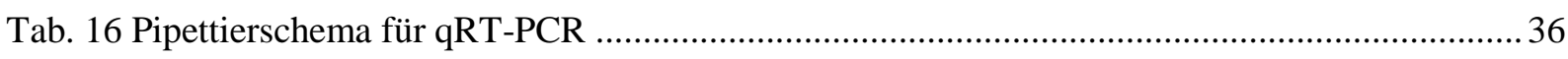

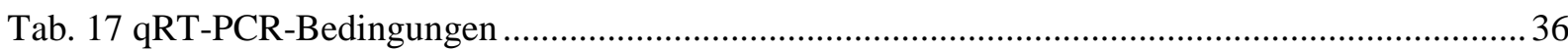

Tab. 18 Verteilung der Patienten- und Tumorcharakteristika in den Studien-Kohorten........................ 42

Tab. 19 Verteilung der Einzelorgan-Akuttoxizitäten in den Studienkohorten ....................................... 43

Tab. 20 Verteilung der Einzelorgan-Spättoxizitäten in den Studienkohorten .........................................4 44

Tab. 21 Analyse von vorbeschriebenen Genpolymorphismen in Bezug auf die beobachtete

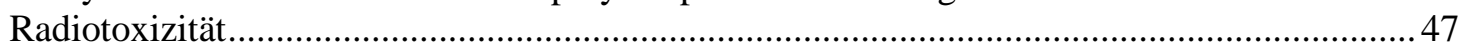

Tab. 22 Regressionsmodelle zur Adjustierung des Effektes von rs1800471 …....................................48

Tab. 23 Verteilung der Akuttoxizität in der Gesamtkohorte in Abhängigkeit von rs11856909 ............49

Tab. 24 Regressionsmodelle zur Adjustierung des Effektes von rs1 1856909 ......................................50

Tab. 25 Verteilung der Darmtoxizität in der Gesamtkohorte in Abhängigkeit von rs11856909 ...........50

Tab. 26 Verteilung der Akuttoxizität in der Gesamtkohorte in Abhängigkeit von TGFBRI *6A ..........51

Tab. 27 Regressionsmodelle zur Adjustierung des Effektes von TGFBRI 6 A ....................................51

Tab. 28 Explorative Testung von 67 Genvarianten in Bezug auf die beobachtete Radiotoxizität........553

Tab. 29 SNP-Assoziationen mit Akuttoxizität in den untersuchten Patientenkohorten ..........................57

Tab. 30 Verteilung der Akuttoxizität in der Gesamtkohorte in Abhängigkeit von rs12967477. ...........57

Tab. 31 Regressionsmodelle zur Adjustierung des Effektes von rs12967477 .....................................57

Tab. 32 Regressionsmodelle zur Adjustierung des Effektes von rs2878889 .......................................58

Tab. 33 SNP-Assoziationen mit Spättoxizität in den untersuchten Patientenkohorten...........................58

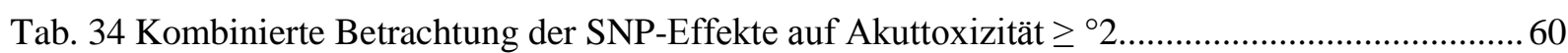

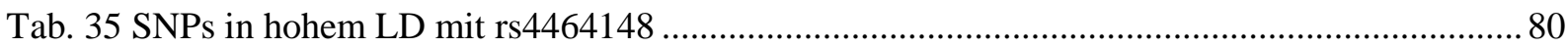




\section{Abbildungsverzeichnis}

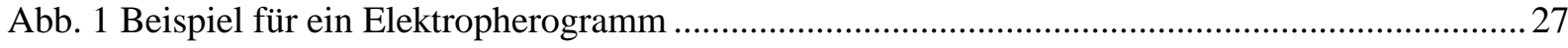

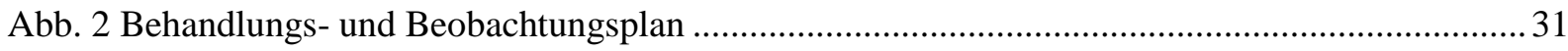

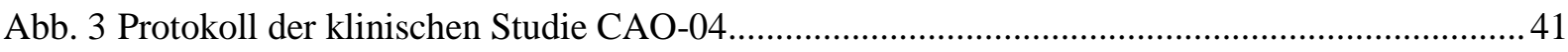

Abb. 4 Architektur des TGFB1-Gens und Kopplungsplot der analysierten Polymorphismen .............. 46

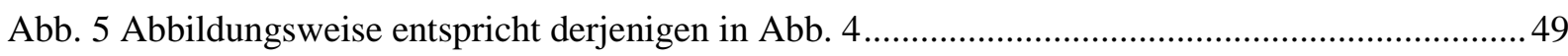

Abb. 6 Expression ausgewählter Kandidatengene im Blut im Verlauf einer Radiochemotherapie........61

Abb. 7 Expressionsverlauf von neun Kandidatengenen nach in vitro-Simulation von N-RCT in

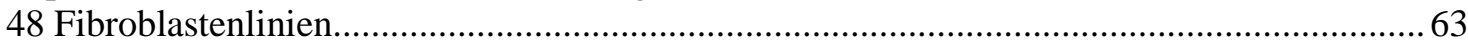

Abb. 8 Zeitverlauf der Gentranskription unter simulierter N-RCT in Fibroblasten................................ 65

Abb. 9 Verteilung von Akut- und Spättoxizität der Patienten mit ex vivo-Analysen an Fibroblasten ... 66

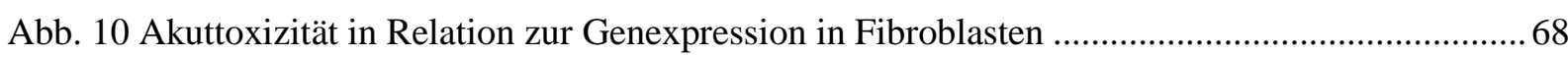

Abb. 11 Assoziation von ex vivo-Gentranskription im Zeitverlauf und klinischer Akuttoxizität...........69

Abb. 12 Spättoxizität in Relation zur Autoinduktion von TGFB1 in Fibroblasten................................ 70

Abb. 13 Einfluss von Bestrahlung und TGF $\beta$ auf die Zellviabilität ....................................................... 71

Abb. 14 Einfluss von Bestrahlung und TGF $\beta 1$ auf die ROS-Bildung .................................................... 73

Abb. 15 Korrelation von oxidativem Stress mit der Expression von $C A T$ und $C T G F$.......................... 73

Abb. 16 Bestrahlungs-bedingte Veränderungen der SMAD7-Expression und der ROS-Bildung........... 74

Abb. 17 Durch Bestrahlung veränderte SMAD3-Transkription in Abhängigkeit von rs11856909........ 79

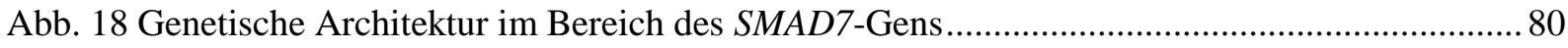

Abb. 19 Durch Bestrahlung veränderte SMAD7-Transkription in Abhängigkeit von rs4464148.......... 83 


\section{Einleitung}

\subsection{Rektumkarzinom}

Definitionsgemäß zählen zu den Rektumkarzinomen diejenigen bis $16 \mathrm{~cm}$ Abstand von der Anokutanlinie. Sie werden weiterhin unterteilt in Karzinome des oberen $(12-16 \mathrm{~cm})$, des mittleren $(6-12 \mathrm{~cm})$ und des unteren Rektumdrittels (<6 cm). Im Jahr 2011 lag die Anzahl der Neuerkrankungen am Rektumkarzinom in Deutschland bei etwa 19.159 Personen (11.760 Männer und 7.399 Frauen), was ca. 4\% aller Krebsneuerkrankungen ausmacht (http://www.krebsdaten.de). Die männliche Sterblichkeit im entsprechenden Berichtsjahr belief sich auf 4702, die weibliche auf 3226 Personen.

In dieser Arbeit wurden nur Patienten mit unterem oder mittlerem Rektumkarzinom berücksichtigt, da nur bei dieser Lokalisation nach aktuellem medizinischem Standard eine neoadjuvante Radiochemotherapie durchgeführt wird.

\subsection{Therapie des Rektumkarzinoms}

Für die Therapieentscheidung ist das UICC-Stadium wesentlich:

Tab. 1 Klassifikation der Tumorstadien nach UICC

\begin{tabular}{llll}
\hline Stadium & Primärtumor & Lymphknotenstatus & Fernmetastasen \\
\hline $\mathbf{0}$ & Tis & N0 & M0 \\
I & T1, T2 & N0 & M0 \\
IIA & T3 & N0 & M0 \\
& T3a $(<1 \mathrm{~mm})$ & & \\
& T3b $(1-5 \mathrm{~mm})$ & & \\
& T3c $(5-15 \mathrm{~mm})$ & & M0 \\
IIB & T3d $(>15 \mathrm{~mm})$ & $\mathrm{N} 0$ & M0 \\
IIIA & T4 & N1 $(1-3$ betroffene LK) & M0 \\
IIIB & T1-2 & N1 $(1-3$ betroffene LK) & M0 \\
IIIC & T3-4 & N2 $(4$ betroffene LK $)$ & M1 \\
IV & Alle T & Alle N & M T
\end{tabular}

Das im mittleren bzw. unteren Rektumdrittel lokalisierte Karzinom wird heute in den UICCStadien II und III (bei kurativem Therapiekonzept auch im Falle singulärer oder oligomerer Fernmetastasen auch im Stadium IV) multimodal therapiert:

Die Therapie besteht aus einer Kombination von Strahlen- und Chemotherapie vor der Operation, für welche das Zytostatikum 5-Fluoruracil (5-FU) Standard ist. Die Chemotherapie wird in diesem kombinierten Setting in geringerer Dosierung als bei alleiniger Gabe eingesetzt und dient als Radiosensitizer. In den letzten Jahren wurde durch mehrere Studien (Nagtegaal et al. 2007; Rodel und Sauer 2007; Sauer et al. 2004) bestätigt, dass die lokale Tumorkontrolle verbessert ist, wenn die kombinierte Radiochemotherapie (N-RCT) vor Operation anstatt danach appliziert wird. 
Obwohl mit diesem Vorgehen gute Ergebnisse bei der lokalen Kontrolle erreicht wurden, verbesserte sich das Langzeitüberleben nicht in gleichem Maße (Sauer et al. 2004; Sauer et al. 2012; Sebag-Montefiore et al. 2009). Daher gibt es Bestrebungen, die Chemotherapie zu intensivieren. Der aktuell am stärksten verfolgte Ansatz besteht in der Hinzunahme von Oxaliplatin zu 5-FU bei der N-RCT. Mit diesem Regime wurde von verbesserten Tumorregressionsraten berichtet (Aschele et al. 2005; Machiels et al. 2005). Durch die Intensivierung stiegen jedoch die Therapie-bedingten Toxizitäten (Rodel und Sauer 2007).

\subsection{Toxizität der Radiochemotherapie}

Bei den zu erwartenden Toxizitäten der kombinierten Behandlungsmodalitäten sind sowohl die einzelnen Komponenten als auch sich gegenseitig verstärkende Effekten zu berücksichtigen. Gegebenenfalls ist eine Dosisreduktion oder sogar ein Therapieabbruch erforderlich. Schwere Akuttoxizitäten mit Grad 3 oder 4 nach CTC wurden dabei bei 27\% im Falle der präoperativen N-RCT im Vergleich zu $40 \%$ bei postoperativer Radiochemotherapie (RCT) beobachtet (Sauer et al. 2004). Die durch 5-FU bedingten Nebenwirkungen sind zumeist hämatologischer Art und in der Regel passager. Seltener, aber gefährlicher ist die potenzielle Kardiotoxizität von 5-FU. Für die Inzidenz schwerer Langzeittoxizitäten wurde eine Rate von $14 \%$ bzw. $24 \%$ berichtet, wenn die Radiochemotherapie vor bzw. nach der OP durchgeführt wurde (Sauer et al. 2004). Langfristige Beeinträchtigungen (chronische Entzündungen und Fibrosen von Blase, Darm, Haut und Bindegewebe) sind in der Regel Folge der Strahlentherapie. Möglicherweise werden diese durch die Chemotherapie noch verstärkt. Für die Entstehung von Fibrosen wird ein Zusammenhang mit dem Transforming Growth Factor Beta (TGFB)-Signalweg angenommen (Dent et al. 2003).

\subsection{TGFB-Signalweg}

Der TGFB-Signalweg, benannt nach dem Liganden TGF $\beta$, ist an vielen unterschiedlichen zellulären Prozessen beteiligt. $\mathrm{Zu}$ den wichtigsten gehören die Embryogenese, Zelldifferenzierung, Proliferation und Apoptose (Derynck und Zhang 2003; Massague 2000). Pathophysiologisch kommt diesem Signalweg eine wichtige Bedeutung bei fibrotischen Reaktionen zu (Border und Noble 1994). Mechanistisch kommt es bei Fibrosierungen u. a. zu einer vermehrten Produktion von Bindegewebsmatrix-Komponenten wie Kollagenen. CTGF (connective tissue growth factor) agiert dabei als Downstream-Mediator des TGF $\beta$ Signalwegs (Chujo et al. 2005; Duncan et al. 1999).

Das Zytokin TGF $\beta$ bindet als Ligand an Rezeptoren auf der Zelloberfläche und beeinflusst über intrazelluläre Faktoren die Gentranskription im Zellkern (Itoh et al. 2000; Massague 
1998; Moustakas et al. 2001). Von den drei TGF $\beta$-Isoformen (Homologie in der Aminosäuresequenz 64-85\%) (Massague 1990), von denen alle pro-fibrotische Wirkungen haben (Yu et al. 2003), ist TGF $\beta 1$ am besten untersucht. TGF $\beta 1$ wird ubiquitär exprimiert, vor allem jedoch in Bindegewebe, Endothel und in hämatopoetischen Zellen (Blobe et al. 2000). In Darmepithelien wird TGF $\beta 1$ besonders stark von terminal differenzierten Zellen exprimiert (BaRNArd et al. 1989). TGFß1 wird zunächst als ein Propeptid mit 390 Aminosäuren (AS) translatiert, wovon die 29 N- terminalen AS ein Signalpeptid darstellen, auf welches 249 AS für LAP (latency-associated peptide) folgen. Die 112 C-terminalen AS bilden das reife TGF $\beta 1$. Das hierfür kodierende Gen liegt auf Chromosom 19q13.1 und hat eine Länge von $26,2 \mathrm{kbp}$.

Die primäre Bindung von TGF $\beta$-Liganden auf der Zelloberfläche erfolgt an Typ-IIRezeptoren (TGFßR2). Durch die Bindung werden die Rezeptoren phosphoryliert und aktivieren danach Typ-I-Rezeptoren (TGF $\beta$ R1), ebenfalls durch Phosphorylierung (Miyazono et al. 2001). Diese beiden Rezeptor-Typen sind für die Bindung des TGF $\beta 1$-Liganden essentiell (Karlsson et al. 2005). Zusätzlich ist für einige Zelltypen noch ein Typ-III-Rezepor bekannt, der TGF $\beta$ binden und dem Typ-II-Rezeptor präsentieren kann (Blobe et al. 2000).

Die intrazelluläre Signalweitergabe erfolgt dann über die sogenannten SMAD-Moleküle (mothers against decapentaplegic homolog). Sie werden in drei Gruppen unterteilt, die regulatorischen (rSMADs), die inhibitorischen (iSMADs) und SMAD4 als co-aktivatorisches SMAD. Diese sind ein gemeinsames Merkmal der zur TGFß-Superfamilie zählenden Signaltransduktionswege. Bei dem Signalweg, bei welchem TGF $\beta$-Proteine als Liganden fungieren, erfolgt die intrazelluläre Signalweitergabe über die beiden regulatorischen Proteine SMAD2 und SMAD3, unterstützt von SMAD4. SMAD7 inhibiert dabei diese Signaltransduktion (Attisano und Wrana 2002; ten Dijke und Hill 2004). Komplexe aus SMAD2 und 3 mit dem SMAD4 gelangen in den Zellkern und wirken dort als Transkriptionsfaktoren, welche die Expression spezifischer Gene vermitteln, u. a. des oben genannten $C T G F$. An diesen Prozessen können noch weitere Proteine beteiligt sein. SMAD7 kann sowohl am TGF $\beta R$ 1-Rezeptor die Phosphorylierung und damit Aktivierung von SMAD2 bzw. 3 inhibieren als auch deren Bindung an SMAD4 antagonisieren (Hayashi et al. 1997; Nakao et al. 1997). SMAD3 scheint eine wichtige Rolle bei fibrotischen Prozessen zu spielen. Mäuse mit einem Knock-out von SMAD3 zeigten sich vergleichsweise resistent gegenüber Strahlen-induzierter Fibrose der Haut (Flanders 2004). Möglicherweise könnten SMAD3-Inhibitoren Fibrosen vermindern (Roberts et al. 2001). Jedoch konnte ein klinischer Einsatz für solche Substanzen bislang nicht etabliert werden. 


\subsection{Bestrahlung und TGFB-Signalweg}

\subsubsection{Aktivierung von TGF $\beta 1$ durch Bestrahlung}

Unter physiologischen Bedingungen liegt nahezu das gesamte TGF $\beta$ inaktiv in Komplexgebundener Form vor. Neben einem sauren pH-Wert, dem Matrix-Glycoprotein Thrombospondin-1 (Crawford et al. 1998) oder Plasmin (Munger et al. 1997) führt ionisierende Strahlung zur Freisetzung und damit Aktivierung von TGF $\beta$ (Barcellos-Hoff 1993; Barcellos-Hoff et al. 1994). Letztere Beobachtung war zentral für die Verknüpfung radiogener Effekte mit dem TGF $\beta$-Signalweg. Vermittelt wird dies mechanistisch über reaktive Sauerstoffspezies (ROS), welche bei Bestrahlung gebildet werden. Durch Oxidation bestimmter Aminosäuren im LAP kommt es vermutlich zu Konformationsänderungen und folglich zur Lösung von aktivem TGF $\beta$ aus seinem latenten Komplex (Barcellos-Hoff und Dix 1996). Diese Art der Aktivierung scheint isoformspezifisch so nur für TGF $\beta 1$ zu gelten (Jobling et al. 2006). Signalwege, die durch Expression von TGF $\beta 1$ aktiviert werden, regulieren ihrerseits die Expression von wesentlichen Komponenten, die zu frühen und späten Strahlenschäden führen können, einschließlich des Plasminogen-Aktivator-Inhibitors Typ 1 (Milliat et al. 2008) und von Bindegewebs-Wachstumsfaktoren (Haydont et al. 2008).

\subsubsection{Radiogene Akuttoxizität}

Durch den zuvor beschriebenen Mechanismus der Aktivierung von TGF $\beta 1$ erscheint eine Beteiligung an akuten radiogenen Reaktionen plausibel. Daneben wurde auch über eine Induktion der TGF $\beta$-Genexpression, hauptsächlich der TGF $\beta 1$-Isoform, wenige Tage nach Bestrahlung berichtet (Fleckenstein et al. 2007; Wang et al. 1998) bzw. in der Haut nach wenigen Stunden (Martin et al. 1997; Randall und Coggle 1995). Der TGFß-Signalweg ist entscheidend an der Initiierung und Förderung von Nebenwirkungen im Rahmen einer Bestrahlung beteiligt (Martin et al. 2000; Martin et al. 1993).

Zellmigration und Angiogenese scheinen bei Aktivierung des TGF $\beta$-R1 (ALK5, activin receptor-like kinase) gehemmt $\mathrm{zu}$ werden. In diesem Sinne könnte ein funktioneller Antagonismus zur Stimulation von ALK1, einem anderen Rezeptor aus der Gruppe der TGF $\beta$-R1-Rezeptorfamilie, vorliegen (Cunha und Pietras 2011). Es wurde berichtet, dass ionisierende Strahlung dieses Verhältnis zu Gunsten einer Aktivierung von ALK5 verschiebt (Scharpfenecker et al. 2009). Dies behindert offenbar die Angiogenese und Proliferation endothelialer Zellen nach Bestrahlung (Imaizumi et al. 2010; Kruse et al. 2009). Daraus ließe sich eine gestörte Wundheilung, vereinbar mit dem klinischen Bild akuter radiogener Toxizität, ableiten. 
Einen Gegenspieler in diesem Geschehen stellt SMAD7 dar, welches das über den ALK5Rezeptor vermittelte Signal inhibiert. Eine Überexpression von SMAD7 ging mit einer gesteigerten Zellmigration und verbesserten Wundheilung einher (Han et al. 2013).

\subsubsection{Radiogene Spättoxizität}

Während akute Nebenwirkungen üblicherweise binnen weniger Wochen wieder abklingen, kann die Lebensqualität durch langfristige Beschwerden infolge einer Radiotherapie erheblich beeinträchtigt sein (Sanoff et al. 2015). Daher verdient die Erforschung etwaiger prädiktiver Faktoren besondere Aufmerksamkeit. Ähnlich wie bei der Akuttoxizität richtet sich auch hier das Augenmerk u. a. auf den TGF $\beta$-Signalweg. Dieser ist wesentlich an der Entstehung von Fibrosen beteiligt (Border und Noble 1994; Kopp et al. 1996; Sanderson et al. 1995).

Während in bestrahltem Gewebe nach anfänglicher Induktion sich die Expression von TGF $\beta 2$ und TGF $\beta 3$ im Zeitverlauf wieder normalisierte, blieb diese für TGF $\beta 1$ nachhaltig gesteigert (Randall und Coggle 1996; Wang et al. 1998). Längerfristig erhöhte Werte von TGFß1 im Blut von Patienten können ein Ausdruck eines gesteigerten Risikos für Strahlentoxizität sein (Novakova-Jiresova et al. 2004; Zhao et al. 2008). Ob der TGFß1-Plasmaspiegel als Biomarker für Strahlenschäden nützlich sein könnte und sich durch ihn wirklich sicher Strahlennebenwirkungen prognostizieren lassen, ist noch umstritten (De Jaeger et al. 2004; Novakova-Jiresova et al. 2004; Zhao et al. 2008). Jedoch käme diese Erkenntnis im Verlauf einer Therapie oft zu spät, um die Nebenwirkungen noch verhindern zu können.

Auch im Falle der Spättoxizität scheinen über den ALK5-Rezeptor vermittelte Signale wesentlich $\mathrm{zu}$ sein. Im Rattenmodell waren bei einer Hemmung dieses Rezeptors späte Nebenwirkungen (chronische Entzündungen, Lungenfibrose) signifikant vermindert (Anscher et al. 2008).

Die Beteiligung des TGF $\beta$-Signalwegs bei der radiogen bedingten Fibrose konnte mittlerweile vielfach nachgewiesen werden). Durch die von Fibroblasten sekretierten Matrix-Proteine kommt es dann zur Förderung profibrotischer Prozesse (Xavier et al. 2004). Diese werden offenbar durch eine anhaltende Expression von CTGF-Protein aufrechterhalten (Haydont et al. 2008). Diese kann unabhängig von TGF $\beta$ auch durch reaktive Sauerstoffverbindungen (ROS) induziert werden (Park et al. 2001).

\subsection{Radiotoxizität und genetische Variabilität im TGFB-Signalweg}

Im Jahre 1999 wurde erstmals über einen Genpolymorphismus in der Promotorregion des TGFB1-Gens berichtet, der vermutlich einen Einfluss auf die Expression des zugehörigen TGF $\beta 1$-Proteins hat (Grainger et al. 1999). Die genetische Variabilität im TGF $\beta$-System 
scheint im Hinblick auf Strahlentherapie-induzierte Nebenwirkungen eine große Rolle zu spielen. Die meisten zum Zeitpunkt meiner Dissertation vorliegenden Literaturberichte zu diesem Thema beziehen sich auf Fibrose als radiogene Spätfolge. Kürzlich sind auch einige Arbeiten erschienen, welche sich mit entsprechenden Untersuchungen zur Akuttoxizität befassen. Nach Anzahl der genetischen Variationen gerechnet stellen die SNPs (single nucleotide polymorphisms) mit $~ 90 \%$ die größte Gruppe (Brockmoller und Tzvetkov 2008) dar. Dabei handelt es sich zumeist um biallelische Austausche, selten um triallelische.

Ab ca. 2005 wurde von ersten Analysen über genetische Polymorphismen in Bezug auf Akuttoxizität bei Strahlentherapie berichtet. Diese bezogen sich auf einige ausgewählte Gene der DNA-Reparatur bzw. die Detoxifikation von ROS. Etwa fünf Jahre später erschien der erste Bericht über einen möglichen Einfluss eines TGFB1-Genpolymorphismus auf akute Radiotoxizität (Zhang et al. 2010). Derselbe Polymorphismus wurde mit Akutreaktionen im Sinne einer Blasenreizung bei Bestrahlung wegen Prostatakarzinom in Verbindung gebracht (De Langhe et al. 2013). Weiterhin wurde berichtet, dass genetische Konstellationen im TGF $\beta$-Signalweg eventuell eine Bedeutung für das Risiko akuter Hautreaktionen im Rahmen einer Strahlentherapie haben könnten (Reuther et al. 2015).

Hinsichtlich der Spättoxizität nach Radiotherapie postulierten einige Studien zunächst einen Effekt insbesondere für die beiden in hohem genetischen Kopplungsungleichgewicht (LD) stehenden TGFB1-Varianten -509C>T und Leu10Pro (Andreassen et al. 2005; De Ruyck et al. 2006). Nachfolgend konnte dies jedoch nicht bestätigt werden, auch nicht von denselben Autoren (Andreassen et al. 2006; Damaraju et al. 2006). Einer umfassenden multizentrischen Studie sowie einer Metaanalyse zufolge scheinen die beiden Genvarianten sowie Arg25Pro in TGFB1 das Risiko chronischer Fibrosen nach Radiotherapie nicht nennenswert zu beeinflussen (Barnett et al. 2012; Zhu et al. 2013). Eine über die genannten SNPs hinausgehende repräsentative Analyse der gesamten genetischen Variabilität von TGFBl in Bezug auf die beobachtete Radiotoxizität wurde bislang nicht durchgeführt.

Über die Variabilität anderer Gene des TGF $\beta$-Signalwegs (Rezeptoren, SMADs) ist bislang keine Literatur hinsichtlich radiogener Toxizität, weder akut noch chronisch, verfügbar. Zusammenfassend lässt sich sagen, dass bislang keine genetischen Parameter in die klinische Routine Eingang gefunden haben, anhand derer das Risiko für Strahlentherapie-bedingte Toxizitäten einigermaßen zuverlässig prognostiziert werden kann. 


\subsection{Zellbiologische Prädiktoren der Radiotoxizität}

Bereits längere Zeit von der Genom-Ära wurden intensive Anstrengungen unternommen, um anhand zellulärer Reaktionen auf Bestrahlung die indiviuelle Radiosensibilität vorhersagen zu können. Als zelluäre Modellsysteme für die Normalgewebsreaktion dienten dabei isolierte Lymphozyten bzw. daraus erzeugte lymphoblastoide Zelllinien sowie Fibroblasten. Nach Bestrahlung der Zellen außerhalb des Körpers wurden radiogene DNA-Schäden über den Comet-Assay (Oppitz et al. 2002), die Quantifizierung von $\gamma \mathrm{H} 2 \mathrm{AX}$-Foci (Bourton et al. 2012; Mumbrekar et al. 2014), die Bildung von Mikronuklei (Djuzenova et al. 2006), die Bestimmung chromosomaler Aberrationen (Borgmann et al. 2008) oder 6-Thioguaninresistente Zellen (Lou et al. 2008) ermittelt. Als zellulärer Endpunkt wurde für Lymphozyten häufig Apoptose, für Fibroblasten klonogenes Überleben (Oppitz et al. 2002) bestimmt.

Eine Reihe von Studien konnte zwischen der Lymphozyten-Strahlensensitivität und den klinischen Akuttoxizitäten einen positiven Zusammenhang erkennen (z. B. Borgmann et al. 2008; Jones et al. 1995; Oppitz et al. 2002). Demgegenüber stehen negative Befunde zu diesem Sachverhalt (Lopez et al. 2005; Twardella et al. 2003). Auffällig dabei ist, dass besonders die Studien mit größeren Fallzahlen (>100) den postulierten Zusammenhang zwischen induzierten DNA-Schäden in Lymphozyten und akuten Strahlenreaktionen bei Patienten fraglich erscheinen lassen. Somit wird die klinische Anwendbarkeit solcher Tests sehr kritisch betrachtet (Barber et al. 2000). Ähnlich diskrepant ist die Literaturlage, wenn man Spättoxizitäten durch die Lymphozytenreaktionen voraussagen will (vergleiche signifikante Korrelation bei (Widel et al. 2003) versus nicht-signifikante bei (Geara et al. 1993)). Eine Arbeit fand eine positive Beziehung zwischen durch 8 Gy ausgelöster T-ZellApoptose mit späten, aber nicht akuten Nebenwirkungen einer Strahlentherapie (Ozsahin et al. 2005).

In Bezug auf Fibroblasten, bei welchen hauptsächlich das klonogene Überleben als Funktionsparameter gemessen und mit dem klinischen Erscheinungsbild in Beziehung gesetzt wurde, stellt sich die Literaturlage ebenfalls sehr uneinheitlich dar. Ein Zusammenhang mit akuter Toxizität wird zumeist verneint (Begg et al. 1993; Brock et al. 1995; Geara et al. 1993; Rudat et al. 1999) und nur wenige sehen hier eine positive Korrelation (Oppitz et al. 2001). Genauso umstritten ist der Wert dieser Funktionsmessung hinsichtlich Spättoxizität (vergleiche Geara et al. 1993) und Oppitz et al. 2001).

Ein neuerer Ansatz macht sich Techniken der genomweiten Analyse von Expressions- und Keimbahn-Variabilität zu Nutze, die innerhalb der letzten Dekade eingeführt wurden. In einer Pilotstudie waren mittels Microarrays Genexpressionsprofile in lymphoblastoiden Zellen von 
Individuen mit und ohne akute Radiotoxizität verglichen worden (Rieger et al. 2004). Später wurde an einem größeren Probenset lymphoblastoider Zelllinien die intrinsische Strahlensensitiviät mit genomweiten Expressionsprofilen und DNA-Polymorphismen in Beziehung gesetzt (Niu et al. 2010). In dieser Studie waren jedoch keine klinischen Daten enthalten. Daher ist fraglich, inwieweit sich diese Ergebnisse auf die klinische Situation übertragen lassen. Alternativ zur genomweiten Herangehensweise in der Identifizierung von Biomarkern für die Radiosensitivität ist der Ansatz über Kandidatengene, deren Auswahl sich auf bekannte bzw. vermutete funktionelle Zusammenhänge stützt. Von besonderem Interesse sind dabei biologische Mechanismen, die wesentlich in die Abläufe der durch die Bestrahlung ausgelösten Entzündungsreaktionen involviert sind, wie der oben beschriebene TGF $\beta$ Signalweg.

\subsection{Zielsetzung}

Bislang fehlen verlässliche und für den klinischen Einsatz taugliche Parameter, die eine zuverlässige Prognose über das individuelle Risiko für Nebenwirkungen einer Strahlentherapie erlauben. Mit der Perspektive einer zukünftigen Therapieoptimierung sollten mit meinen Untersuchungen Biomarker für schwere Nebenwirkungen einer neoadjuvanten Radiochemotherapie bei Rektumkarzinom identifiziert werden.

Als solche potenziellen Biomarker sollten einerseits die ererbte genetische Variabilität als individuell unveränderliche und anderseits Behandlungs-induzierte Expressionsänderungen in der Zellkultur als veränderliche Faktoren detailliert analysiert werden. Diese sollten jeweils mit den dokumentierten Akut- und Spättoxizitäten der Behandelten in Bezug gesetzt werden. Die genetische Variabilität sollte für zentrale Komponenten des kanonischen TGF $\beta$ Signalwegs als Kandidatengene umfassend durch Bestimmung eines repräsentativen Satzes an Genpolymorphismen dargestellt werden. Der klinische Datensatz sollte dabei in ein Trainings- und Testset unterteilt werden, um Assoziationen gegebenenfalls überprüfen zu können. In Fibroblasten der Behandelten sollte die neoadjuvante Radiochemotherapie simuliert und Genexpressionsveränderungen in diesen Zellen mit klinischen Toxizitätsausprägungen verglichen werden. Als Kandidaten für die Analyse dieser Genexpressionsänderungen wurden auch hier die oben genannten Komponenten des TGF $\beta$ Signalwegs ausgewählt.

Die Identifikation von Genpolymorphismen mit einem Bezug zu Therapie-bedingter Toxizität könnte klinisch vergleichsweise einfach umgesetzt werden, da diese mit nur geringem Aufwand prätherapeutisch bestimmt werden könnten. Dies würde nicht nur einen großen Gewinn für die Therapiesicherheit bedeuten. Vergleichsweise unempfindliche Patienten 
könnten zum Beispiel eine intensiviertere Therapie mit der Chance auf ein besseres Ansprechen erhalten. Ein Zusammenhang zwischen klinischer Toxizität und Genexpressionsänderungen bei ex vivo-simulierter Radiochemotherapie in Fibroblasten könnte mechanistische Prozesse besser verstehen helfen und würde ein Modellsystem bereitstellen, mit welchem gezielte (pharmakologische) Interventionen getestet werden könnten. 


\section{Material}

\subsection{Geräte}

Accu-jet

Brand, Wertheim

Autoklav

Teconorama, Femwald

Bestrahlungsgerät Xstrahl RS225

Gulmay MEDICAL, UK

Biofuge fresco

Heraeus, Hanau

Biofuge pico

Heraeus, Hanau

Biophotometer 6313

Eppendorf, Hamburg

BioRobot ${ }^{\circledR}$ EZ1

Qiagen, Hilden

Feinwaage BL 610

Sartorius, Göttingen

Fluor-S ${ }^{\mathrm{TM}}$ Multilmager

BioRad, München

Hämatocytometer (Neubauer Zählkammer Typ

Brand, Wertheim

Improved)

HPLC-System, D-7000

Gewindeflaschen $(1,5 \mathrm{ml})$

Merck, Darmstadt

Hitachi LaChrom UV Detector L 7400

Merck, Darmstadt

Hitachi LaChrom Autosampler L 7200

Hitachi Interface Modul D-7000

Merck, Darmstadt

Merck, Darmstadt

Säule Atlantis T3; 4,6 x 250 mm, $5 \mu \mathrm{m}$

Vorsäule Atlantis T3; 4,6 x 20 mm, $5 \mu \mathrm{m}$

Merck, Darmstadt

Merck, Darmstadt

Mini-Centrifuge, Model GMC-060

LMS, Tokyo, Japan

Multipipette Plus

Eppendorf, Hamburg

PCR-Gradienten-Cycler (384-Well), Typ Master

Eppendorf, Hamburg

Cycler

PCR-Gradienten-Cycler (96-Well), PTC-200

MJ Research/BioRad., Hercules, USA

Peltier

pH-Meter CG 822

Schott Geräte

Pipetten (0,5-10 $\mu \mathrm{l}, 10-100 \mu \mathrm{l}, 100-$

Eppendorf, Hamburg

$1000 \mu l)$, Typen Research und Reference

Rahmen und Septen für Sequenzierer

Applied Biosystems, Darmstadt

Sequenzierer 3100 Genetic Analyser

Applied Biosystems, Darmstadt 
Sequenzierplatten

Sterilbank Clean Air Typ DFL/REC4 KL 2A

TaqMan ABI PRISM 7900HT

Vertikal-Autoklav KSG 40/60

Vertikal-Autoklav: FV für Sterilgut

Vortexer (MS 2 minishaker)

Wärmeschrank

Wasserbad GFL 1083

Zentrifuge 5810R

\subsection{Verbrauchsmaterialien}

Adhesive PCR Foil Seals

Deckgläser für Hämatocytometer

Flat cap strips, 8er

HPLC Septen 8 mm, PTFE

HPLC Mikroeinsätze

Kryo-Röhrchen

Labortücher

Mehrkanal Pipette (8er) 0,5 - $10 \mu \mathrm{l}$

Multipipette plus

PCR Softtubes Flachdeckel, RNAse- und DNAsefrei $(0,2 \mathrm{ml})$

Pipetten, serologisch, steril $(5 \mathrm{ml}, 10 \mathrm{ml}, 25 \mathrm{ml})$

Pipettenspitzen $(10 \mu \mathrm{l}, 100 \mu \mathrm{l}, 1000 \mu \mathrm{l})$

Pipettenspitzen RNAse-, DNAse-frei $(10 \mu \mathrm{l}, 100 \mu$ $1000 \mu \mathrm{l})$

Platten, Maxi-Sorb mit Deckel

Platten, 6-Well steril für Zellkultur

Platten für Fluoreszenz, 96-Well, schwarz

Platten, Thermo fast 96-Well

Platten, Thermo fast 384-Well

Reaktionsgefäße 1,5 ml und $2 \mathrm{ml}$
Applied Biosystems, Darmstadt

Mahl, Trendelburg

Applied Biosystems, Darmstadt

KSG, Olching

Tecnorama, Fernwald

IKA, Staufen

Binder, Tuttlingen

Schütt, Göttingen

Eppendorf, Hamburg

ABgene, Portsmouth, USA

Menzel Gläser, Braunschweig

ABgene, Portsmouth, USA

VWR InteRNAtional, Darmstadt

VWR InteRNAtional, Darmstadt

Nunc, Wiesbaden

Kimberly-Clark, Irving, USA

Eppendorf, Hamburg

Eppendorf, Hamburg

Biozym, Hessisch Oldendorf

Sarstedt, Nümbrecht

Sarstedt, Nümbrecht

Kisker, Steinfurt

Nunc, Roskilde, Dänemark

Nunc, Roskilde, Dänemark

Costar, Corning, USA

ABgene, Portsmouth, USA

ABgene, Portsmouth, USA

Sarstedt, Nümbrecht 
Reaktionsgefäß 1,5 ml; Protein LoBind

Röhrchen $5 \mathrm{ml}$

Röhrchen 5 ml für FACS

Röhrchen $50 \mathrm{ml}$

Vorsäule LichroCART 4-4 LiCrospher 100CN (5 $\mu \mathrm{m})$

Skalpell, Technocut, Edelstahlklinge

Spitzen für Multipipette plus, verschiedene Größen

Sterile Filter, $50 \mu \mathrm{m}$ Porengröße

Streifen (8er) für PCR-Platten

Streifen (8er) für PCR-Platten, RNAse frei

TaqMan Adhesive Optical Covers

Zellkulturflaschen $25 \mathrm{~cm}^{2}, 75 \mathrm{~cm}^{2}, 175 \mathrm{~cm}^{2}$

Zellkulturschalen $10 \mathrm{~cm}$ Durchmesser

\subsection{Chemikalien}

Acetonitril

Anodenpuffer (für Sequenzierer)

5-Chlorouracil

DCF; DCFH-DA

di-Natriumhydrogen-phosphat

DMEM

DMEM + Glutamax

DMSO

dNTP-Set

Ethanol

Ethylacetat

Exonuklease I

FCS (Fetales Kälberserum)

5-FU

GeneScan $^{\mathrm{TM}} \mathrm{LIZ}^{\circledR} 120$ Size Standard
Eppendorf, Hamburg

Sarstedt, Nümbrecht

Becton Dickinson, Franklin Lakes, USA

Sarstedt, Nümbrecht

Merck, Darmstadt

HMD Healthcare Ltd., Hereford UK

Eppendorf, Hamburg

Becton Dickinson, Franklin Lakes, USA

ABgene, Portsmouth, USA

ThermoScientific, Waltham, USA

Applied Biosystems, Darmstadt

Sarstedt, Nümbrecht

Sarstedt, Nümbrecht

Merck, Darmstadt

Applied Biosystems, Darmstadt

Sigma, Deisenhofen

Sigma, Deisenhofen

Merck, Darmstadt

Gibco/Invitrogen, Karlsruhe

Gibco/Invitrogen, Karlsruhe

Merck, Darmstadt

ABgene, Portsmouth, USA

J. T. Baker, Phillipsburg, USA

Merck, Darmstadt

USB, Staufen

Gibco/Invitrogen, Karlsruhe

Zentralapotheke Klinikum Göttingen

Applied Biosystems, Darmstadt 
Gene Scan ${ }^{\circledR} 400$ HD[ROX] Size Standard

Glycerol 85\%

Helipur ${ }^{\circledR} \mathrm{H}$ plus N Desinfektionsmittel

Hepes

HiDi mit Formamid

Kaliumchlorid

Kaliumdihydrogenphosphat

Kaliumhydrogenphosphat-Dihydrat

Kalziumchlorid

Methanol

Natriumchlorid

Penicillin-/Streptomycin-Lösung

Phosphorsäure $85 \%$

PicoGreen ${ }^{\circledR}$

Polymer POP7 (für Sequenzierer)

Primer für PCR und qRT-PCR

Propidiumiodid

Q-Solution

Random Primer dN6

RNAse Inhibitor, rekombinant

RNAse Zap

Shrimp Alkalische Phosphatase (SAP)

SuperScript ${ }^{\mathrm{TM}}$ II Reverse Transkriptase

TaqMan® Universal PCR Mastermix

TGF-beta 1 (human)

Tris

TrypLE ${ }^{\text {TM }}$ Express
Applied Biosystems, Darmstadt

Zentralapotheke Klinikum Göttingen

Braun, Melsungen

Applied Biosystems, Darmstadt

Applied Biosystems, Darmstadt

Riedel-DeHaën AG, Seelze

Merck, Darmstadt

Merck, Darmstadt

Merck, Darmstadt

Merck, Darmstadt

J. T. Baker, Phillipsburg, USA

Gibco/Invitrogen, Karlsruhe

Merck, Darmstadt

Applied Biosystems, Darmstadt

Applied Biosystems, Darmstadt

MWG-Biotech, Ebersberg

Becton Dickinson, Franklin Lakes, USA

Qiagen

Roche, Mannheim

USB, Staufen

Ambion, Austin, USA

USB, Staufen

Invitrogen, Karlsruhe

Applied Biosystems, Darmstadt

PromoCell, Heidelberg

Roth, Karlsuhe

Gibco/Invitrogen, Karlsruhe

\subsection{Kits und Assays}


Human TGF- $\beta$ CytoSet ${ }^{\mathrm{TM}}$

Multiplex PCR Kit

5x HOT FIREPol@ EvaGreen® qPCR Mix Plus $(R O X)$

RNeasy Plus Mini Kit

SNaPshot ${ }^{\mathrm{TM}}-$ Mastermix

Super Script II Reverse Transcriptase

Taq DNA-Polymerase
Invitrogen, Karlsruhe

Qiagen, Hilden

Solis BioDyne, Estland

Qiagen, Hilden

Applied Biosystems, Darmstadt

Invitrogen, Karlsruhe

Qiagen, Hilden

\subsection{Lösungen und Puffer}

\begin{tabular}{|c|c|c|}
\hline $\begin{array}{l}\text { Annexin-Puffer, pH 7,4, eingestellt mit } \\
\mathrm{NaOH}\end{array}$ & $\begin{array}{l}\text { HEPES } \\
\mathrm{NaCl} \\
\mathrm{CaCl}_{2}\end{array}$ & $\begin{array}{l}10 \mathrm{mM} \\
140 \mathrm{mM} \\
5 \mathrm{mM}\end{array}$ \\
\hline Fließmittel für HPLC & $\begin{array}{l}\mathrm{KH}_{2} \mathrm{PO}_{4} \mathrm{pH} 3,0 \\
\text { Methanol }\end{array}$ & $\begin{array}{l}25 \mathrm{mM} \\
10 \%\end{array}$ \\
\hline $\begin{array}{l}\text { PBS-Puffer, } \mathrm{pH} 7,4 \\
\text { mit } \mathrm{NaOH} \text { eingestellt }\end{array}$ & $\begin{array}{l}\mathrm{NaCl} \\
\mathrm{KCl} \\
\mathrm{Na}_{2} \mathrm{HPO}_{4} \\
\mathrm{KH}_{2} \mathrm{PO}_{4}\end{array}$ & $\begin{array}{l}128,5 \mathrm{mM} \\
2,8 \mathrm{mM} \\
8,1 \mathrm{mM} \\
1,5 \mathrm{mM}\end{array}$ \\
\hline $\begin{array}{l}\text { TE-Puffer, } \mathrm{pH} 7,5 \\
\text { eingestellt mit } \mathrm{HCl}\end{array}$ & $\begin{array}{l}\text { Tris } \\
\text { EDTA }\end{array}$ & $\begin{array}{l}10 \mathrm{mM} \\
1 \mathrm{mM}\end{array}$ \\
\hline
\end{tabular}

\subsection{Medien}

Primärmedium (vor Einfrieren)

Kulturmedium

$\begin{array}{ll}\text { DMEM-Medium } & 89 \%(\mathrm{v} / \mathrm{v}) \\ \text { FCS } & 10 \%(\mathrm{v} / \mathrm{v}) \\ \text { Penicillin / Streptomycin / } & 1 \%(\mathrm{v} / \mathrm{v}) \\ \text { Amphotericin B } & \\ \text { DMEM+Glutamax Medium } & 89 \%(\mathrm{v} / \mathrm{v}) \\ \text { FCS } & 10 \%(\mathrm{v} / \mathrm{v}) \\ \text { Penicillin / Streptomycin } & 1 \%(\mathrm{v} / \mathrm{v})\end{array}$

\subsection{Primer}

Die zur Genotypisierung erforderlichen Primer für PCR- und SNaPshot ${ }^{\mathrm{TM}}$-Reaktionen wurden unter Verwendung der Software OLIGO ausgewählt. Die Synthese sämtlicher in dieser Arbeit verwendeten Primer wurde von der Firma Eurofins MWG Operon (Ebersberg) durchgeführt. 


\section{Tab. 2 Für die Genotypisierung verwendete Primer}

\begin{tabular}{|c|c|c|c|c|c|c|}
\hline Polymorphismus & PCR-Primer, vorwärts $\left(5^{\prime}->3^{\prime}\right)$ & PCR-Primer, rückwärts $\left(5^{\prime}->3^{\prime}\right)$ & FL (bp) & PP & SNaPshot ${ }^{\mathrm{TM}}$-Primer $\left(5^{\prime}->3^{\prime}\right)$ & SP \\
\hline \multicolumn{7}{|l|}{ TGFB1 } \\
\hline rs 10417924 & AGCCCAGGCGACAGAGCAAGA & GCCTGTGTGCTGTTTGGTATGGATG & 397 & III & CTGACTGACTGACTCGTGCTGGGGACACACA & C \\
\hline rs1800468 & GGACCCAGAACGGAAGGAGAGTCAG & TGCTGCATGGGGACACCATCTACA & 550 & III & TGAGGGACTCTGCCTCCAAC & C \\
\hline rs1800469 & " & " & $"$ & $"$ & ACTGACTGACTGACTGGGGGCAACAGGACACCTGA & C \\
\hline rs1800470 & CCCCACCACACCAGCCCTGTT & GCTTCACCAGCTCCATGTCGATAGTCTTG & 185 & III & AAAAAAAAAAAAAAAAGCAGCGGTAGCAGCAGC & C \\
\hline rs1800471 & " & " & $"$ & " & ACTGACTCTGACGCCTGGCC & C \\
\hline rs2241717 & TCGGCTGGTTACAAGGTCCACCTAG & CCAGCTTGGCAACAGAGTGAGACAC & 119 & III & AGAACACAAACCATACAATCCTAGAAC & \\
\hline rs2241713 & ATGCCCCACTTGCAGAAGAGGCTAC & CAGCAACAACCACGGAAACCAAGAC & 711 & III & CTGACTGACTGACTGACTATCACAACCCTGTGAGGTAA & C \\
\hline rs6508976 & AGCTGACAGCTCTGGGGTGGAGTC & AGGGGGAGAAACCACTTCCTCAAGGT & 437 & III & TC (TGAC) ${ }_{8}$ TGAGCAGCTGGGACTAAAGGC & \\
\hline rs 7254679 & GGGGCTTTCTCTCACCCACCAATC & GGACAAGTGCTGGCTGCACATTC & 517 & III & GACTGACTGACTGACTGGCGGGGCAGGGGGAGG & \\
\hline rs8179181 & TCATCTTCGCCTCTTGCCTTGTTG & CCGTGGATGGTCATCTGGCTTCTTAC & 815 & III & ACTGACTGACTGACTGACTGACTTGCAGGCAGGAGAGACGC & $\mathrm{C}$ \\
\hline \multicolumn{7}{|l|}{ TGFBR1 } \\
\hline rs 11466445 & CCACAGGCGGTGGCGGCGGGACCAT & FAM-CCCGCGCCATGTTTGAGAAAGAGCA & 212 & $\mathrm{E}$ & - & \\
\hline s11568785 & TGTGGGATTTCAGATGCCAGTATATCTC & GGAGCAGTTGTTGCCTAGGGCTAAG & 355 & I & $\left(\right.$ TGAC) ${ }_{6}$ TAGTTGTCCACTTGCAACCCA & \\
\hline rs10819635 & GTCTGGGATTCTACAGTGGAATTTTGTC & TTCACCACTTGAAGTCAGTCTTGATTG & 961 & II & TGATCTGCTTTCCCAAAGAAAA & \\
\hline rs 10988716 & CGGAAGGAGGTGTCTTCGTTTACG & " & 280 & II & ATTTGGCCCCTGGATAC & $\mathrm{A}$ \\
\hline rs 10512263 & GTCTGGGATTCTACAGTGGAATTTTGTC & TTCGTAGGCCACCAAAGGTAAACTTC & 68 & II & (ACTG) 6ATTCTACAGTGGAATTTTGTCACTACTTT & \\
\hline rs6478974 & CTTGGCTGGAGAGGATGGCATGTG & TCCCTCTGCGGCACAATTAGACATTC & 173 & II & $(\mathrm{CTGA})_{7} \mathrm{CTTATGGGCCTTGAAAATCAGG}$ & \\
\hline rs10733710 & СCTGCTCTGAAGCCAGAGTTACCTGAC & GCAGGGCTAGCTACTGCACAGTATTTG & 210 & III & $(\mathrm{GACT}){ }_{5} \mathrm{GCACATAGTAGGTGCCCTATAAA}$ & \\
\hline \multicolumn{7}{|l|}{ TGFBR2 } \\
\hline rs11466531 & GGGGTTCCTGTGTGCCCTTATTTC & GGCTGGGAGCAGAGAATAGTAACATAAGTG & 280 & II & TGGGGTAGAGTTTCTAAACTAGGTTGAG & \\
\hline rs11466536 & TGTGGGTGGGCTGAGAGTTAAAGAC & GGCAACAGCTATTGGGATGGTATCAG & 108 & II & ACTGACTGACTGACTGCGCCTAGAAATTCCACTTGCAC & \\
\hline rs3087465 & AAACCCTTGCCTCTGCAATCTTCCT & AAGTGGGTTGGGAGTCACCTGAATG & 371 & II & $(\mathrm{TGAC})_{6} \mathrm{TGGGTAACATGGGAGCAGAACAG}$ & \\
\hline rs3773663 & CACACCCAGGAAGGAGCCCTTAGTG & CAGACCAGACTTCCTGCTCCATTTGTC & 241 & II & CTGACTGACTGACTGACTGTGTGGCCCTATCTCACTGAGAD & \\
\hline rs1551762 & GGCCAACTTGGTAAATAAAATCCTATGTG & CCGAGTGGAGGAATTGCCAAAC & 132 & II & GACTGACTTAAAGTAGGAGCCTATCTCCCAAAT & \\
\hline
\end{tabular}


rs 3773650

rs3773651

\section{SMAD2}

rs17814648

rs 1787177

rs1792658

rs 1792666

rs8085335

\section{SMAD3}

rs16950556

rs11856909

rs1470003

rs 1470002

rs 17293408

rs 12443188

rs11632964

rs16950559

rs3809572

rs 4776892

rs11630297

rs 12914140

rs 17294280

rs16950553

rs2289263

rs2118613

rs17213990

rs 6494629

rs1866320
ATCCTGCACCCTGCTGAACCTCAC

CTTAAGATCGTGCCCCTTTTCTCTCAG

CTACATGTCCCTGCTGCAGTAACATTTTC

ATTCCCAGTTTTCTGGAAGGTTTGTGAAC

CATCTTGGGGCATATTGGATTGTTG

CAGAGAGGAACGGTTTCAGCCTGAG

GGCCCCTGGCTTCCTCTTCTATAAAC

GCTCAGCCTAGAGGTGAAACTGCTCTTC

CAGCAGTAGTCCCCAGGATGAGACAG

GAGGAGAACCCATGAGAGGTGGAAAAC GGCCCCTGGCTTCCTCTTCTATAAAC CGGACTACCCGGAATGAAGAAAGC

GAGCTTGCTCTTGGGGCAGTTTG

ACCACGCCAGGCCTTATATCTCAGTC

GTCAGAGTTTCTCCGGGCTTCTCTTTC

TCCGGTCTTCCCCACACTTGTGA

TGCCTCACCTGCTTGAGTACCTGAGT

CTGTAGCTGCCTCTTCAGGGTCAGAC

ATCTCTGGGTCAGTGGTTTCTCAACATC

TCCCTAGGAGAAGCTGAATAAGGTTTGAG

GCATCAGAAGGTCTCAGGAGCCTTAC

AGGCTCAGACAAGGCATTTGCTGAC

GGTTCCCCAGGGCTGTCTCTTCTTATC

CTTTTCACGCTACCTCTTCCAGTACTCTC

GGAAGTTCTGTTAGGATCTCGGTGTGTC

TGCCAAGGAAATTAGGTGGACATAGAAAG

ATTTCCTGGTTGTAAGGCTCAAAACACAG

AAAGGCTAACGACAGGGGCACTGTAG GCCACATACCGGAATCACCTAGGAAAG GGCGGCTATAAATGGGATAACCATGAG

GGGTGGACTCAAGGTATCGGACTTTC

$$
\text { " }
$$

CCAAGTCACTAGCTGTTCAGTGCCAGTTAC

GCCACATACCGGAATCACCTAGGAAAG

CAGCCGACTAGCCGGTGTCTAAG

CCACTAGCCTACCCGTGCACTTG

GGATATTGAATGCTTCCAACCCAAAGAAATG GGGTTTCCTACAGTTGCTTCCTGACATC GCCGACAGCTGACTTCCTGTCATTATG CCTTATTCCTCATATAACGCTCACACACCAA GCCCCATCTAGCTCCCAAATCA

TGGAGTTGGCTAAGGCCTCTAACTTAGTTTC GCAGATGCTTACACCAACTCCATAAGATAG AGGCTTCTGAGGGTCCATTATTTCTGTC CCATCCCTCGAACCCTCAGAGTACTTC
(GACT) ,CCAAGTTTCAGCCACTGAGAATAATTTT

(GACT) \&CAGAGTTGAAAGGATAGGGAATGATAC

A

CTGACTGACTGACTGACTCTGCTATTTCAGAACCGGGAG D (ACTG) ${ }_{3}$ ACTTTAAAGTTTTCAACAAGAAGAGAAGTTG F (TGAC) 5 TTGGGCATATCTTACATATCTGCAACT F (GACT) 5 ACAGGAATTCCACTCCAAGAGATA G CTGACTGGTAGTCAGAATCCTGCTATTGAGTTCTT G

$$
\text { GGAACGGTTTCAG }
$$

(CTGA) 6CTCCCCTGGAGACCAGTGAATTTC GACTGACTGGCTCCTCTAGGAGAATGACTACGG (ACTG) 7 ACTCACCAACCAGAGCCATAGACC (TGAC) 6TATCGGACTTTCCAGGTAATGAAAAA CTGACTGACTGCCGCCTGGTCCTGGTAC TACCAAAAAGTTCCCAACATCATACT ACTGACTGACTGAGTTGACTATACAGTGATTCTGAAACTAI B (GACT) ᄀAGGAATCTCCCACCCCCA

CTGACTGACTGGTATCGGACAATATAGCCTTAGACTG B AGCATGAGCCATTGCACC B

CTGACTGACTGACTGACTTCTCCGGGCTTCTCTTTCTC G ACTGACTGACTGACTTGACTTCCTGTCATTATGTTGCC E CCTTATTCCTCATATAACGCTCACACACCAA E GCCCCATCTAGCTCCCAAATCA E

(ACTG) ${ }_{5}$ ACTCCCACTTTGTACTGTGAGTTTCTGA E (CTGA) ${ }_{5}$ CTCGATCTTGTCATTCCTTGCCTA E CTGACTGACTACAAGATACCAGGAGGCTCCC E (GACT) \&TCCAATCCCCCACCTGAA 
rs 4776344

rs3743342

rs 1065080

rs12900401

rs 3743343

rs 12439792

rs 17293443

rs11637580

rs 718663

rs11637580

rs718663

rs16950635

rs 8028147

rs991157

\section{SMAD4}

rs10502913

rs3764465

rs17663887

\section{SMAD7}

rs 3736242

rs 1316447

rs 1873191

rs2878889

rs 4939830

rs 4464148

rs 6507876

rs 884013

rs 12953717
GGTGCCATTCCCACCTTAGAGTGCTAC GAATGCCACTCCCTGAAGAGCAGTAC CAACACAGCGAAGCTGTACTGTCTTTG GGCAACTTTTCAAAAACACAGCTATCA TAGAGCTGCCGTGTTCTTAGACACAAAG CTCCCAGATGATGTTTCTAGAATGTTCTGAC GGATGGAACCCTGGCTGAATTATCTC

GGATGGAACCCTGGCTGAATTATCTC CTCCCCACTTTCTTGCTTGTTGTTTC GAAGCGCACTGACCATAAGAGCAAC

CCAAGGACAGAGCCCTTTCCTGTCT

CCTATCCCTTCTCCTGCCATTTAAGGAC GCATGGGGTTTATGAGTTGAGACAGACA GCCACCAAAACATTGGGTAATTGTTGTC

ATGGATTTTCTCAAACCAACTGGTGAGTA CGCTGCTGTGTAAGAATTTAGCATCAG GCACTGCCAACAGTAGGAGCTGTAATTG CCCGGCCTCTTTGCTCCTTTATTATTG

GCAGTTACCAGGGTGTTTCCTTTTCAC

TGTCTTCGGACAGTTTTCCTACCCTCTAG GAACCCTGTTTTAGGGATGAGCTGAAC
GCTAGCTGCACTTGGGTCAGTCTCAG ACGCAGACCTCGTCCTTCTTCATATTG GAGAAGCGGCTGATGCTCCTTAAACT ACTACACCCTCCACCAACATTCAGAAC CCCAGCTGTGCTATGAGTGCTTATTC CAATGATGTTGCCGAACATCCACT CTGCCACAGGCTCTTATCACCTCTG

GCGTGTGCCTATAATCCCAGCTACCT CTGCCACAGGCTCTTATCACCTCTG

GAGTGTGGGTTTCCATGCAGTTG

CCACAGAGCTGAGGAAGAGACATACTCATC

TGAGGGAGCATGGAAAGTTCATAGGTAAC GCCACTGTTGTAGTTTTGAGCCTCTTCAG GGTGAAACCGCGTCTCTACGAAAAATAG

CCACCGGCTACACAGCACAAATAC ACCACCTTTTCCTAAGATGGAGACTTCAC CTTTTCGCATCCTCAGGAACAACAATG TGCCAGGTGAAGACAACTGCTTTGAG "

AAGTCCCGACTTTGCAAGATGAAATTG $"$

GCTCTGTGTGTGCAAGAAACCAAGCTAC GAGACGCGTAAAACTTGCTGAGATATCTG
326

444

118

282

602

113

735

376

155

155

12

252

123

345

273

413

163

143

"

234

"

187

594
$\mathrm{V}$

$\mathrm{V}$

$\mathrm{V}$

IV

IV

IV

IV

IV

IV

"
GACTGACTGACTGACTGACTGGGACCACAGACATAGCCATC D CGCCATGACATCTTCAC

CACAGCCACCACGAGCT

(GACT) 6TTGTAGGCCCCTTTCAGGTAAC

GGCAACTTTTCAAAAACACAGCTATCA

(TGAC) 7TTCCAACTCCCCAGCAACAC

(ACTG)

GCTTATAGTCCAAAGGTAGAATTGCC D

GACTCCCACATCACGTTAAGCAGC B

GCTTATAGTCCAAAGGAGAATTCC D

(ACTG) ${ }_{6}$ ACTTGGGACAGACTTTGCCCTG D

(ACTG) ${ }_{6}$ CACTGGGGTAATTTATTGCC E

TGACTGACTGACTGACTTCACCAGGAACCCCACAC D

CTGACTGACTGACTCCTGTCTTGTCCACACCATGT D

GACTGACTGACTGCATAGACTAGCCAATCCTGACTGATAC G

GCATGGGGTTTATGAGTTGAGACAGACA

GACTGACTGACTAACCAGTGTACCTATCAGTTGTTTGC F

ATGGATTTTCTCAAACCAACTGGTGAgtA F

GACTGACTGAATGTAAATGGTCCATGTAGATTCCC F AGCGGGGCAGGTTTTCTC F

CTTTGCTCCTTTATTATTGTTGTACTGTG F

TGCCAGGTGAAGACAACTGCTTTGAG G

(GACT) ${ }_{3}$ GGGAACAGACAGAGAAGGATGAA F

(TGAC) ๆTGAAGCCCCACCAGGAAGA F

(ACTG) ${ }_{5}$ GTAGCCTGGGGCTTTATTAAAAC F ACACCAACCTCGCATGCAG 


\section{rs4939827 \\ rs4939826}

rs 17186485

rs 12953717

rs 4939827

rs2337143

rs7351039

rs12967477

rs 4939832 Fragmentlängenanalyse mittels Einzel-PCR (E) durchgeführt, wobei der Rückwärtsprimer am E'-Ende mit dem Fluoreszenz-Farbstoff FAM markiert war. In den beiden rechten Spalten finden sich die Sequenzen für die SNaPshot ${ }^{\text {TM}}$-Primer zur Alleldetektion der interessierenden SNPs und die jeweilige Zuordnung zur den sieben Multiplex- SNaPshot ${ }^{\text {TM}}$-Reaktionen (A-G).

GAGACGCGTAAAACTTGCTGAGATATCTG

CAAATCACAACATGCAGACCGGTATTAAC
"

77

AAAACATGGGCCTTGGAGCAACTTC

TCAGCTTCCTTCCCCAAATGGTAAG

$$
\text { " }
$$

CAGCCTCATCCAAAAGAGGAAA

(GACT) 6 GGATTAGAGACAGCCCCTTAAAGT TGACTGACTGACTACATGCAGACCGGTATTAACCC

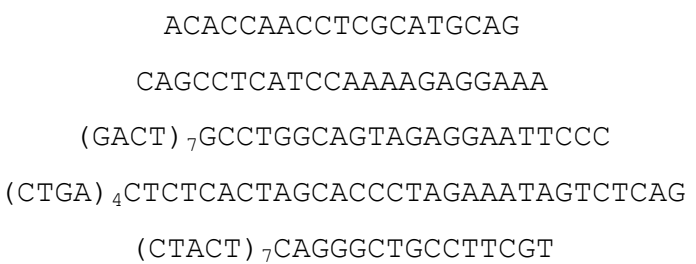

(GACT) 7 GATTCCTCGGTCTGGGAAAA 
Tab. 3 Primer für quantitative real-time PCR (qRT-PCR)

\begin{tabular}{|c|c|c|c|c|c|}
\hline Gene & Vorwärts Primer & $\underline{\text { Rückwärts Primer }}$ & $\frac{\text { Annealing }}{\frac{- \text { Temp }}{\left[{ }^{\circ} \mathrm{C}\right]}}$ & $\frac{\text { Amplikonlänge }}{\underline{\text { [bp] }}}$ & Quelle \\
\hline \multicolumn{6}{|c|}{$\frac{\text { Referenz- }}{\text { gene }}$} \\
\hline$G A P D H$ & CCСTTCATTGACCTCAACTACAT & ACGATACCAAAGTTGTCATGGAT & $60{ }^{\circ} \mathrm{C}$ & $407 \mathrm{bp}$ & (Calcagno et al. 2006) \\
\hline HPRT1 & TGACACTGGCAAAACAATGCA & GGTCCTTTTCACCAGCAAGCT & $60{ }^{\circ} \mathrm{C}$ & 93 & (Calcagno et al. 2006) \\
\hline \multicolumn{6}{|c|}{$\underline{\text { Zielgene }}$} \\
\hline$C A T$ & ACTTTGAGGTCACACATGACATT & CTGAACCCGATTCTCCAGCA & $60,1{ }^{\circ} \mathrm{C}$ & 117 & http://pga.mgh.harvard.edu/primerbank/ \\
\hline$C D K N 1 A$ & GGAAGACCATGTGGACCTGT & ACTGCAGGCTTCCTGTGG & $64{ }^{\circ} \mathrm{C}$ & 198 & http://pga.mgh.harvard.edu/primerbank/ \\
\hline$C T G F$ & GCTTACCGACTGGAAGACACG & CGGATGCACTTTTTGCCCTT & $62{ }^{\circ} \mathrm{C}$ & 233 & http://pga.mgh.harvard.edu/primerbank/ \\
\hline$S M A D 2$ & GCCATCACCACTCAAAACTGT & GCCTGTTGTATCCCACTGATCTA & $60^{\circ} \mathrm{C}$ & 111 & http://pga.mgh.harvard.edu/primerbank/ \\
\hline SMAD3 & GAACGTCAACACCAAGTGCAT & ACGCAGACCTCGTCCTTCT & $62{ }^{\circ} \mathrm{C}$ & 192 & http://pga.mgh.harvard.edu/primerbank/ \\
\hline$S M A D 4$ & ACGAACGAGTTGTATCACCTGG & ATGGCTGTCCCTCAAAGTCAT & $61,2{ }^{\circ} \mathrm{C}$ & 114 & http://pga.mgh.harvard.edu/primerbank/ \\
\hline SMAD7 & ACTCCAGATACCCGATGGATTT & CCTCCCAGTATGCCACCAC & $60^{\circ} \mathrm{C}$ & 174 & http://pga.mgh.harvard.edu/primerbank/ \\
\hline$T G F B 1$ & GGTACCTGAACCCGTGTTGCT & TGTTGCTGTATTTCTGGTACAGCTC & $60^{\circ} \mathrm{C}$ & 101 & (Gambichler et al. 2007) \\
\hline TGBFRI & АСССТTCATTAGATCGCCСTTT & CGCAATTGTTCTCTGAACAAGC & $65^{\circ} \mathrm{C}$ & 119 & (Zidek 2005) \\
\hline
\end{tabular}




\subsection{Software}

Betriebssoftware für 16-Kapillar-Sequenzierer: 3100 Data Collection Software Version 1.0 und GeneScan Analysis Version 3.5.1 (Applied

Biosystems)

HaploView-Software

(http://www.broad.mit.edu/mpg/haploview):

MS Office (Microsoft)

Oligo (Version 6.58, Molecular Biology Insights, USA

SDS 2.1 (Applied Biosystems)

SPSS Version 12.0

XFluor4 (Tecan)
Akquirierung und Analyse von genetischen Daten (SNaPshot ${ }^{\mathrm{TM}}$ und Fragmentlängenanalyse)
Software zur grafischen Aufbereitung von Daten aus den Genotyp-Datenbanken

Textverarbeitung

Präsentationen

Tabellenkalkulation

Primerdesign

Analyse von Expressionsmessungen, die mit TaqMan 9100 HAT gewonnen wurden

Grafische Darstellung von Messdaten und

Testung auf mögliche Assoziationen

Erfassung von Fluoreszenz-Messdaten des

Tecan-Ultra

\subsection{Datenbanken}

NCBI (National Center for Biotechnology information) (http://www.nih.gov/), stellt Zugang zu einer umfassenden Sammlung von Datenbanken zur Verfügung. Für die vorliegende Arbeit wurden daraus Informationen zu folgenden Aspekten gewonnen :

- Gene (http://www.ncbi.nlm.nih.gov/gene)

- Genpolymorphismen (http://www.ncbi.nlm.nih.gov/SNP/)

- Veröffentlichte Literatur (http://www.ncbi.nlm.nih.gov/pubmed)

HapMap-Projekt (http://www.hapmap.org/index.html.en). Dieses inteRNAtionale Projekt wurde 2002 als die bis dahin weltweit umfangreichste und detaillierteste Kartographierung von Polymorphismen im menschlichen Genom gestartet. Aus Markern, welche genomweit in gewissen Abständen in denselben DNA-Proben analysiert wurden, sollten Haplotypen, d. h. 
Kombinationen von genetischen Markern, bestimmt werden. Unter Verwendung von ChipArrays wurden mehrere hunderttausend einzelner Marker genotypisiert. Die Einträge in dieser Datenbank bildeten die Grundlage für die Auswahl repräsentativer Sätze von Genpolymorphismen (tagging SNPs) für die einzelnen Kandidatengene, welche in dieser Dissertation untersucht wurden. Es sei angemerkt, dass das HapMap-Projekt mittlerweile nicht weiter gepflegt wird, sondern dessen Daten in das nachfolgende 1000 humane genomeProjekt (http://www.1000genomes.org/) eingeflossen sind. 


\section{Studienkohorte und Methoden}

\subsection{Patienten für Genotypisierung}

Für die Genotypisierung lag DNA aus Blutzellen von 164 Patienten mit Rektumkarzinom im unteren und mittleren Drittel vor. Alle Karzinome wurden als Adenokarzinome klassifiziert und befanden sich im UICC-Stadium II oder III. Das bedeutet, dass die Patienten zwar befallene Lymphknoten haben konnten, Fernmetastasen hatten sie jedoch keine. Die Studienkohorte der 164 Patienten bestand aus zwei Patientengruppen, einer mit 88 Patienten, die prospektiv betrachtet wurden und einer mit 76 Patienten, die retrospektiv betrachtet wurden.

\subsection{Auswahl der Genvarianten}

Es wurden 74 Genpolymorphismen in sieben Kandidatengenen des TGFbeta-Signalwegs (TGFB1, TGFBR1, TGFBR2 SMAD2/3/4/7) bestimmt. Das Ziel war die komplette Erfassung der Keimbahn-Variabilität von Varianten mit einer Mindestallelfrequenz von $5 \%$ in diesen Genen bei der kaukasischen Bevölkerung, wie sie in der HapMap-Datenbank (Release 24 vom November 2008) annotiert war. Unter diesen Vorgaben wurden zunächst Genvarianten ausgewählt, für die in der aktuellen Literatur eine medizinische oder funktionelle Bedeutung bereits beschrieben war. Für jedes Gen wurde dann - basierend auf den HapMap-Daten - ein Satz von Genpolymorphismen bestimmt, mit dem die verbleibende genetische Variabilität abgebildet wurde. Diese Analyse wurde mit dem Programm HaploView und dem darin implementierten Tagging-Algorithmus durchgeführt. Die Etablierung der Bestimmung dieser Genvarianten ist in einer früheren Dissertation der Abteilung Klinische Pharmakologie beschrieben (Janke 2009) und wurde von mir ergänzt. Wie sich die insgesamt 74 SNPs auf die Gene verteilten, ist in Tab. 4 dargestellt.

Tab. 4 Kandidatengene mit Anzahl untersuchter Genvarianten (SNPs)

\begin{tabular}{lc}
\hline Gen & Anzahl der Genvarianten (SNPs) \\
\hline TGFB1 & 9 \\
TGFBR1 & 6 \\
TGFBR2 & 7 \\
SMAD2 & 5 \\
SMAD3 & 30 \\
SMAD4 & 3 \\
SMAD7 & 15 \\
\hline Gesamt & 74 \\
\hline
\end{tabular}




\subsection{Bestimmung von Genpolymorphismen}

\subsubsection{Polymerasekettenreaktion (PCR)}

Zur Amplifikation von DNA-Bereichen mit interessierenden Genvarianten wurde zunächst eine Polymerasekettenreaktion (PCR) durchgeführt. Für den Reaktionsansatz wurde ein PCRMastermix von Qiagen verwendet, der bereits Nukleotide mit den vier bekannten Basen, eine thermostabile DNA-Polymerase und einen Reaktionspuffer enthielt. Je nach zu amplifizierendem Genabschnitt wurden Primer mit spezifischer Sequenz und bei GC-reichen Regionen Q-Solution (Firma Qiagen) hinzugefügt. Q-Solution führt in diesen Bereichen zu einer Verbesserung der Amplifikation, da es die Schmelzeigenschaften der DNA verändert. Die PCR wird in drei sich zyklisch wiederholende Schritte eingeteilt: Denaturierung, Hybridisierung (Annealing) und Elongation. Dieser Reaktionsablauf gilt sowohl für EinzelPCRs als auch für die Multiplex-PCRs, bei der gleichzeitig mehrere DNA-Abschnitte vervielfältigt werden können. Aus ökonomischen Gründen wurde, wenn möglich, das Multiplex-Verfahren bevorzugt (Pipettierschema siehe Tab. 5, PCR-Bedingungen siehe Tab. 6). Von den insgesamt $74 \mathrm{zu}$ analysierenden Genvarianten wurden für 72 die umgebenden Sequenzbereiche mittels fünf Multiplex-PCR vervielfältigt (Zuordnung der einzelnen Fragmente $\mathrm{zu}$ den jeweiligen Reaktionen in Tab. 2). Insgesamt drei Fragmente, eine Deletionsvariante im TGFBR1-Gen und zwei Fragmente im Promotor- bzw. Intron ${ }^{\circ} 2-B^{2}$ ereich des TGFB1-Gens, mussten jeweils mit Einzel-PCRs amplifiziert werden (Pipettierschema siehe Tab. 7, PCR-Bedingungen siehe Tab. 8). Die Kontrolle der PCR-Fragmente war bereits zuvor bei der Assayetablierung erfolgt (Janke 2009). PCR-Reaktionen stellen in der Regel den ersten Schritt bei unterschiedlichen Genotypisierungsverfahren dar.

Tab. 5 Pipettierschema der Multiplex-PCRmit Q-Solution bei Pool I/II/III sowie SMAD3 und ohne QSolution bei $S M A D 2 / 4 / 7$

\begin{tabular}{lll}
\hline & Volumen/Reaktion & Volumen/Reaktion \\
& Pool I,II,III, SMAD3 & SMAD2/4/7 \\
\hline 2x Multiplex Mastermix Qiagen & $6 \mu \mathrm{l}$ & $6 \mu \mathrm{l}$ \\
Q-Solution & $1,2 \mu \mathrm{l}$ & --- \\
$10 x$ Primer-Mix & $1,2 \mu \mathrm{l}$ & $1,2 \mu \mathrm{l}$ \\
$\mathrm{ddH}_{2} \mathrm{O}$ & $1,6 \mu \mathrm{l}$ & $2,8 \mu \mathrm{l}$ \\
Genomische DNA & $2 \mu \mathrm{l}$ & $2 \mu \mathrm{l}$ \\
\hline Gesamt & $12 \mu \mathrm{l}$ & $12 \mu \mathrm{l}$ \\
\hline
\end{tabular}


Tab. 6 PCR-Programm für Pool I/II/III und SMAD2/4/7

\begin{tabular}{llll}
\hline Phase & Zeit & Temperatur & \\
\hline Initiale Denaturierung & $15 \mathrm{~min}$ & $95^{\circ} \mathrm{C}$ & 39 Zyklen \\
- Denaturierung & $30 \mathrm{~s}$ & $94^{\circ} \mathrm{C}$ & \\
- Annealing & $1.30 \mathrm{~s}$ & $64,8^{\circ} \mathrm{C}$ & \\
- Elongation & $1.30 \mathrm{~s}$ & $72^{\circ} \mathrm{C}$ & \\
\hline Terminale Elongation & $10 \mathrm{~min}$ & $72^{\circ} \mathrm{C}$ & \\
\hline Lagerung & $\infty$ & $8^{\circ} \mathrm{C}$ & \\
\hline
\end{tabular}

Bei $S M A D 3$ betrug die Annealing-Temperatur $69^{\circ} \mathrm{C}$.

Tab. 7 Pipettierschema für Einzel-PCRs mit standardmäßigem 12- $\mu$ l-Ansatz

\begin{tabular}{lll}
\hline & Volumen/Reaktion & Endkonzentration \\
\hline 10 x PCR-Puffer & $1,1 \mu \mathrm{l}$ & $1 \mathrm{x}$ \\
Q-Solution $(5 \mathrm{x})$ & $2,2 \mu \mathrm{l}$ & $1 \mathrm{x}$ \\
$\mathrm{dNTP}(10 \mathrm{mM})$ & $0,22 \mu \mathrm{l}$ & $0,2 \mathrm{mM}$ \\
Primer-forward $(100 \mu \mathrm{M})$ & $0,055 \mu \mathrm{l}$ & $0,5 \mu \mathrm{M}$ \\
Primer-reverse $(100 \mu \mathrm{M})$ & $0,055 \mu \mathrm{l}$ & $0,5 \mu \mathrm{M}$ \\
Taq DNA-Polymerase $(5 \mathrm{U} / \mu \mathrm{l})$ & $0,055 \mu \mathrm{l}$ & $0,025 \mathrm{U} / \mu \mathrm{l}$ \\
$\mathrm{ddH}_{2} \mathrm{O}$ & $6,315 \mu \mathrm{l}$ & \\
Total & $10 \mu \mathrm{l}$ & \\
Genomische DNA & $2 \mu \mathrm{l}$ & \\
\hline Summe & $12 \mu \mathrm{l}$ & \\
\hline
\end{tabular}

Für die Amplifikation des TGFB1-Promotorfragments wurde ein Ansatz von $22 \mu$ verwendet, wobei die Volumina der einzelnen Komponenten jeweils verdoppelt wurden und die DNA bei $2 \mu$ l belassen wurde.

Tab. 8 PCR-Bedingungen für die beiden TGFB1-Fragmente

\begin{tabular}{|c|c|c|c|c|}
\hline PCR-Programm & \multicolumn{2}{|c|}{ Intron 2-Fragment } & \multicolumn{2}{|c|}{ Promotor-Fragment } \\
\hline $\begin{array}{l}\text { Initiale Denaturierung } \\
\text { Amplifikation ( } 35 \text { mal): }\end{array}$ & $95^{\circ} \mathrm{C}$ & $5,30 \mathrm{~min}$ & $95^{\circ} \mathrm{C}$ & $10 \min$ \\
\hline -Denaturierung & $95^{\circ} \mathrm{C}$; & $30 \mathrm{~s}$ & $95^{\circ} \mathrm{C}$ & $75 \mathrm{~s}$ \\
\hline $\begin{array}{l}\text {-Annealing } \\
\text {-Elongation }\end{array}$ & $\begin{array}{l}58,4^{\circ} \mathrm{C} \text {; } \\
72^{\circ} \mathrm{C} .\end{array}$ & $30 \mathrm{~s}$ & $\begin{array}{l}69,6^{\circ} \mathrm{C} \text {; } \\
72^{\circ} \mathrm{C} \text {. }\end{array}$ & $30 \mathrm{~s}$ \\
\hline Terminale Elongation & $72^{\circ} \mathrm{C}$ & $10 \mathrm{~min}$ & $72^{\circ} \mathrm{C}$ & $10 \mathrm{~min}$ \\
\hline Lagerung & $8^{\circ} \mathrm{C}$ & & $8^{\circ} \mathrm{C}$ & \\
\hline
\end{tabular}

\subsubsection{Bestimmung von Genotypen mittels Primerextentionsverfahren}

Bei dieser Methode können mehrere genetische Polymorphismen in einer Reaktion bestimmt werden. Typischerweise wird diese Methode bei der Bestimmung von EinzelnukleotidPolymorphismen (single nucleotide polymorphisms, SNPs) angewandt. Zunächst werden die Genbereiche, welche die zu bestimmenden SNPs enthalten, mittels PCR amplifiziert (siehe Kapitel 3.3.1). In meiner Arbeit kam ein Kit der Firma Applied Biosystems zum Einsatz (SNaPshot ${ }^{\mathrm{TM}}$-Mastermix). Nach der PCR erfolgte eine enzymatische Aufreinigung. Mittels Exonuklease 1 (Exo1) wird einzelsträngige Primer-DNA abgebaut. Damit wird eine Interferenz überschüssiger Primer aus der PCR-Reaktion mit der nachfolgenden verhindert. Mittels SAP (shrimp alkalic phosphatase) werden überschüssige dNTPs an deren 3'-Ende dephosphoryliert, wonach kein Einbau in einen Nukleotidstrang mehr möglich ist. Der 
Reaktionsansatz wurde in einer 384-Well Platte; die Zusammensetzung ist in Tab. 9 aufgelistet. Da diese Reaktionen auch die Komponenten der SNaPshot ${ }^{\text {TM}}$-Reaktion betreffen, müssen Exo1 und SAP vor dieser inaktiviert werden. Dies erfolgte bei $80^{\circ} \mathrm{C}$ für $15 \mathrm{~min}$ im Thermo-Cycler.

Tab. 9 Zusammensetzung des Verdaumixes zur Aufreinigung von PCR-Produkten

\begin{tabular}{ll}
\hline & Volumen/Reaktion \\
\hline SAP-Puffer & $0,6 \mu \mathrm{l}$ \\
EXO $1(10 \mathrm{U} / \mu \mathrm{l})$ & $0,705 \mu \mathrm{l}$ \\
SAP $(1 \mathrm{U} / \mu \mathrm{l})$ & $1,695 \mu \mathrm{l}$ \\
PCR-Produkte & $6 \mu \mathrm{l}$ \\
\hline
\end{tabular}

Standardmäßig wurde ein Reaktionsvolumen von $3 \mu \mathrm{l}$ verwendet. Sollte ein derartiger Ansatz für mehr als drei SNaPshot ${ }^{\mathrm{TM}}$-Reaktionen verwendet werden, wurden die Volumina entsprechend angepasst.

Mit den aufgereinigten PCR-Produkten wurde nun die SNaPshot ${ }^{\mathrm{TM}}$-Reaktion entspreched des Pipettierschemas in Tab. 10 auf einer 384-Well-Platte angesetzt und die Reaktion gemäß

Tab. 11 gestartet.

Tab. 10 Reaktionsansatz für SNaPshot ${ }^{\mathrm{TM}}$-PCR (auf Eis pipettiert)

\begin{tabular}{ll}
\hline & Volumen/Reaktion \\
\hline $\mathrm{ddH}_{2} \mathrm{O}$ & $2 \mu \mathrm{l}$ \\
$\mathrm{SNaPshot}^{\mathrm{TM}}$-Mastermix & $0,5 \mu \mathrm{l}$ \\
Pooled Primer & $0,5 \mu \mathrm{l}$ \\
Aufgereinigtes PCR-Produkt & $2 \mu \mathrm{l}$ \\
\hline
\end{tabular}

Tab. 11 Reaktionsbedingungen für SNaPshot ${ }^{\mathrm{TM}}$-Reaktion

\begin{tabular}{llll}
\hline Phase & Zeit & Temperatur & \\
\hline Initiale Denaturierung & $2 \mathrm{~min}$ & $96^{\circ} \mathrm{C}$ & 26 Zyklen \\
\hline - Denaturierung & $10 \mathrm{~s}$ & $96{ }^{\circ} \mathrm{C}$ & \\
- Annealing & $5 \mathrm{~s}$ & $50^{\circ} \mathrm{C}$ & \\
- Elongation & $30 \mathrm{~s}$ & $60^{\circ} \mathrm{C}$ & $72^{\circ} \mathrm{C}$ \\
\hline Terminale Elongation & $10 \mathrm{~min}$ & $8^{\circ} \mathrm{C}$ \\
\hline Lagerung & $\infty$ &
\end{tabular}

Im SNaPshot ${ }^{\mathrm{TM}}$-Mastermix sind Puffer, ddNTPs und Polymeraseenzym enthalten. Den ddNTPs fehlt im Gegensatz zu Desoxyribonukleosiden (dNTPs) der klassischen PCR am 3'Ende eine Hydroxylgruppe, weshalb keine Elongation über das ddNTP hinaus mehr möglich ist. Auf diese Weise wird sicher gestellt, dass am 3'-Ende des spezifischen Primers genau ein ddNTP komplementär zum vorliegenden Allel der Matrize eingebaut wird. Dabei sind die vier Basen mit unterschiedlichen Fluoreszenzfarbstoffen gekoppelt (Tab. 12). 
Tab. 12 Fluoreszenz-Markierungen der verwendeten ddNTPs für die SNaPshot ${ }^{\mathrm{TM}}$-Reaktion

\begin{tabular}{|c|c|c|}
\hline ddNTP & Fluoreszenzfarbstoff & Farbe \\
\hline$A$ & $\mathrm{dR6G}$ & grün \\
\hline C & dTAMRA $^{\text {TM }}$ & schwarz \\
\hline G & $\mathrm{dR} 110$ & blau \\
\hline $\mathrm{T}$ & $\mathrm{dROX}^{\mathrm{TM}}$ & rot \\
\hline
\end{tabular}

Die für diese Reaktion eingesetzten spezifischen Primer binden komplementär direkt neben dem zu bestimmenden Genpolymorphismus und müssen sich in ihrer Länge zur späteren basengenauen Auftrennung im Sequenzierer mittels Kapillar-Gelelektrophorese unterscheiden. Dazu tragen gegebenenfalls auch unspezifische Verlängerungen an deren 5'Ende bei. Die 74 zu analysierenden Genpolymorphismen wurden über insgesamt sieben SNaPshot ${ }^{\mathrm{TM}}$-Reaktionen bestimmt (Zuordnung zu den jeweiligen Pools siehe Tab. 2).

Die darauf folgende zweite Aufreinigung mit SAP und SAP-Puffer im Verhältnis 1:1 diente der Eliminierung überschüssiger ddNTPs, die durch die Bildung von Nebenprodukten bei der späteren Auswertung im Sequenzer zu unspezifischen Störsignalen führen könnten. Dieser Ansatz wurde bei $37^{\circ} \mathrm{C}$ für $30 \mathrm{~min}$ im Wärmeschrank inkubiert. Anschließend wurden $1 \mu \mathrm{l}$ dieser aufgereinigten Produkte zu $10 \mu \mathrm{l}$ einer vorgelegten Formamid-Lösung, welche zuvor mit dem Längenstandard Gene Scan 120 versetzt wurde, auf eine 96-Well-Sequenzierplatte pipettiert. Dieser Ansatz wurde für $5 \mathrm{~min}$ bei $95{ }^{\circ} \mathrm{C}$ im Thermo-Cycler denaturiet und anschließend sofort für ca. $10 \mathrm{~min}$ auf Eis gelagert. Die Zugabe des Formamids sollte die Renaturierung der Primer verhindern. Schließlich wurden die Proben in einem 16-KapillarSequenzierer analysiert. Die Auswertung der Daten erfolgte mittels der Genescan ${ }^{\mathrm{TM}}$ Analysis Version 3.5.1.Software. Ein Beispiel für ein Elektropherogramm ist in Abb. 1 zu sehen. 


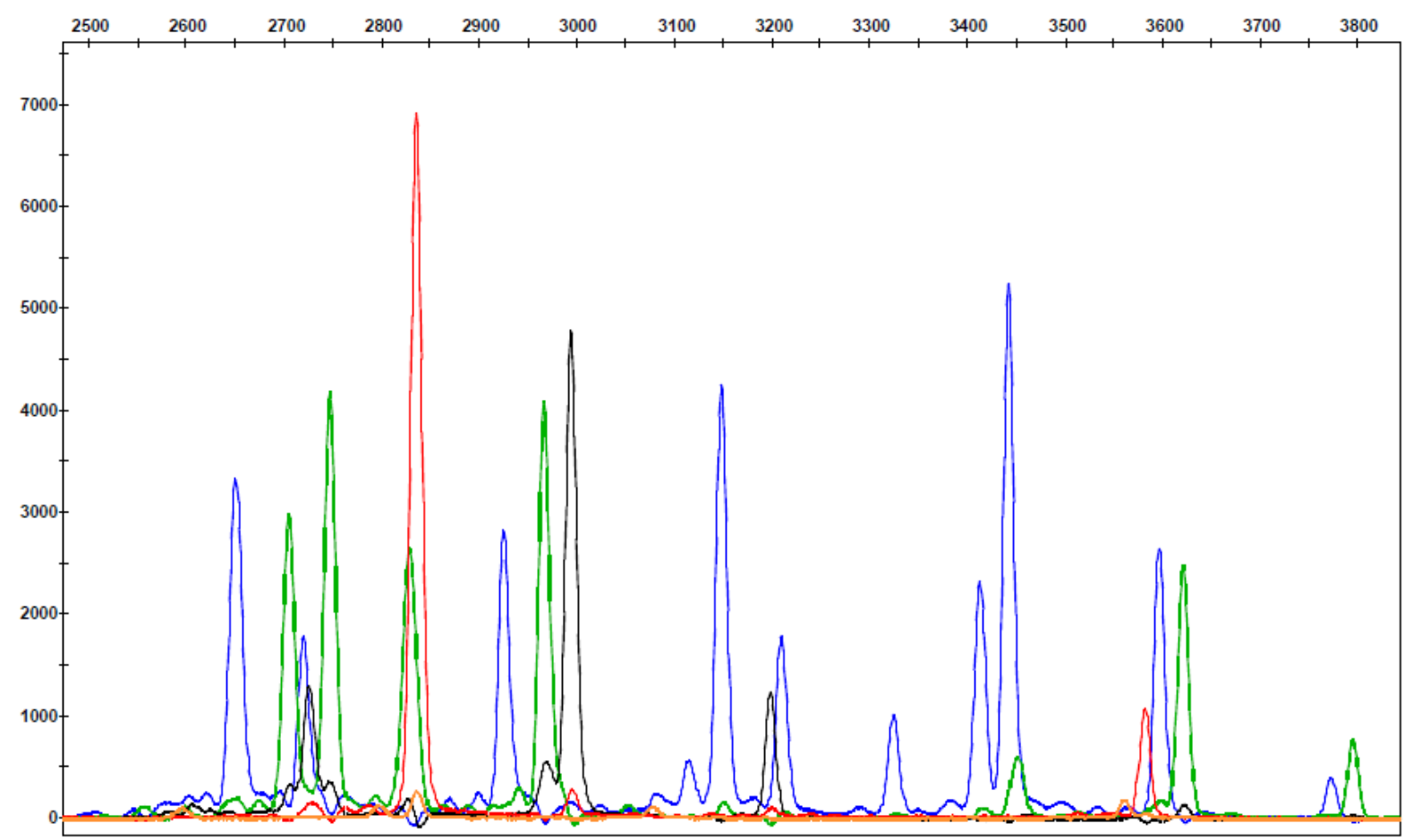

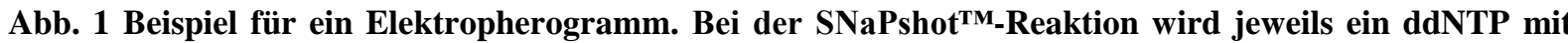
Fluoreszenzmarkierung der Base $($ blau $=$ Guanin, grün $=$ Adenin, schwarz $=$ Cytosin, rot $=$ Thymin $)$ am 3'-Ende des SNaPshot ${ }^{\text {TM}}$-Primers eingebaut, welche anschließend in einem Kapillarsequenzierer entsprechend ihrer Länge aufsteigend von links nach rechts aufgetrennt wurden.

\subsubsection{Fragmentlängenanalyse einer 9bp-Deletion im $T G F B R 1^{\star} 6 A$}

Die TGFBRI*6A-Genvariante, welcher einer Deletion von $9 \mathrm{bp}$ entspricht, wurde mittels Fragmentlängenanalyse im Sequenzierer bestimmt. Zunächst wurde der Bereich um die Deletion mittels PCR amplifiziert. Die exakte Differenzierung der Allelkonfiguration erfolgt bei dieser Methode über den Längenunterschied von 9 bp der amplifizierten PCR-Fragmente (Wildtyp-Allel mit 221 bp, Deletion mit 212 bp). Durch Farbmarkierung (FAM) einer der beiden Primer am 5'-Ende können diese Fragmente im Sequenzierer detektiert werden (Primersequenz siehe Tab. 2). Der Ansatz der PCR wurde entsprechend Tab. 13 erstellt. Die Bedingungen der PCR sind in Tab. 14 dargestellt.

Für die Sequenzierung der TGFBRI-Deletion wurde eine 1:200-Verdünnung des fluoreszenzmarkierten Längenstandards Gene Scan 400HD in Formamid auf einer 96-WellSequenzierplatte vorgelegt und $1 \mu 1$ des PCR-Reaktionsproduktes hinzugefügt. Dieser Ansatz

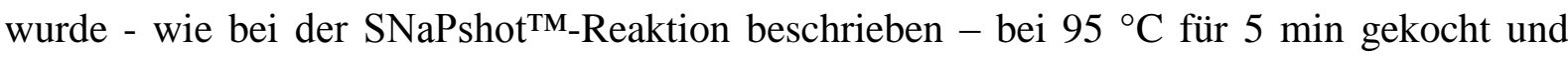
dann rasch auf Eis abgekühlt. Die Analyse der Proben erfolgte wiederum in einem 16-Kapillarsequenzierer. Zur Auswertung kam erneut die Software Genescan Analysis Version 3.5.1. zur Anwendung. 
Tab. 13 Pipettierschema für Einzel-PCR der TGFBR1-Deletionsvariante

\begin{tabular}{lll}
\hline & Volumen/Reaktion & Endkonzentration \\
\hline 10 x PCR-Puffer & $1,1 \mu \mathrm{l}$ & $1 \mathrm{x}$ \\
Q-Solution $(5 \mathrm{x})$ & $2,2 \mu \mathrm{l}$ & $1 \mathrm{x}$ \\
dNTP $(10 \mathrm{mM})$ & $0,22 \mu \mathrm{l}$ & $0,2 \mathrm{mM}$ \\
Primer-forward $(100 \mu \mathrm{M})$ & $0,11 \mu \mathrm{l}$ & $1 \mu \mathrm{M}$ \\
Primer-reverse $(100 \mu \mathrm{M})$ & $0,22 \mu \mathrm{l}$ & $2 \mu \mathrm{M}$ \\
Taq DNA-Polymerase $(5 \mathrm{U} / \mu \mathrm{l})$ & $0,055 \mu \mathrm{l}$ & $0,025 \mathrm{U} / \mu \mathrm{l}$ \\
ddH $_{2} \mathrm{O}$ & $6,095 \mu \mathrm{l}$ & \\
Summe MasterMix & $10 \mu \mathrm{l}$ & \\
Genomische DNA & $1 \mu \mathrm{l}$ \\
\hline Summe & 11 & \\
\hline
\end{tabular}

Tab. 14 PCR-Programm zur Amplifikation des Sequenzbereichs der TGFBR1-Deletionsvariante

\begin{tabular}{llll}
\hline Phase & Zeit & Temperatur & \\
\hline Initiale Denaturierung & $10 \mathrm{~min}$ & $95^{\circ} \mathrm{C}$ & 35 Zyklen \\
- Denaturierung & $75 \mathrm{~s}$ & $95^{\circ} \mathrm{C}$ & \\
- Annealing & $1 \mathrm{~min}$ & $65^{\circ} \mathrm{C}$ & \\
- Elongation & $1 \mathrm{~min}$ & $72^{\circ} \mathrm{C}$ & \\
\hline Terminale Elongation & $10 \mathrm{~min}$ & $72^{\circ} \mathrm{C}$ & \\
\hline Lagerung & $\infty$ & $8^{\circ} \mathrm{C}$ \\
\hline
\end{tabular}

\subsection{Primärkultur von Fibroblasten}

\subsubsection{Patienten für Fibroblastenkultur}

Für die Primärkultur von Fibroblasten wurden Hautproben eines Teils $(n=48)$ der oben beschriebenen Patienten (siehe Abschnitt 3.1) mit Rektumkarzinom angezüchtet. Von den Patienten wurden aus dem Randbereich des Operationsgebietes außerhalb des Bestrahlungsfeldes Hautproben entnommen. Die Hautstücke wurden in 0,9 \% Kochsalzlösung eingelegt. Diese Untersuchungen sind Teil des Projekts der Klinischen Forschergruppe KFO179, wofür ein Ethikvotum vorliegt und in welches die Patienten nach Aufklärung schriftlich eingewilligt hatten.

\subsubsection{Fibroblasten-Auswuchstechnik}

Die Hautstücke wurden unter sterilen Bedingungen weiter verarbeitet. Das Zuschneiden der Hautproben erfolgte in einer Petrischale. Subkutanes Fettgewebe wurde entfernt. Das verbleibende Präparat aus Epidermis und Dermis wurde in kleine Stücke $(5 \times 5 \mathrm{~mm})$ geschnitten und diese mit der Eipdermis nach oben in eine $125 \mathrm{~cm}^{2}$ große Zellkulturflasche gesetzt und leicht angedrückt. Um ein Ablösen der Hautstiucke zu verhindern, wurde in einer Ecke der Flasche vorsichtig $20 \mathrm{ml}$ Primärmedium zugegeben, mit dem die Proben langsam umspült wurden. Die Hautstücke wurden dann für ca. 3-4 Wochen in einem Brutschrank inkubiert. Mindestens 1x pro Woche wurden die Ansätze mikroskopisch kontrolliert und ggf. schwimmende Hautstücke entfernt. Während der Wachstumsphase wurde bei Bedarf das 
Primärmedium gewechselt (Farbumschlag rot zu gelb). Wenn genügend Fibroblasten aus dem Hautstück ausgewachsen waren und sich eine Kolonie um das Hautstïck gebildet hatte, wurden die Hautstücke vorsichtig entfernt. Um den Zellrasen möglichst unbeschadet zu lassen, wurde mit einem Skalpell um das Hautstück gefahren und dieses vorsichtig abgelöst. Die Zellkulturflaschen wurden bis zur vollständigen Konfluenz der Fibroblasten im Brutschrank weiter inkubiert und dann passagiert.

\subsubsection{Passagieren der Primärkultur}

Zum Passagieren wurde das Primärmedium entfernt und die Zellkulturflasche mit $20 \mathrm{ml}$ PBS gespült. Anschließend wurden $5 \mathrm{ml}$ Trypsin zugegeben und für $3 \mathrm{~min}$ im Brutschrank inkubiert. Danach konnten die Fibroblasten durch leichtes Klopfen vom Boden der Zellkulturflasche gelöst werden. Die Zellsuspension wurde abgenommen und zum Inaktivieren des Trypsins in ein mit $10 \mathrm{ml}$ Primärmedium befülltes $50 \mathrm{ml}$-Röhrchen gegeben. Es folgte eine Zentrifugation bei $500 \mathrm{~g}$ für $8 \mathrm{~min}$ bei RT. Der Überstand wurde anschließend dekantiert und das Zellpellett mit $15 \mathrm{ml}$ Primärmedium in einem $50 \mathrm{ml}$-Röhrchen resuspendiert. In fünf Zellkulturflasche $\left(75 \mathrm{~cm}^{2}\right)$ wurden jeweils $17 \mathrm{ml}$ Primärmedium vorgelegt und von der Zellsuspension jeweils $3 \mathrm{ml}$ zugegeben. Daraufhin wurden die Zellkulturflaschen wieder zur Inkubation in den Brutschrank gelegt. Nach Konfluenz wurden die Zellen erneut abtrypsiniert und gesplittet (1:2 auf zehn Zellkulturflaschen). Sobald zehn Flaschen gut bewachsen waren, erfolgte die Kryokonservierung der Zellen.

\subsubsection{Cryokonservierung der Fibroblasten}

Das Primärmedium wurde verworfen und die Zellen mit $10 \mathrm{ml}$ PBS gespült. Anschließend wurden sie, wie oben beschrieben (siehe 3.4.3), aus den Zellkulturflaschen abgelöst und abzentrifugiert. Danach wurden die Zellen konsequent gekühlt $\left(4{ }^{\circ} \mathrm{C}\right)$ gehalten, da das im Einfriermedium enthaltene DMSO (Dimethylsulfoxid) bei RT zytotoxisch ist. Nach dem Zentrifugieren wurde der Überstand verworfen und das Zellpellet in 7,5 ml kaltes Einfriermedium resuspendiert. Davon wurden jeweils $1,5 \mathrm{ml}$ in fünf auf Eis gelagerte Kryoröhrchen verteilt. Diese wurden dann vor dem Einfrieren bei $-80{ }^{\circ} \mathrm{C}$ in einen Einfrierbehälter mit Isopropanol (Mister Frosty ${ }^{\mathrm{TM}}$ ) gesetzt, der ein gleichmäßiges Herunterkühlen der Zellen gewährleistet. Am nächsten Tag wurden die Zellen in Stickstoff überführt, bis sie zu Beginn der Versuche wieder aufgetaut wurden. 


\subsection{Fibroblastenstudie}

\subsubsection{Auftauen von Fibroblasten}

Für die experimentelle Studie wurden die kryokonservierten Fibroblasten aufgetaut. Zur Verdünnung des zytotoxischen DMSO wurden zunächst $20 \mathrm{ml}$ Kulturmedium in ein $50 \mathrm{ml}-$ Röhrchen vorgelegt. Pro Zelllinie wurde ein Kryoröhrchen aus dem flüssigen Stickstoff entnommen und in der Hand aufgetaut, bis der Eiskern mobil war und sofort in das vorlegte Kulturmedium gegeben. Nach dem Zentrifugieren dieser Ansätze (500 g, 7 min, RT) wurde der Überstand abgegossen, das Zellpellett in Kulturmedium resuspendiert, in eine Zellkulturflasche gegeben und im Brutschrank inkubiert.

\subsubsection{Passagieren der aufgetauten Fibroblasten}

Das Wachstum der Fibroblasten wurde mit dem Mikroskop kontrolliert. Wenn der Boden der Zellkulturflasche geschlossen bewachsen war, wurden die Fibroblasten passagiert. Dafür wurde das Kulturmedium entfernt und die Flaschen mit $10 \mathrm{ml}$ PBS gespült. Anschließend wurden $3 \mathrm{ml}$ Trypsin pro Flasche zugegeben und für $3 \mathrm{~min}$ im Wärmeschrank inkubiert. Danach konnten die Fibroblasten vom Boden der Zellkulturflasche durch leichtes Klopfen gelöst werden, in ein mit $5 \mathrm{ml}$ Kulturmedium gefülltes 50-ml-Röhrchen zum Inaktivieren des Trypsins gegeben und zentrifugiert (500 g, $5 \mathrm{~min}$, RT) werden. Der Überstand wurde anschließend abgegossen und das Zellpellet mit $12 \mathrm{ml}$ Kulturmedium im 50-ml-Röhrchen resuspendiert. Es wurden jeweils $3 \mathrm{ml}$ der resuspendierten Fibroblasten in vier Zellkulturflaschen $\left(75 \mathrm{~cm}^{2}\right)$ gegeben, in die vorher schon $17 \mathrm{ml}$ Kulturmedium vorgelegt wurde. Anschließend wurden die Flaschen wieder in den Brutschrank gelegt.

\subsubsection{Zellzahlbestimmung}

Das Wachstum der Zellen wurde wieder regelmäßig mit dem Mikroskop kontrolliert. Wenn die Zellen einen dichten Rasen gebildet hatten, wurde eine Zellzahlbestimmung durchgeführt. Dazu wurden die Zellen nach Trypsinierung und Zentrifugation in $5 \mathrm{ml}$ Kulturmedium resuspendiert und mittels einer Neubauer-Zählkammer ausgezählt. Dazu wurde die Zellsuspsension in einem Verhältnis von 1:1 mit $15 \mu \mathrm{l}$ Trypanblau, welches tote Zellen anfärbt, vermischt und auf die Neubauer-Kammer gegeben. Dabei wurden vier Großquadranten, welche in der Hämatologie für die Zählung von Leukozyten benutzt werden, ausgezählt. Eines dieser Großquadrate hat ein Volumen von $0,1 \mu 1$. Anschließend wurden die Zellen auf eine Konzentration von 50.000 Zellen pro ml eingestellt. 


\subsubsection{Vorbereitung der Versuchsreihe}

Für die Messreihen wurden 6-Well-Platten für RNA- und Proteinanalytik sowie schwarze 96-Well-Platten für fluorometrische Funktionsmessungen (Zellviabilität, ROS-Bildung) verwendet. Die 6-Well-Platten wurden mit jeweils $2 \mathrm{ml}$ der Zellsuspension (gesamte Zellzahl 100.000/pro Well) befüllt, pro nachfolgender Behandlung wurden drei Wells verwendet. In die 96-Well-Platten wurden jeweils $100 \mu \mathrm{l}$ (d. h. insgesamt 5.000 Zellen/pro Well) gegeben, hierbei wurden sechs Wells pro Behandlung (siehe unten Kapitel 3.5.5) verwendet. Die Platten wurden anschließend in den Wärmeschrank gestellt. Es erfolgte wieder eine tägliche Wachstumskontrolle durch Mikroskopieren. Wenn die Wells dicht bewachsen waren, wurden die Versuche gestartet.

\subsubsection{Simulation der klinischen Radiochemotherapie}

Die Zellen wurden einer Behandlung unterzogen, die das neoadjuvante Therapie-Protokoll bei den Patienten abbilden soll. Hierbei betrug die Behandlungsphase eine Woche und die Beobachtungsphase zwei Wochen (Abb. 2).

\section{Kultivierte Fibroblasten, $\mathrm{n}=48$}
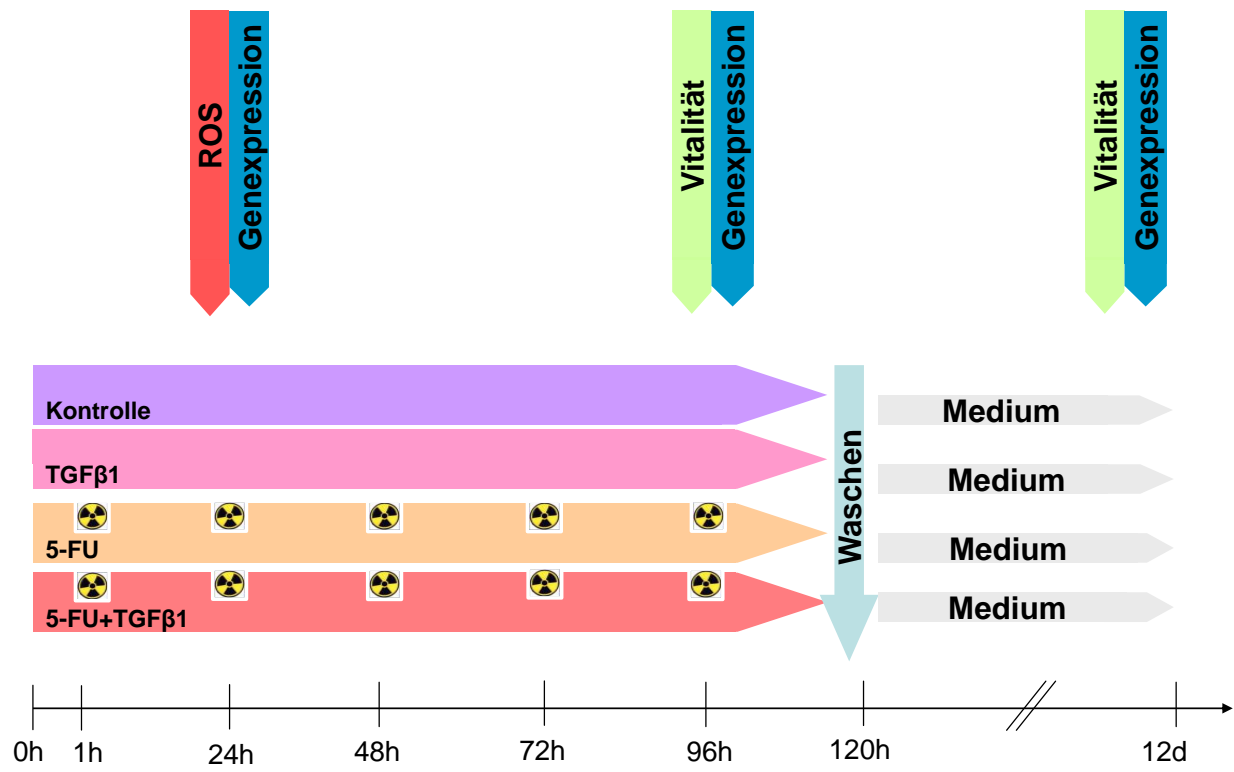

Abb. 2 Behandlungs- und Beobachtungsplan. Für detaillierte Beschreibung siehe Text.

Die 6- und 96-Well-Platten wurden zu Behandlungsbeginn entweder nur mit Medium (Kontrolle), mit TGFß1 (ad $10 \mathrm{ng} / \mathrm{ml}$ ), mit 5-FU (ad $600 \mathrm{ng} / \mathrm{ml}$ ) oder einer entsprechenden Kombination aus TGF $\beta 1$ und 5-FU befüllt. Dabei wurden bei den 6-Well-Platten jeweils drei Wells, bei den 96-Well-Platten jeweils sechs Wells pro Behandlung angesetzt. Eine Stunde später und an den vier darauffolgenden Tagen erfolgte immer zur gleichen Uhrzeit eine 
Bestrahlung (1,8 Gy) der Platten mit 5-FU und der Kombination aus 5-FU und TGF $\beta 1$. Die Messung Behandlungs-induzierte Effekte auf die Bildung von Sauerstoffradikalen (DCFHAssay) fand an Tag 2, $3 \mathrm{~h}$ nach Bestrahlung, die Bestimmung der Zellviabilität (mittels Alamar Blue-Assay) an Tag 5 wiederum 3 h nach Bestrahlung und Tag 12 zur entsprechenden Uhrzeit statt. Jeweils $1 \mathrm{~h}$ nach diesen Funktionsmessungen wurde aus den 6-Well-Platten Probenmaterial für spätere RNA- und Proteinanalytik gewonnen. Die Stabilität von TGF $\beta 1$ und 5-FU nach einmalierg Applikation wurde für die Dauer der Behandlungsphase über 5 Tage nachgewiesen (durch ELISA Kapitel 3.7.1 bzw. HPLC Kapitel 3.7.2). Nach 120 h wurden die Zellansätze gewaschen und mit frischem Medium versetzt.

Die Fibroblasten wurden in der Abteilung Strahlentherapie der Universität Göttingen bestrahlt. Dazu wurde das Gerät Stabiliplan der Firma Siemens benutzt, mit dem die Zellen an fünf aufeinanderfolgenden Tagen mit 1,8 Gy bei einer Anodenspannung von $200 \mathrm{kV}$ und einer Stromstärke von $15 \mathrm{~mA}$ bestrahlt wurden. Insgesamt ergab sich also eine Dosis von 9 Gy. Dabei wurden die Zellen immer mittig im Strahlengang platziert und immer der gleiche Abstand zur Strahlenquelle eingehalten, um eine möglichst gleichmäßige Dosisapplikation zu gewährleisten. Danach wurden die Platten weiter inkubiert.

\subsubsection{Gewinnung von mRNA- und Proteinproben}

Die Asservierung erfolgte am zweiten, fünften und zwölften Tag jeweils $4 \mathrm{~h}$ nach Bestrahlung. Das Medium wurde abgesaugt und jedes Well mit $2 \mathrm{ml}$ PBS gewaschen. Anschließend wurden pro Well $500 \mu \mathrm{l}$ Trypsin zugegeben und die Platten für $3 \mathrm{~min}$ im Brutschrank inkubiert. Danach ließen sich die Zellen durch leichtes Klopfen lösen. Diese wurden rasch in $5 \mathrm{ml}$-Röhrchen überführt, in welchen zuvor 2,5 ml Kulturmedium vorgelegt wurde. Nach Zentrifugation bei $500 \mathrm{~g}$ und RT für $5 \mathrm{~min}$ wurde der Überstand vorsichtig dekantiert. Nach Waschen mit $4 \mathrm{ml}$ PBS und erneutem Zentrifugieren wurde das trockene Pellet in $100 \mu \mathrm{l}$ des APL-Puffer (aus AllPrep RNA/Protein Kit) resuspendiert. Pro $10 \mathrm{ml}$ APL-Puffer waren zuvor jeweils eine Tablette EDTA-free-Complete Mini bzw. PhosStop aufgelöst worden. Nach einer Inkubation von 5 min bei $37{ }^{\circ} \mathrm{C}$ wurde der Ansatz durch Pipettieren gemischt, in 1,5 ml Eppendorf überführt und bis zur weiteren Verwendung bei $-80{ }^{\circ} \mathrm{C}$ gelagert.

\subsubsection{Intrazelluläre ROS-Messung}

Durch Verwendung von DCFH-DA (2',7'-Dichlorfluorescein-Diacetat) kann Wasserstoffperoxid als globaler Parameter für ROS nachgewiesen werden. Das lipophile DCFH-DA diffundiert nach Zugabe schnell ins Zellinnere und wird dort durch Esterasen in DCFH 
deacetyliert. Wasserstoffperoxid oxidiert das DCFH, wodurch schließlich das fluoreszierende DCF entsteht.

Für die ROS-Messung wurden schwarze 96-Well-Mikrotiterplatten mit klarem Boden verwendet. Pro Well wurden 5.000 Zellen in $100 \mu$ Kulturmedium eingesetzt und bis zur Konfluenz wachsen gelassen (3-6 d). Jede Zelllinie wurde auf zwei Platten entsprechend dem Versuchsansatz für die Funktionsmessungen ausgebracht (Kapitel 3.5.5). Jede der vier Bedingungen wurde in sechs identischen Replikaten angelegt. Am zweiten Tag wurden $1 \mathrm{~h}$ vor Bestrahlung $10 \mu \mathrm{l}$ einer 1:100-Verdünnung von DCFH-DA (ad $10 \mu \mathrm{M}$ ) pro Well zugegeben, die Platte leicht gevortext und weiter im Brutschrank inkubiert. Nach Bestrahlung mit 1,8 Gy und nachfolgend weiterer Inkubation für $3 \mathrm{~h}$ wurde die Fluoreszenz im Tecan Ultra gemessen. Für alle Fibroblastenlinien wurden einheitliche Einstellungen bei einer Anregung mit $485 \mathrm{~nm}$ und einer Emission bei $535 \mathrm{~nm}$ verwendet. Die Platten mit den unbestrahlten und bestrahlten Proben einer Fibroblastenlinie wurden unmittelbar nacheinander gemessen.

\subsubsection{Zellviabilitätsmessung mittels Alamar Blue}

Die Vitalitätsmessung erfolgte durch einen dunkelblauen Farbindikator (Resazurin, oxidierte Form), der in den Mitochondrien durch Elektronenaufnahme seine Farbe zu rot (Resorufin, reduzierte Form) ändert. Die Quantifizierung von letzterem spiegelt hierbei die Viabilität der Zellen wider.

Die Vibilitätsmessung erfolgte ebenfalls auf schwarzen 96-Well-Mikrotiterplatten mit klarem Boden. Die Versuchsbedingungen, abgesehen von den Zeitpunkten (hier an Tag 5 und Tag 12), entsprachen denen für die ROS-Messung. Pro Bedingung und Zeitpunkt wurden sechs identische Ansätze pipettiert. An Tag 5 wurden 1 h vor Bestrahlung $10 \mu$ l Alamar Blue pro Well zugegeben, die Platte leicht gevortext und in den Brutschrank gestellt. Die Platten wurden für die Bestrahlung mit 1,8 Gy kurzzeitig aus dem Brutschrank genommen. Nach weiteren $3 \mathrm{~h}$ Inkubation wurde die Fluoreszenz-Messung in einem Tecan Ultra-Gerät mit Anregung bei $485 \mathrm{~nm}$ und Emission bei $612 \mathrm{~nm}$ durchgeführt. Die Messung an Tag zwölf verlief analog zu der anTag 5, außer dass hier keine Bestrahlung stattfand.

\subsection{RNA-Analytik}

\subsubsection{Isolierung und Quantifizierung von RNA}

Um den Expressionszustand der uns interessierenden Zielgene zu bestimmen, musste zunächst die RNA isoliert werden. Dafür wurden die in $-80{ }^{\circ} \mathrm{C}$ gelagerten Proben auf Eis 
aufgetaut. Um die Degradierung von RNA durch RNAsen zu verhindern, fanden alle Arbeiten unter RNAse-freien Bedingungen statt (entsprechendes Verbrauchsmaterial, Behandlung der Arbeitsflächen mit RNAse-Zap).

Zur Aufreinigung der Proben und Trennung von RNA und Proteinen wurde das AllPrep RNA/Protein Kit in Kombination mit dem QiaCube-Roboter gemäß der Herstelleranleitung verwendet. Dieses Kit beinhaltet eine Entfernung von DNA. Am Ende wurden die isolierten Proben auf Eis gelagert, um das Risiko einer enzymatischen Degradierung zu minimieren. Die Quantifizierung erfolgte mit einem BioPhotometer und einer speziellen Küvette für Mikrovolumina (LabelGuard). Dazu wurde ein Probenvolumen von $3 \mu$ l auf die Messzelle aufgetragen. Über Absorption bei $260 \mathrm{~nm}$ wurde der Nukleinsäure-Gehalt bestimmt. Dabei entspricht eine Extinktion von 1 bei $260 \mathrm{~nm}$ einer RNA-Konzentration von $40 \mu \mathrm{g} / \mathrm{ml}$. Die Konzentration der Proteine wurde auf gleiche Weise bei ihrem Absorptionsmaximum von $280 \mathrm{~nm}$ bestimmt. Der Reinheitsgrad der RNA kann durch den Quotienten von 260/280 nm abgeschätzt werden, welcher zwischen 1,8 und 2,3 liegen sollte. Nach jeder Messung erfolgte die Reinigung der Messzelle. Als Leerwert diente die Absorption von doppelt destilliertem Wasser. Anschließend wurden die isolierten und quantifizierten Proben bei $-80^{\circ} \mathrm{C}$ gelagert.

\subsection{2 cDNA-Synthese}

Die Quantifizierung von RNA-Molekülen über DNA-basierte PCR-Verfahren erfordert zunächst eine Umschreibung in cDNA mittels reverser Transkriptase. Hierbei synthetisieren RNA-abhängige Polymerasen anhand einer RNA-Matrize einen komplementären cDNAStrang.

Für die resverse Transkription wurde standardmäßig $1 \mu \mathrm{g}$ Gesamt-RNA eingesetzt. Das entsprechende Volumen wurde mit 0,1 U dN6 Random-Primer und RNAse-freiem Wasser auf $18,5 \mu \mathrm{l}$ ergänzt. Dieser Ansatz wurde dann auf $72^{\circ} \mathrm{C}$ für $10 \mathrm{~min}$ im Thermocycler erhitzt, um die RNA zu denaturieren, und danach sofort auf Eis gebracht. Dann wurden pro Probe 11,5 $\mu 1$ Mastermix (Zusammensetzung siehe Tab. 15) zugefügt. Anschließend erfolgt die reverse Transkription im Thermocycler bei $50^{\circ} \mathrm{C}$ für 60 min und danach das Enzym bei $75^{\circ} \mathrm{C}$ für 15 min aktiviert.

Die cDNA-Proben wurden mit TE-Puffer auf eine finale Konzentration von $2 \mathrm{ng} / \mu \mathrm{l}$ (auf Basis der Quantifizierung für Gesamt-RNA) verdünnt und auf 96-Well-PCR-Platten ausgebracht, welche dann für die quantitativen real-time PCR-Messungen eingesetzt wurden. 
Tab. 15 Pipettierschema Mastermix Reverse Transkription

\begin{tabular}{ll}
\hline & Volumen/Reaktion \\
\hline $5 \times$ RT-Puffer & $6 \mu \mathrm{l}$ \\
$0,1 \mathrm{M}-\mathrm{DTT}$ & $2,5 \mu \mathrm{l}$ \\
$\mathrm{ddH} \mathrm{H}_{2} \mathrm{O}$ & $1,5 \mu \mathrm{l}$ \\
$10 \mathrm{mM}$ dNTPs & $1 \mu \mathrm{l}$ \\
RNAse Inhibitor & $0,5 \mu \mathrm{l}$ \\
Super Script III & $0,25 \mu \mathrm{l}$ \\
\hline Gesamt & $11,75 \mu \mathrm{l}$ \\
\hline
\end{tabular}

\subsubsection{Quantitative real-time PCR (qRT-PCR)}

Die qRT-PCR ist eine quantitative Echtzeit-PCR, die der Bestimmung der Expressionsstärke von Genen dient. In dieser Arbeit wurde dabei ein Verfahren mit einem spezifischen Primerpaar zur Amplifikation und einem sich in dsDNA interkalierenden Fluoreszenzfarbstoff zur Signaldetektion gewählt. Dabei wird das Fluoreszenzsignal während der Elongationsschritte gemessen, welches in einem bestimmten Bereich von Amplifikationszyklen der PCR proportional zur Menge der gebildeten PCR-Produkte ist. Im Bereich der exponenziellen Signalzunahme (in logarithmischer Darstellung linear) wird eine Signalintensität definiert und für die zu vergleichenden Proben einer Messplatte jeweils die zugehörige Zyklenzahl ermittelt. Über diese kann eine quantitative Aussage über die in der Probe enthaltenen RNA-Kopien des gemessenen Gens getroffen werden. Folgende Qualitätskriterien wurden für die einzelnen qRT-PCR-Assays festgelegt: Amplifikationseffizienz von mindestens 90\% (Bestimmung über Eichgerade in qRT-PCR), zum Nachweis der Spezifität ein singulärer Peak in der anschließenden Schmelzkurve (entspricht der ersten Ableitung des Fluoreszenzsignals bei einem graduell ansteigenden Temperaturgradienten) sowie eine singuläre Bande auf Agarosegel (letzteres nur bei Assayetablierung durchgeführt). Um messtechnische Variabilitäten so gering wie möglich zu halten, wurden alle Proben einer Messreihe für jedes zu analysierende Gen einzeitig auf einer Platte gemessen.

Für die einzelnen qRT-PCR-Assays wurde zunächst ein Mastermix gemäß Tab. 16 pipettiert. Davon wurden jeweils $7 \mu$ auf einer 384-Well-Platte vorgelegt (jede Probe als Duplikat) und dann jeweils $3 \mu \mathrm{l}$ der in TE-Puffer auf $2 \mathrm{ng} / \mu \mathrm{l}$ eingestellten cDNA-Proben hinzugefügt. Die Messung erfolgte mit einem ABI 7900HT-Gerät gemäß des in Tab. 17 genannten Ablaufs. Bei der initialen Aktivierung kommt es zur Dissoziiation der blockierenden Antikörper von der Polymerase. Anschließend werden die durch das spezifische Primerpaar flankierten Sequenzabschnitte amplifiziert, wobei das Fluoreszenzsignal bei dem hier verwendeten Verfahren, wie oben ausgeführt, während der Elongation gemessen wird. Zuletzt wird eine 
Schmelzkurve aufgezeichnet. Die Ergebnisse wurden mit Hilfe der SDS 2.1 Software ausgewertet.

Als Zielgene wurde in dieser Arbeit die mRNA-Expression der TGFB-Signalweg-Gene TGFB1, TGFBR1 und SMAD2, SMAD3, SMAD4 und SMAD7 sowie von CAT (in Bezug auf ROS), CDKN1A (als Postitivkontrolle für Strahlenwirkung) und CTGF (als Effektor des TGFB-Signalwegs) bestimmt. Ein wichtiger Aspekt beim Vergleich der zu messenden Proben ist die Normierung. Ungenauigkeiten beim Pipettieren der qRT-PCR-Platten wurden durch eine hoch standardisierte Vorgehensweise und eine Kalibrierung auf den Fluorszenzfarbstoff ROX (im qRT-PCR-Mastermix enthalten) als internem Standard minimiert. Kritischer sind etwaige Inhomogenitäten im Vorfeld der qRT-PCR, d. h. bei der RNA-Quantifizierung und insbesondere bei der reversen Transkription. Um diese Faktoren kontrollieren zu können, wurde die Expression der Zielgene auf die von Referenzgenen bezogen. Als solche dienten im Rahmen dieser Arbeit GAPDH und HPRT1, aus welchen zur Normierung ein gewichtetes Mittel gebildet wurde. Eine Anforderung an die Referenzgene war, dass sich deren Expression möglichst wenig durch die durchgeführten Behandlungen (1,8 Gy, $3 \mu \mathrm{M}$ 5-FU, TGF $\beta 1$ ) verändern.

Die Primersequenzen für die qRT-PCR-Assays sind in Tab. 3 gelistet.

Tab. 16 Pipettierschema für qRT-PCR

\begin{tabular}{ll}
\hline & Volumen/Reaktion \\
\hline Mastermix & $5 \mu \mathrm{l}$ \\
Primermix $(1: 10)$ & $0,2 \mu \mathrm{l}$ \\
ddH $_{2} \mathrm{O}$ & $1,8 \mu \mathrm{l}$ \\
$\mathrm{cDNA}(1: 10 \mathrm{ng} / \mu \mathrm{l})$ & $3 \mu \mathrm{l}$ \\
\hline Gesamt & $10 \mu \mathrm{l}$ \\
\hline
\end{tabular}

Tab. 17 qRT-PCR-Bedingungen

\begin{tabular}{llll}
\hline Phase & Zeit & Temperatur & \\
\hline Initiale Aktivierung & $15 \mathrm{~min}$ & $95^{\circ} \mathrm{C}$ & \multirow{2}{*}{45 Zyklen } \\
- Denaturierung & $15 \mathrm{~s}$ & $95^{\circ} \mathrm{C}$ & \\
- Annealing & $20 \mathrm{~s}$ & $60^{\circ} \mathrm{C}$ & \\
- Elongation & $40 \mathrm{~s}$ & $72^{\circ} \mathrm{C}$ & Ramp rate $2 \%$ bis $95^{\circ} \mathrm{C}$ \\
\hline Schmelzkurve & $15 \mathrm{~s}$ & $95^{\circ} \mathrm{C}$ & \\
& $15 \mathrm{~s}$ & $60^{\circ} \mathrm{C}$ & \\
\hline
\end{tabular}

\subsection{Protein-Analytik}

\subsubsection{TGF $\beta$-ELISA}

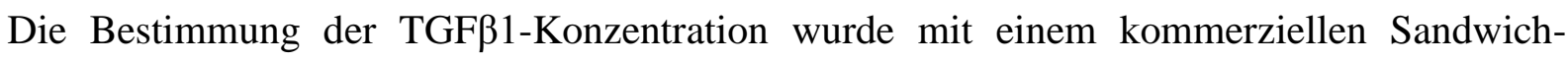
ELISA-Kit (human TGFß1-CytoSet) durchgeführt. Zu Beginn wurde nach Vorgabe des 
Herstellers die Coating Solution mit dem Coating Antibody hergestellt $(5 \mathrm{ml}$ Coating Buffer plus $20 \mu \mathrm{l}$ Coating Antibody im Verhältnis 1:250). Damit erfolgte eine Beschichtung von 96-Well-Maxi-Sorp-Platten mit je $100 \mu$ l, jede zu messende Probe in Doppelbestimmung. Die Platte wurde nun für $12-18 \mathrm{~h}$ bei $4^{\circ} \mathrm{C}$ inkubiert. Danach wurde die Lösung vorsichtig aus den Wells ausgeschüttet und die Flüssigkeitsreste mit saugfähigem Papier aufgenommen. Anschließend wurden die Wells zweimal mit $350 \mu 1$ gewaschen (Waschpuffer aus CytoSet Buffer Set). Danach wurde mit $350 \mu 1$ 5\% Milchpulver geblockt. Nach einer $1 \mathrm{~h}$ bei RT wurde die Platte erneut zweimal gewaschen. Die zu messenden Proben wurden 1:10 in Kulturmedium verdünnt und dann entsprechend den Angaben des Herstellers zunächst mit $\mathrm{HCl}$ angesäuert und dann mit $\mathrm{NaOH}$ neutralisiert. Aus diesen Ansätzen sowie den Standards für die Eichgerade wurden jeweils $100 \mu$ l (in Doppelbestimmung) in die Wells pipettiert. Sofort nach Zugabe der einzelnen Proben wurden $50 \mu$ l Detection Antibod zugefügt. Die Platte wurde sodann für $2 \mathrm{~h}$ bei RT und kontinuierlichem Schütteln bei $700 \mathrm{rpm}$ inkubiert. Anschließend wurde fünfmal mit jeweils $350 \mu \mathrm{l}$ Waschpuffer gewaschen. Dann wurden $100 \mu \mathrm{l}$ HRP-Streptavidin zugefügt und mit $700 \mathrm{rpm}$ für $30 \mathrm{~min}$ bei RT geschüttelt. Nach erneutem fünfmaligem Waschen wurden dann $100 \mu \mathrm{T}$ TMB (Tetramethylbenzidin) pro Well zugefügt und wieder mit 700 rpm für 30 min bei RT inkubiert. Nach Zugabe von $100 \mu 1$ Stop Solution wurde binnen $30 \mathrm{~min}$ bei $450 \mathrm{~nm}$ die Absorption gegen eine Referenzwellenlänge von $650 \mathrm{~nm}$ gemessen.

\subsubsection{Substanz-Analytik von 5-FU mit HPLC}

Die Bestimmung von 5-FU erfolgte mittels HPLC (high performance liquid chromatography). Zu Beginn wurden Stammlösungen verschiedener Konzentrationen von

5-FU $(1000 \mathrm{mg} / \mathrm{ml}, 100 \mu \mathrm{g} / \mathrm{ml}, 10 \mu \mathrm{g} / \mathrm{ml}, 1 \mu \mathrm{g} / \mathrm{ml})$ und von 5-Chlorouracil (5-CU) als internem Standard $(1000 \mu \mathrm{g} / \mathrm{ml}, 20 \mu \mathrm{g} / \mathrm{ml})$ hergestellt. Anschließend wurde das Fließmittel angesetzt. Die Herstellung der drei Qualitätskontrollen (80 ng/ml, 200 ng/ml, 1000 ng/ml) erfolgte aus den 5-FU-Stammlösungen durch Verdünnung in Rinderserum. Davon wurden Aliquots zu je $600 \mu \mathrm{l}$ bei $-80{ }^{\circ} \mathrm{C}$ eingefroren.

Vor Inbetriebnahme der HPLC-Maschine mussten die Säulen vor Beginn der Messung 30 min mit Wasser gespült werden. Danach wurde das Fließmittel mindestens $30 \mathrm{~min}$ bei einer Flussrate von 1,0 ml/min eingespült. Zur Überprüfung der chromatographischen Trennung wurden vor jedem Analyselauf $50 \mu \mathrm{l}$ eines Gemisches aus $50 \mu \mathrm{l}$ Stammlösung $(10 \mu \mathrm{g} / \mathrm{ml})$ von

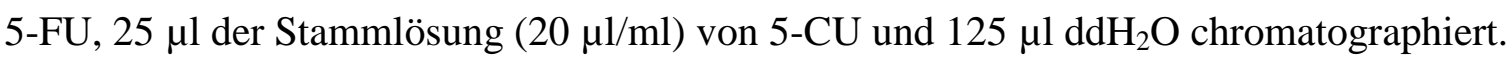

Die Retentionszeit unter den gegebenen Bedingungen beträgt für 5-FU 9,05 min, für 5-CU $18,50 \mathrm{~min}$. 
$\mathrm{Zu}$ jeder Analysenserie gehören eine Serie Eichproben, drei Qualitätskontrollen und die zu bestimmenden Proben. Alle Proben wurden nach dem Auftauen kurz zentrifugiert, um feste Bestandteile (Fibrinfasern, Proteinkonglomerate etc.) zu entfernen. Alle Proben wurden bis zur Extraktion auf Eis pipettiert. Die Aufarbeitung der Proben erfolgte, indem zunächst $250 \mu \mathrm{l}$ Probe in ein HPLC-Zentrifugenglas oder in ein 15-ml-Röhrchen gegeben und $25 \mu 1$ Stammlösung des internen Standards hinzu pipettiert wurden. Dieses Gemisch wurde anschließend mit $250 \mu \mathrm{l}$ 0,1 M Phosphatpuffer $\mathrm{pH}$ 6,0 versetzt. Nach Zugabe von $5 \mathrm{ml}$ Ethylacetat wurden die Proben 15 min geschüttelt und zur Phasentrennung anschließend $5 \mathrm{~min}$ bei $4500 \mathrm{rpm}$ zentrifugiert. Vom Überstand wurden $4 \mathrm{ml}$ in ein weiteres Zentrifugenglas überführt. Zum verbleibenden Rest wurden nochmals $5 \mathrm{ml}$ Ethylacetat wie zuvor hinzugegeben und zentrifugiert. Davon wurden $5 \mathrm{ml}$ des Überstandes abgenommen und mit den $4 \mathrm{ml}$ des Überstandes aus der ersten Zentrifugation vereinigt. Die vereinigten Überstände wurden bei $40{ }^{\circ} \mathrm{C}$ unter Stickstoffzufuhr eingedampft. Der Rückstand wurde in $150 \mu \mathrm{l}$ Flie $\beta$ mittel aufgenommen und bei Ultraschall für 5 min gelöst. Anschließend wurde für $30 \mathrm{~s}$ gevortext und danach bei $4500 \mathrm{~g}$ kurz zentrifugiert. Daraus wurden $50 \mu \mathrm{l}$ in HPLCEinsätze transferiert und dann chromatographiert.

Bei der Auswertung der Chromatogramme wurden die Rohdaten der 5-FU-Messwerte zunächst auf den internen Standard normiert. Zur Ermittlung der 5-Konzentrationen wurde zunächst auf Basis der Eichproben für den Bereich von 50-2000 ng/ml täglich die Eichfunktion berechnet. Mit den Regressionsparametern aus dieser Funktion wurden die 5-FU-Konzentrationen in den zu bestimmenden Proben berechnet.

\subsection{Bioinformatik}

Der numerisch größte Anteil der Variabilität im humanen Keimbahn-Genom entfällt mit ca. 12 Millionen auf so genannte Einzelbasen-Austausche (single nucleotid polymorphisms, SNPs) mit einer Frequenz des selteneren Allels von mindestens 1\% (Brockmoller und Tzvetkov 2008). Bei einer Gesamtgröße des menschlichen Genoms von 3 Milliarden Basenpaaren machen diese Positionen somit 0,4\% aus. Mit anderen Worten: Im Durchschnitt findet sich alle 250 Basenpaare ein solcher SNP.

Im Rahmen dieser Arbeit sollte die Bedeutung der Variabilität von sieben zentralen Genen des TGF $\beta$-Signalwegs (TGFB1, TGFBR1, TGFBR2, SMAD2, SMAD3, SMAD4, SMAD7) in Bezug auf Nebenwirkungen bei Radiochemotherapie untersucht werden. Die Auswahl der jeweiligen Polymorphismen sollte die genetische Vielfalt des entsprechenden Gens repräsentieren. Dafür wurden die Daten aus dem HapMap-Projekt zu Grunde gelegt. Mit der 
Haploview-Software wurde mittels des darin implementierten Tagging-Algorithmus ein Satz an Markern bestimmt, welcher alle in HapMap annotierten Polymorphismen mit einer Frequenz des selteneren Allels von mindestens $5 \%$ im betreffenden Genbereich $\pm 5 \mathrm{~kb}$ flankierender Sequenzen mit einer Stringenz von $r^{2}=0,5$ erfasst. Diese so ausgewählten Marker wurden dann an den klinischen Proben analysiert.

\subsection{Statistik}

In der Statistik können grundsätzlich deskriptive und analytische Verfahren unterschieden werden.

Mittels deskriptiver, d. h. beschreibender Statistik wurden in meiner Dissertation Datensätze geordnet, zusammengefasst, Häufigkeitsverteilungen erstellt und diese in Tabellenform oder grafisch veranschaulicht. Dies erfolgte zum Beispiel bei der Verteilung von Akut- und Spättoxizität, welche tabellarisch mit EXCEL von Microsoft dargestellt wurden. Veränderungen von Messparametern im Zeitverlauf oder als Vergleich unterschiedlicher Behandlungsbedingungen wurden als Säulen- oder als zweidimensionale Punktdiagramme ebenfalls mit EXCEL visualisiert. Bei Abhängigkeit eines Messparameters von einer unabhängigen Variablen, typischerweise einer Genotyp-Ausprägung, wurden Boxplots verwendet, welche mit SPSS-Softwarepaket, Version 12.0 (IBM, Chicago, IL) erstellt wurden.

Mittels analystischer Statistik wurde geprüft, ob

(i) die Verteilung der ermittelten Genotypen dem Hardy-Weinberg-Gleichgewicht entsprach (untersucht mittels $\mathrm{X}^{2}$-Test)

(ii) bei intervallskalierten Messparametern eine signifikante Abweichung von einer Normalverteilung vorlag (Kolmogorov-Smirnov-Test)

(iii) zwischen zwei intervallskalierten Datensätzen eine statistisch signifikante Korrelation bestand (Korrelationstest nach Pearson bei Annahme von normalverteilten Messparametern, Rangsummentest nach Spearman bei nicht-normalverteilten Daten)

(iv) sich intervallskalierte verbundene Datensätze (unterschiedliche Behandlungsbedingungen der in Fibroblasten simulierten Radiochemotherapie) signifikant unterschieden (gepaater t-Test, nachdem Vereinbarkeit mir Normalverteilung bestätigt)

(v) eine Abhängigkeit eines kontinuierlichen Messparameters (hier: Genexpressionsdaten) von einzelnen Genvarianten bzw. Toxizitätsgraden bestand: wurden mehrere Gruppen einer Genotyp- bzw. Toxizitätsgrad-Ausprägung verglichen, wurde der Jonckheere- 
Terpstra-Trend-Test verwendet, welcher einen auf- bzw. absteigenden Trend zwischen den Gruppen berücksichtigt; bei einem Vergleich von zwei Gruppen wurde hier der Mann-Whitney-U-Test eingesetzt.

(vi) zwischen zwei diskreten Variablen (Toxizitätsgrade versus Genotyp-Ausprägungen) eine signifikante Abweichung zwischen der beobachteten und der erwarteten Häufigkeitsverteilung zu verzeichnen war: mittels Fisher's exaktem Test bei einer 2x2-Kontigenztabelle, bei allen größeren Formaten mittels des nicht-parametrischen Kendall's-tau-Test)

(vii) nach Adjustierung auf nicht-genetische Merkmale als potenzielle Störfaktoren ein in univariater Analyse beobachteter Einfluss einer Genvariante auf die klinische Toxizität noch statistisch signifikant war (logistische Regression bei dichotomisierter Toxizität, ordinale Regression bei Betrachtung der Toxizität in mehrstufiger Ausprägung)

(viii) ein additiver Effekt einzelner, die Toxizität beeinflussender Genvarianten festzustellen war (ebenfalls mittels logistischer bzw. ordinaler Regression)

Um falsch-positive Ergebnisse bei der Assoziationsprüfung zwischen der klinischen Toxizität und 74 analysierten Genvarianten zu minimieren, wurde die Gesamtzahl der zur Verfügung stehende Datensätze von Patienten $(n=164)$ in eine Trainings- und Testkohorte mit 88 bzw. 76 Personen aufgeteilt (Details zu den Patientenkohorten siehe unter Kapitel 4.1). Die Ergebnisse der statistischen Testung in der Trainingskohorte wurden entsprechend der p-Werte, beginnend mit dem kleinsten, geordnet, welche die Signifikanz der Assoziation beschreiben. In dieser Reihenfolge wurden in der Testkohorte die Beziehungen zwischen Genotypen und Toxizität hierarchisch geprüft. Für den ersten dieser Tests galt ein Signifikanzniveau von 0,05. Für die nächst folgenden Tests wurde dieses Niveau herabgesetzt, indem der Wert von 0,05 durch die Anzahl der durchgeführten Tests nach Bonferroni dividiert wurde. Wurde die Gesamtkohorte ohne Unterteilung in Trainings- und Testset betrachtet, galt für alle untersuchten Genotyp-Toxizitäts-Assoziationsprüfungen ein Signifikanzniveau von 0,05/74 = $6,8 * 10^{-4}$. 


\section{Ergebnisse}

\subsection{Patientenkohorte}

Für die Prüfung eines möglichen Einflusses der genetischen Variabilität im TGF $\beta$-Signalweg auf akute und chronische Toxizitäten der Strahlentherapie mussten zunächst Patientenkohorten definiert werden. Dazu wurde eine erste Kohorte von 88 Patienten, die zwischen Juli 2007 und Februar 2010 rekrutiert wurden, als exploratives Trainingset verwendet. Als konfirmatorisches Testset diente eine Kohorte von 76 Patienten, die zwischen Mai 2003 und Juni 2007 behandelt wurden. Die Patienten wurden wegen eines lokal fortgeschrittenen Karzinoms im mittleren oder unteren Drittel des Mastdarms mit Stadium II oder III nach UICC/AJCC nach dem Protokoll der CAO/ARO/AIO-04-Studie mit N-RCT behandelt. Diese Studie wurde als zweiarmig randomisierte, kontrollierte Studie geführt, um den Nutzen einer Zugabe von Oxaliplatin zur Standardchemotherapie mit 5-FU während der $\mathrm{N}$-RCT und der adjuvanten Chemotherapie zu bewerten (Studienprotokoll eingetragen in der EU als EudraCT Nummer 2006-002385 und in den USA als NCT00349076, http://clinicaltrials.gov/ct2/show/NCT00349076). Das Pateintenkollektiv von Arm A (5-FU) umfasste 103, das von Arm B (5-FU plus Oxaliplatin) 61 Patienten. Für die Studie lag ein positives Ethikvotum vor, die Durchführung erfolgte in Übereinstimmung mit den ethischen Standards nach der Deklaration von Helsinki. Alle Patienten hatten nach Information in die Teilnahme schriftlich eingewilligt.

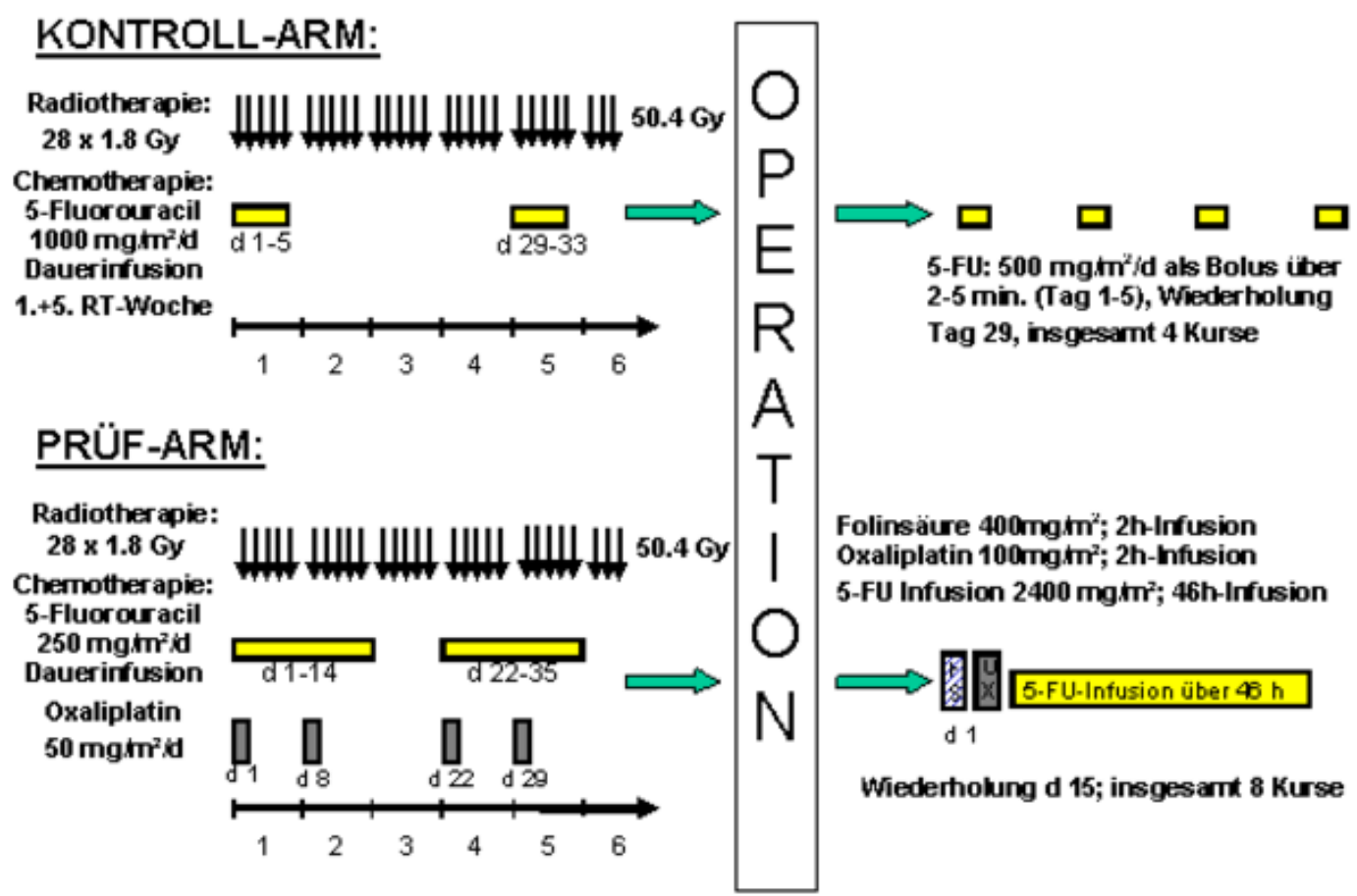

Abb. 3 Protokoll der klinischen Studie CAO-04. 
Die untersuchte Kohorte bestand aus 54 Frauen und 110 Männern, insgesamt also aus 164 Patienten. Die Patienten waren zu Behandlungsbeginn im Median 63 Jahre alt. Die Basisdaten der Patienten und die initialen Tumorcharakteristika sind in Tab. 18 zusammengefasst. Vor der Behandlung wurden auf Basis von Staging-Untersuchungen 45 Patienten als UICCStadium II und 119 Patienten als UICC-Stadium III eingestuft. Die Untersuchungen umfassten Anamnese, klinische Untersuchung, Blutbild, Blut-Konzentration von CEA (Carcinoembryonales Antigen), Röntgenaufnahmen des Brustkorbs, Bauch-Ultraschall und Kernspintomographie oder Kontrastmittel-Computertomographie des Beckens. Die Entnahme von Biopsien erfolgte während einer Untersuchung durch ein starres Rektoskop mit Endosonographie. Die untere Grenze aller Tumoren lag zwischen 0 und $12 \mathrm{~cm}$ vom Analrand entfernt. Alle Tumoren wurden histologisch als Adenokarzinome klassifiziert.

Tab. 18 Verteilung der Patienten- und Tumorcharakteristika in den Studien-Kohorten

\begin{tabular}{lcc}
\hline & Trainingset, $\mathbf{n = 8 8}$ & Testset, $\mathbf{n = 7 6}$ \\
\hline $\begin{array}{l}\text { Alter Median[Jahre], } \\
\text { (Spanne) }\end{array}$ & 63 & 63 \\
BMI Median & $(36-81)$ & $(42-82)$ \\
(Spanne) & $27,5 \mathrm{~kg} / \mathrm{m}^{2}$ & $26 \mathrm{~kg} / \mathrm{m} 2$ \\
Geschlecht, Nr. (\%) & $\left(15,8-55 \mathrm{~kg} / \mathrm{m}^{2}\right)$ & $(18,8-34,4 \mathrm{~kg} / \mathrm{m} 2)$ \\
$\quad$ & & \\
$\quad$ weiblich & $34(39)$ & $20(26)$ \\
männlich & $54(61)$ & $56(74)$ \\
UICC-Stadium, Nr. (\%) & & \\
$\quad$ II & $20(23)$ & $25(33)$ \\
III & $68(77)$ & $51(67)$ \\
T-Stadium, Nr. & & $70(92)$ \\
$\quad 3$ & $80(91)$ & $6(8)$ \\
$\quad 4$ & $8(9)$ & $26(34)$ \\
N-Stadium, Nr. & $20(23)$ & $50(66)$ \\
$\quad 0$ & $68(77)$ & $53(70)$ \\
$\quad 1$ & & $23(30)$ \\
Behandlungsarm, Nr. & $50(57)$ & \\
Arm A (5-FU mono) & $38(43)$ & \\
Arm B (5-FU + Oxaliplatin) & & \\
\hline
\end{tabular}

\subsection{Häufigkeitsverteilung der Radiotoxizität}

Die Akuttoxizität wurde wöchentlich während der N-RCT überwacht und ein Score von 0 (keine Reaktion) bis 4 (lebensbedrohlich) nach der Einteilung der Common Toxicity Criteria for Adverse Events (CTCAE) bestimmt. Dabei wurde die Akuttoxizität der vier Organe Haut, Darm, Enddarm und Harnblase dokumentiert. Diese sind in Tab. 19 aufgeführt. Für die maximale Toxizität wurde für jeden Patienten der höchste Wert aus den beobachteten vier organspezifischen Toxizitäten gebildet. 


\subsubsection{Akuttoxizität}

Tab. 19 Verteilung der Einzelorgan-Akuttoxizitäten in den Studienkohorten

\begin{tabular}{|c|c|c|c|}
\hline 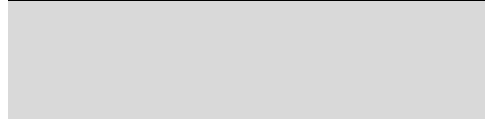 & $\begin{array}{c}\text { Common Toxicity } \\
\text { Criteria } \\
\text { Score (CTCAE) }\end{array}$ & Trainingset, n (\%) & Testset, n (\%) \\
\hline
\end{tabular}

\section{Akute Organtoxizität}

\begin{tabular}{|c|c|c|c|}
\hline Dermatitis & $\begin{array}{l}0 \\
\text { I } \\
\text { II } \\
\text { III } \\
\text { IV }\end{array}$ & $\begin{array}{c}21(24) \\
35(40) \\
23(26) \\
9(10) \\
0(0)\end{array}$ & $\begin{array}{c}8(11) \\
29(38) \\
35(46) \\
4(5) \\
0(0)\end{array}$ \\
\hline \multirow[t]{5}{*}{ Enteritis } & 0 & $44(50)$ & 48 (63) \\
\hline & I & $25(28)$ & 25 (33) \\
\hline & II & $10(11)$ & $2(3)$ \\
\hline & III & $3(3)$ & $0(0)$ \\
\hline & IV & $6(7)$ & $1(1)$ \\
\hline \multirow[t]{5}{*}{ Proktitis } & 0 & $10(11)$ & 7 (9) \\
\hline & I & $40(45)$ & $50(66)$ \\
\hline & II & $20(23)$ & $16(21)$ \\
\hline & III & $16(18)$ & $2(3)$ \\
\hline & IV & $2(2)$ & $1(1)$ \\
\hline \multirow[t]{5}{*}{ Zystitis } & 0 & $51(58)$ & $54(71)$ \\
\hline & I & $30(34)$ & $18(24)$ \\
\hline & II & $3(3)$ & $3(4)$ \\
\hline & III & $3(3)$ & $1(1)$ \\
\hline & IV & $1(1)$ & $0(0)$ \\
\hline \multirow[t]{5}{*}{ Maximale Toxizität } & 0 & $2(2)$ & $1(1)$ \\
\hline & I & $26(30)$ & $27(36)$ \\
\hline & II & 30 (34) & $41(54)$ \\
\hline & III & $22(25)$ & $6(8)$ \\
\hline & IV & $8(9)$ & $1(1)$ \\
\hline
\end{tabular}

Die maximale Toxizität beschreibt die jeweils höchste Ausprägung aus den beobachteten vier organspezifischen Toxizitäten.

\subsubsection{Spättoxizität}

Die Überwachung und Auswertung erfolgte hier gemäß der Bewertung nach LENT-SOMA mit Schweregraden von 0 (keine) bis 4 (hochgradige Beeinträchtigung). Im Trainingset lagen für 10 Patienten keine Daten vor, im Testset gab es für 4 Patienten keine Daten. Im Unterschied zur Akuttoxizität wurde hier Enteritis nicht bewertet. Die Ergebnisse sind in Tab. 20 aufgeführt. 
Tab. 20 Verteilung der Einzelorgan-Spättoxizitäten in den Studienkohorten

\begin{tabular}{cccc}
\hline & LENT-SOMA & Trainingset, $\mathbf{n}(\%)$ & Testset, $\mathbf{n}(\%)$ \\
\hline Späte Organtoxizität & & & \\
Dermatitis & 0 & $71(91)$ & $65(90)$ \\
& I & $3(4)$ & $6(8)$ \\
& II & $3(4)$ & $1(1)$ \\
III & $1(1)$ & $0(0)$ \\
Proktitis & IV & $0(0)$ & $0(0)$ \\
& 0 & $54(69)$ & $41(57)$ \\
& I & $6(8)$ & $13(18)$ \\
Zystitis & II & $9(12)$ & $14(19)$ \\
& III & $7(9)$ & $4(6)$ \\
& IV & $2(3)$ & $0(0)$ \\
& 0 & $63(81)$ & $64(89)$ \\
Maximale Toxizität & I & $4(5)$ & $2(3)$ \\
& II & $5(6)$ & $6(8)$ \\
& III & $3(4)$ & $0(0)$ \\
IV & $3(4)$ & $0(0)$ \\
& 0 & $42(54)$ & $32(44)$ \\
& I & $10(13)$ & $17(24)$ \\
& II & $12(15)$ & $19(26)$ \\
& III & $9(12)$ & $4(6)$ \\
IV & $5(6)$ & $0(0)$ \\
\hline
\end{tabular}

Die maximale Toxizität beschreibt die jeweils höchste Ausprägung aus den beobachteten drei organspezifischen Toxizitäten.

\subsection{Testung vorbeschriebener genetischer Marker im TGF $\beta$ - Signalweg in Bezug auf die beobachtete Radiotoxizität}

In der ersten Phase meiner Analysen wurden Genpolymorphismen mit vorbeschriebener klinischer oder funktioneller Bedeutung betrachtet. Diese bezogen sich auf die Variabilität des für den TGF $\beta 1$-Liganden kodierenden Gens TGFB1 als ganzes sowie auf zwei singuläre Polymorphismen, eine im Gen für SMAD3 und eine im Gen für den Rezeptor TGFBRI. Anschließend wurde die genetische Variabilität umfassend in sechs zentralen Genen des klassischen TGF $\beta 1$-Signalwegs untersucht.

\subsubsection{TGFß1-Ligand}

Die Daten zur Assoziation des für den TGF $\beta 1$-Liganden kodierenden Gens TGFB1 in Bezug auf die klinischen Akuttoxizität wurden bereits publiziert (Schirmer et al. 2012).

Dabei wurde zunächst ein Satz von Genpolymorphismen im Bereich von TGFB1 definiert, welcher die genetische Variabilität in der Allgemeinbevölkerung abbildet. Dazu wurden von 48 kaukasischen Individuen die Daten von Genvarianten mit einer MAF von mindestens $10 \%$ im Bereich von TGFB1 $\pm 10 \mathrm{~kb}$ aus der HapMap-Datenbank (Version 02/2009) heruntergeladen. An vorhandener Keimbahn-DNA derselben Personen wurden von mir sechs 
weitere TGFB1-Genpolymorphismen bestimmt. Fünf davon wurden in der Literatur häufig untersucht, und es wird eine Funktionalität vermutet (Schirmer et al. 2011). Einer repräsentiert einen tri-allelischen Basenaustausch (rs6508976). Die Genotypen aus HapMap und die selbst bestimmten wurden mit der Software HaploView dargestellt (Abb. 4). Diese insgesamt 24 Genvarianten werden durch neun Polymorphismen mit einem paarweisen LD von $\mathbf{r}^{2} \geq 0,8$ erfasst (entsprechend dem in HaploView enthaltenen paarweisen TaggingAlgorithmus). Diese neun Polymorphismen wurden für die Genotypisierung in den Patientenkollektiven ausgewählt und sind in der AbbildungAbb. 4 mit Rechtecken gekennzeichnet. Für den tri-allelischen SNP rs6508976 ergab sich für die beiden häufigen Allele ein hohes LD $\left(r^{2}=0,94\right)$ mit rs2241717. Nach Genotypisierung der Patientenkohorten zeigte sich weiterhin, dass das seltene Allel von rs6508976 ein LD von nahezu $100 \%$ mit dem seltenen Allel von rs1800471 aufweist. Somit wurden insgesamt acht TGFB1Genvarianten mit einem paarweisen LD von $\mathrm{r}^{2} \leq 0,8$ bestimmt, welche für die statistische Analyse als voneinander unabhängig gewertet wurden. Deren Assoziationen mit der Akutund Spättoxizität der neoadjuvanten Radiochemotherapie sind in Tab. 21 gelistet. 


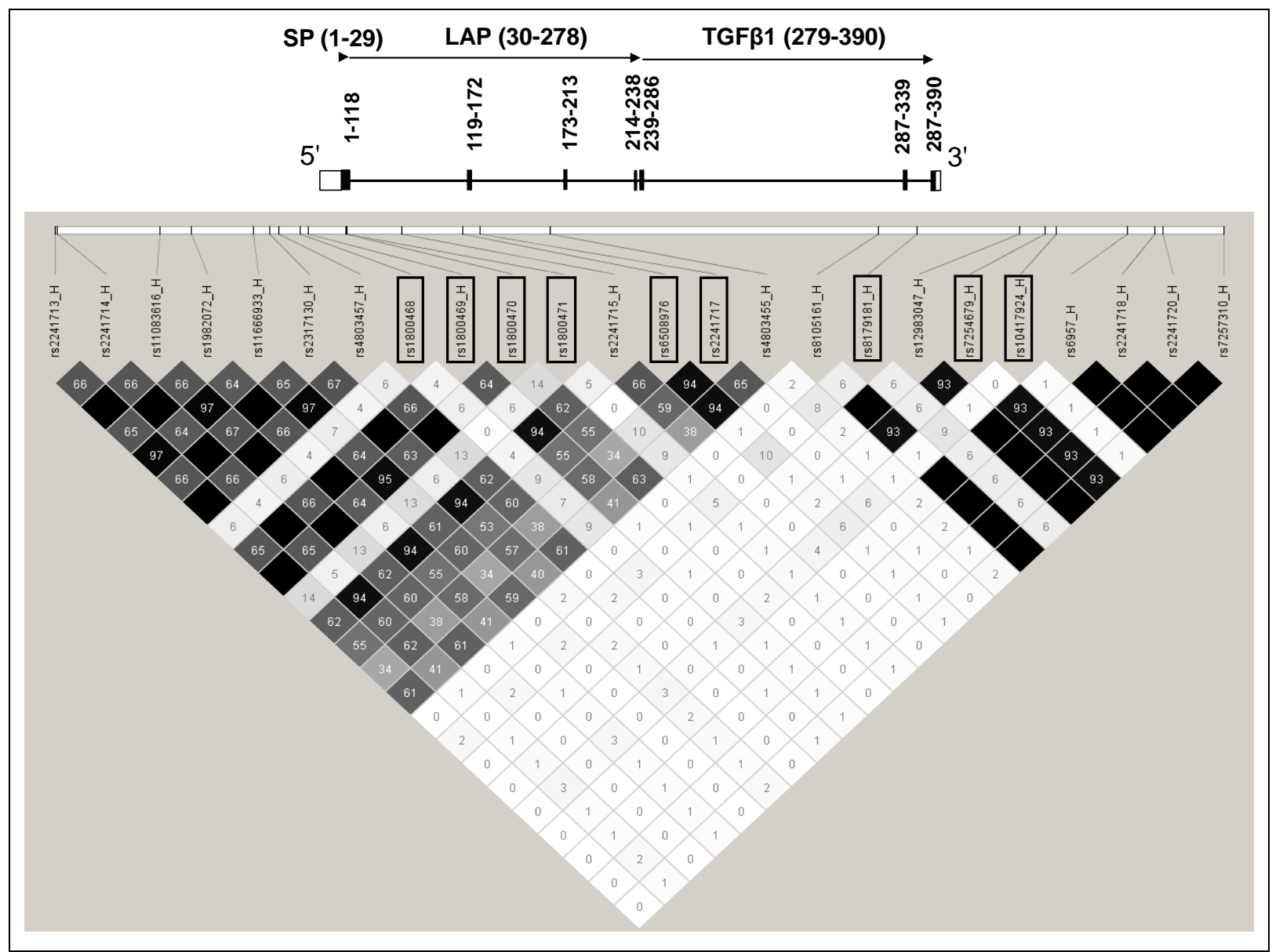

Abb. 4 Architektur des TGFB1-Gens und Kopplungsplot der analysierten Polymorphismen. Im oberen Teil der Abbildung ist die Architektur des TGFB1-Gens dargestellt: Die einzelnen genetischen Elemente sind maßstabsgetreu wiedergegeben. Die untranslatierten Regionen sind weiß, die Protein-kodierenden Exone (mit Angabe der Aminosäuren-Abschnitte) schwarz gefärbt. Dazwischen liegen die Introne. Der TGFB1-Genbereich wird zunächst als Vorläuferprotein, bestehend aus Signalpeptid (SP), dem LAP und dem eigentlichen TGFß1, synthetisiert. Im unteren Teil der Abbildung ist das paarweise Kopplungsungleichgewicht (linkage disequilibrium, LD) der Genvarianten als Plot dargestellt; hierbei wurden zusätzlich $\pm 10 \mathrm{~kb}$ flankierender Gensequenzen berücksichtigt. Jeder SNP ist mit seiner rsNummer bezeichnet. Dabei zeigen die Striche über den rs-Nummern die Lokalisation der SNPs in Relation zur genetischen Architektur an. Der Plot wurde von SNPs abgeleitet mit einer MAF von mindestens $10 \%$ zuzüglich der beiden SNPs rs1800468 und rs1800471 mit jeweils $8 \%$. Die Zahlen $\left(r^{2}-\right.$ Wert) und die Farbgebung innerhalb der Rauten geben paarweise das Ausmaß der gemeinsamen Vererbung (linkage disequilibrium, LD) an: Je dunkler eine Raute eingefärbt ist, desto höher das LD. Ein schwarzes Feld ohne Zahlenwert steht für ein LD von $100 \%$. Ein „,H“ nach der rs-Nummer bezeichnet Genvarianten aus der HapMap-Datenbank. 
Tab. 21 Analyse von vorbeschriebenen Genpolymorphismen in Bezug auf die beobachtete Radiotoxizität

\begin{tabular}{|c|c|c|c|c|c|c|c|}
\hline \multirow{2}{*}{ SNP } & \multirow{2}{*}{$\begin{array}{l}\text { Genetisches } \\
\text { Element }^{1}\end{array}$} & \multirow{2}{*}{$\begin{array}{l}\text { Basenaus- } \\
\text { tausch }\end{array}$} & \multirow{2}{*}{$\begin{array}{c}\text { MAF }^{2} \\
(\%)\end{array}$} & \multicolumn{2}{|c|}{ Akuttoxizität $^{3}$} & \multicolumn{2}{|c|}{ Spättoxizität $^{3}$} \\
\hline & & & & Modell & p-Wert ${ }_{\text {adj. }}$ & Modell & p-Wert ${ }_{\text {adj. }}$ \\
\hline rs10417924 & $\begin{array}{l}\text { Downstream } \\
+3645\end{array}$ & $C>T$ & $16,5 \%$ & $C C$ vs. $C T+T T$ & $>0,5$ & $T T$ vs. $C T+C C$ & $>0,5$ \\
\hline rs1800468 & $\begin{array}{c}\text { Upstream -756 (- } \\
800)\end{array}$ & $G>A$ & $11,0 \%$ & $\begin{array}{c}A A \\
\text { vs. } G A+G G\end{array}$ & $>0,5$ & $\begin{array}{c}A A \\
\text { vs. } G A+G G\end{array}$ & $>0,5$ \\
\hline rs1800469 & $\begin{array}{l}\text { Downstream } \\
+465(-509)\end{array}$ & $G>A$ & $28,0 \%$ & $\begin{array}{c}A A \\
\text { vs. } G A+G G\end{array}$ & $>0,5$ & $\begin{array}{c}G G \\
\text { vs. } G A+A A\end{array}$ & 0,22 \\
\hline rs1800470 & $\begin{array}{c}\text { Exon 1 } \\
\text { (Leu10Pro) }\end{array}$ & $A>G$ & $36,0 \%$ & $\begin{array}{c}G G \\
v s . A G+A A\end{array}$ & $>0,5$ & $\begin{array}{c}A A \\
\text { vs. } A G+G G\end{array}$ & 0,09 \\
\hline rs1800471 & $\begin{array}{c}\text { Exon } 1 \\
\text { (Ar25Pro) }\end{array}$ & $G>C$ & $6,7 \%$ & $G G / G C / C C$ & 0,05 & $\begin{array}{c}C C \\
\text { vs. } G C+G G\end{array}$ & $>0,5$ \\
\hline rs2241717 & Intron 2 & $T>G$ & $42,6 \%$ & $T T$ vs. $T G+G G$ & $>0,5$ & $T T$ vs. $T G+G G$ & $>0,5$ \\
\hline rs7254679 & $\begin{array}{c}\text { Downstream } \\
+3243\end{array}$ & $A>G$ & $13,8 \%$ & $\begin{array}{c}G G \\
\text { vs. } A G+A A\end{array}$ & $>0,5$ & $\begin{array}{c}G G \\
\text { vs. } A G+A A\end{array}$ & $>0,5$ \\
\hline rs8179181 & Intron 5 & $G>A$ & $25,9 \%$ & $\begin{array}{c}A A \\
\text { vs. } G A+G G\end{array}$ & $>0,5$ & $G G / G A / A A$ & 0,23 \\
\hline
\end{tabular}

${ }^{1}$ Die Angaben „,+“ bzw. „,-“ beziehen sich auf die Position relativ zum Transkriptionsstart bzw. -ende. ${ }^{2}$ Die Angaben in der Spalte MAF beziehen sich auf die Gesamtkohorte ( $n=164$ Patienten) und angegeben ist die Häufigkeit desjenigen Allels hinter dem ,>“-Symbol in der Spalte „Basenaustausch“. ${ }^{3}$ Für Akut- und Spättoxizität ist jeweils der auf multiples Testen adjustierte p-Wert mit der stärksten Assoziation aus den drei Erbmodellen (dominant, ko-dominant, rezessiv) angegeben. Die p-Werte wurden nach Kendall's tau berechnet und sind auf die Zahl von acht unabhängigen Tests entsprechend der Zahl der SNPs adjustiert.

Ein reproduzierbares Risiko für höhergradige Akuttoxizität zeigte sich für Patienten mit dem Pro25-Allel des SNPs rs1800471. Dabei war der statistische Zusammenhang bei Annahme eines ko-dominanten bzw. dominanten Effektes für das Pro25-Allel nahezu identisch (in der Gesamtkohorte fanden sich nur zwei homozygote Träger von Pro25).

Um artifizielle Stratifizierungen nicht-genetischer Faktoren für die Assoziation dieser Genvariante auszuschließen, wurde ein ordinales Regressionsmodell angewandt. Dabei wurden außer dem SNP rs1800471 noch die dichotomen Faktoren Geschlecht, Therapiearm (ohne und mit Oxaliplatin), Stadium (UICC II oder III) sowie Alter und BMI berücksichtigt. Für die dichotomisierte Akuttoxizität $\geq{ }^{\circ} 2$ zeigte sich auch nach Adjustierung auf nichtgenetische Parameter ein Einfluss von rs1800471 mit $p<0,05$ (Tab. 22).

Bei Betrachtung der einzelnen Organtoxizitäten war am ehesten das Auftreten einer akuten Proktitis mit dem Pro25-Allel verbunden, jedoch ohne dass eine statistische Signifikanz im vorliegenden Stichprobenumfang erreicht wurde $(\mathrm{p}=0,1)$. Die anderen untersuchten TGFB1Genvarianten wiesen keinen Bezug zur Akuttoxizität auf, abgesehen von dem seltenen Allel des tri-allelischen SNPs, welches aber in nahezu komplettem LD zu Pro25 steht und somit keinen eigenständigen Befund darstellt. 
Tab. 22 Regressionsmodelle zur Adjustierung des Effektes von rs1800471

\begin{tabular}{|c|c|c|c|c|c|c|}
\hline \multirow[t]{2}{*}{ Modell } & \multicolumn{2}{|c|}{$\frac{\text { Akuttoxizität }^{2}}{\text { ordinal }}$} & \multicolumn{2}{|c|}{$\frac{\text { Akuttoxizität } \geq^{\circ} 2^{3}}{\text { binär logistisch }}$} & \multicolumn{2}{|c|}{$\frac{\text { Akuttoxizität } \geq^{\circ} 3^{3}}{\text { binär logistisch }}$} \\
\hline & OR (95\% KI) & $p$ & OR $(95 \% \mathrm{KI})$ & p & OR $(95 \% \mathrm{KI})$ & $p$ \\
\hline Alter $^{1}$ & $2,0(1,1-3,6)$ & 0,02 & $1,0(0,9-1,0)$ & 0,2 & $1,0(0,9-1,0)$ & 0,1 \\
\hline
\end{tabular}

(alt vs. jung)

\begin{tabular}{|c|c|c|c|c|c|c|}
\hline $\begin{array}{l}\text { BMI }^{1} \\
\text { (größer vs. kleiner) }\end{array}$ & $1,3(0,7-2,3)$ & 0,4 & $1,0(0,9-1,1)$ & 0,8 & $1,0(0,9-1,0)$ & 0,7 \\
\hline $\begin{array}{l}\text { Geschlecht } \\
\text { (weiblich vs.männlich) }\end{array}$ & $0,7(0,3-1,2)$ & 0,2 & $0,9(0,4-1,9)$ & 0,8 & $1,9(0,9-4,2)$ & 0,1 \\
\hline $\begin{array}{l}\text { Stadium } \\
\text { (III vs. II) }\end{array}$ & $1,3(0,7-2,6)$ & 0,4 & $0,6(0,3-1,3)$ & 0,2 & $0,7(0,3-1,6)$ & 0,4 \\
\hline $\begin{array}{l}\text { Oxaliplatin } \\
\text { (ja vs. nein) }\end{array}$ & $0,9(0,5-1,7)$ & 0,8 & $0,7(0,4-1,5)$ & 0,4 & $1,3(0,6-2,8)$ & 0,5 \\
\hline $\begin{array}{l}\text { TGF } \beta 1 \text { rs1800471 } \\
\text { (Arg25/Pro25+Pro25/Pro25 } \\
\text { vs. Arg25/Arg25) }\end{array}$ & $2,0(0,8-4,8)$ & 0,1 & $10,3(1,3-81,1)$ & 0,03 & $0,8(0,3-2,6)$ & 0,7 \\
\hline
\end{tabular}

Bei allen drei Modellen wurde der SNP gemeinsam mit den fünf nicht-genetischen Faktoren als unabhängige Variablen eingeschlossen. Die entsprechenden p-Werte sind mit den zugehörigen Odds ratios (mit 95\%-Konfidenzintervall) angegeben. ${ }^{1}$ Alter und BMI wurden für das ordinale Modell gemäß des Medians der jeweiligen Verteilung dichotomisiert; für das binär logistische Modell wurden Alter und BMI als stetige Größen verwendet. ${ }^{2}$ Bei der Betrachtung der Akuttoxizitätsgrade 0-4 wurde ein ordinales Regressionsmodell gewählt. ${ }^{3}$ Bei Dichtomisierung der Toxizitätsgrade wurde ein logistisches Regressionsmodell angewandt. Es ist jeweils das Odds ratio (OR) mit zugehörigem 95\%Konfidenzintervall angegeben.

Für die Assoziation mit der Spättoxizität fand sich ein Trend für den Leu10ProAminosäureaustausch, wobei das Vorliegen des PCR-Allels (heterozygot und homozygot) ein höheres Risiko beinhaltete.

\subsubsection{SMAD3 rs11856909}

Für die SMAD3-Genvariante rs11856909 (G>A) lagen bereits funktionelle Daten früherer Dissertationen vor (Hoffmann 2008; Janke 2009; Neumann 2012), welche konsistent auf eine Radioresistzenz bei Homozygotie des A-Varianten-Allels an dieser Stelle hinweisen. Für diese Variante wurde daher für die gesamte Patienten-Kohorte ein Signifikanzniveau von 0,05 gefordert. Dabei wurde die Hypothese getestet, dass der $A A$-Genotyp mit einer verminderten Akuttoxizität einhergeht. 


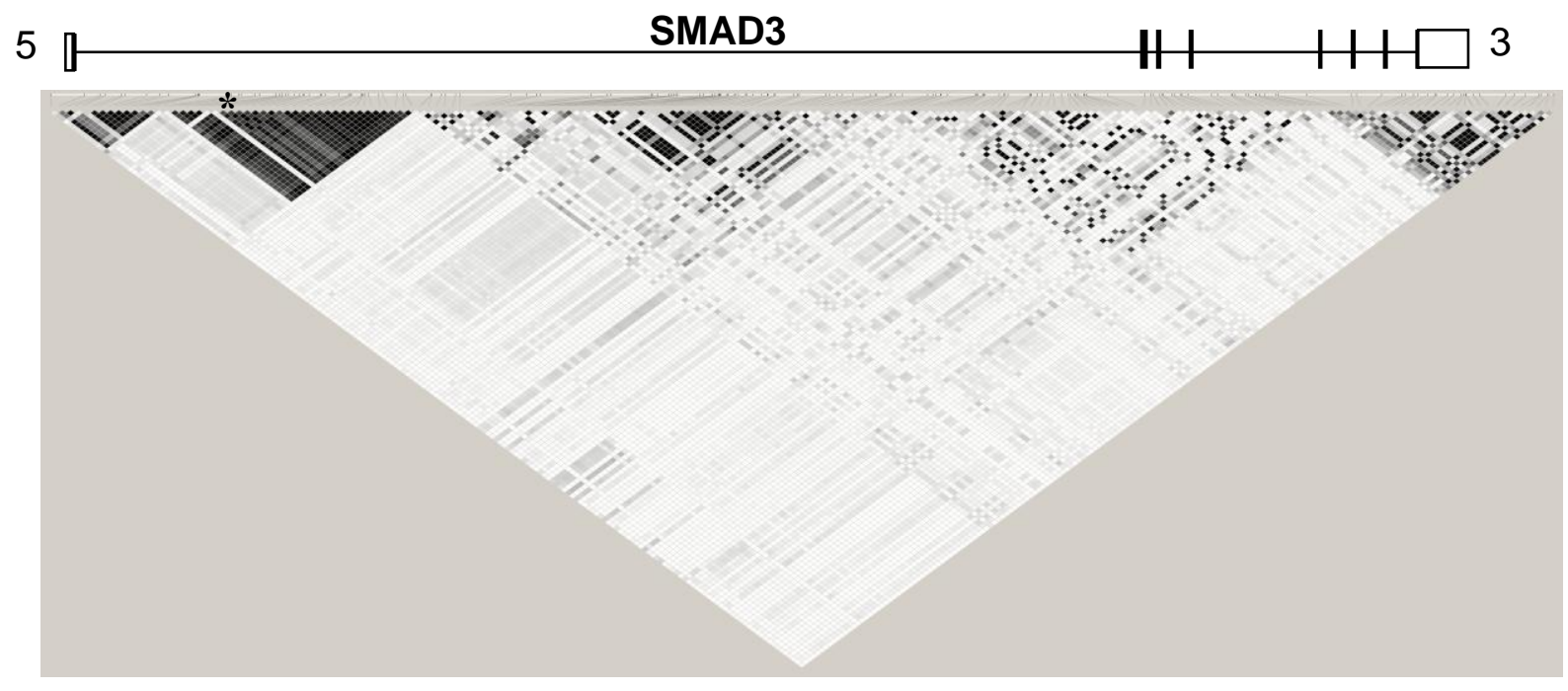

Abb. 5 Abbildungsweise entspricht derjenigen in Abb. 4. (S. 46). Die Lokalisation des SNPs rs11856909 ist mit einem Stern (*) markiert.

In der Gesamtkohorte von 164 Patienten wurde das A-Allel mit einer Häufigkeit von 35,2\% vorgefunden; 22 Patienten waren homozygot für dieses Allel. Im rezessiven Modell wurde die statistische Signifikanz mittels Kendall's-tau-Test nachgewiesen $(p=0,009, n=164)$. Ein ähnlicher Befund wurde bei Anwendung eines kodominanten Modells erhoben $(p=0,013)$. Wurden die beiden Studienteile getrennt betrachtet, war im rezessiven Modell ein statistischer Zusammenhang mit $\mathrm{p}=$ 0,05 (exploratorische Kohorte) bzw. 0,04 (konfirmatorische Kohorte) zu erkennen.

Die Verteilung zeigte, dass homozygote Träger der Variante geringere Schweregrade an Akuttoxizitäten aufwiesen (siehe Tab. 23). Wurde die Akuttoxizität im rezessiven Modell dichotomisiert, ergab sich für den Schutz gegenüber einer Akuttoxizität $\geq{ }^{\circ} 2$ ein $\mathrm{p}$-Wert von 0,045 und in Bezug auf eine Akuttoxizität $\geq{ }^{\circ} 3$ von 0,038 .

Auch nach Adjustierung auf die oben genannten fünf nicht-genetischen Parameter zeigte sich, dass homozygote Träger des $A$-Varianten-Allels von rs11856909 hinsichtlich der nicht dichotomoisierten Akuttoxizität ein deutlich niedrigeres Risiko aufwiesen (Odds ratio von 0,3, siehe Tab. 24). Für Ältere war das Risiko etwas höher (2,1), für Frauen in diesem Modell tendenziell niedriger $(0,6)$.

Tab. 23 Verteilung der Akuttoxizität in der Gesamtkohorte in Abhängigkeit von rs11856909

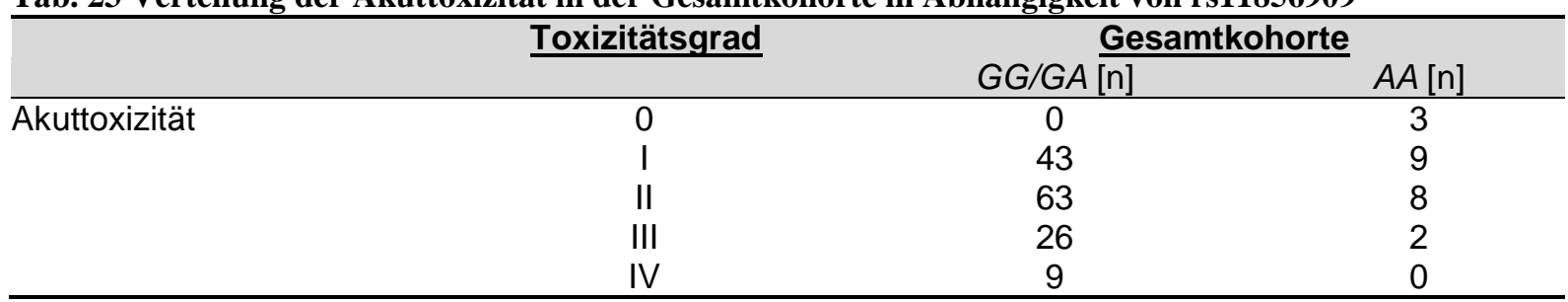


Tab. 24 Regressionsmodelle zur Adjustierung des Effektes von rs11856909

\begin{tabular}{|c|c|c|c|c|c|c|}
\hline \multirow[t]{2}{*}{ Modell } & \multicolumn{2}{|c|}{$\frac{\text { Akuttoxizität }^{2}}{\text { ordinal }}$} & \multicolumn{2}{|c|}{$\frac{\text { Akuttoxizität } \geq^{\circ} 2^{3}}{\text { binär logistisch }}$} & \multicolumn{2}{|c|}{$\frac{\text { Akuttoxizität } \geq^{\circ} 3^{3}}{\text { binär logistisch }}$} \\
\hline & OR (95\% KI) & $\mathbf{p}$ & OR $(95 \% \mathrm{KI})$ & p & OR $(95 \% \mathrm{KI})$ & $\mathbf{p}$ \\
\hline $\begin{array}{l}\text { Alter }^{1} \\
\text { (alt vs. jung) }\end{array}$ & $2,1(1,2-3,8)$ & 0,01 & $1,0(0,9-1,0)$ & 0,1 & $1,0(0,9-1,0)$ & 0,1 \\
\hline $\begin{array}{l}\text { BMI }^{1} \\
\text { (größer vs. kleiner) }\end{array}$ & $1,3(0,7-2,4)$ & 0,4 & $1,0(0,9-1,1)$ & 0,9 & $1,0(0,9-1,1)$ & 0,8 \\
\hline $\begin{array}{l}\text { Geschlecht } \\
\text { (weiblich vs.männlich) }\end{array}$ & $0,6(0,3-1,0)$ & 0,06 & $1,0(0,5-2,2)$ & 0,9 & $1,8(0,9-4,2)$ & 0,1 \\
\hline $\begin{array}{l}\text { Stadium } \\
\text { (III vs. II) }\end{array}$ & $1,2(0,6-2,4)$ & 0,5 & $0,6(0,2-1,3)$ & 0,2 & $0,7(0,3-1,7)$ & 0,5 \\
\hline $\begin{array}{l}\text { Oxaliplatin } \\
\text { (ja vs. nein) }\end{array}$ & $0,8(0,5-1,5)$ & 0,6 & $0,8(0,4-1,6)$ & 0,5 & $1,4(0,6-3,1)$ & 0,4 \\
\hline $\begin{array}{l}\text { rs } 11856909^{2} \\
\text { AA vs. GG/GA }\end{array}$ & $0,3(0,1-0,6)$ & 0,003 & $0,4(0,2-1,0)$ & 0,06 & $0,3(0,1-1,3)$ & 0,1 \\
\hline
\end{tabular}

Vorgehensweise analog zu Tab 21. ${ }^{2}$ Für den SNP rs11856909 wurde ein rezessiver Effekt für das Varianten-Allel zu Grunde gelegt.

Bei Betrachtung der Einzelorgantoxizitäten fiel auf, dass der toxizitätsprotektive Effekt von 11856909 vor allem bei Haut ( $\mathrm{p}=$ 0,02 im rezessiven Modell nach Kendall's-tau) und Darm $(0,005)$ erkennbar war. Die Darmtoxizität (siehe Tab. 25), die sich v. a. in schweren Durchfällen äußert, zwingt mitunter zum Therapieabbruch, wenn diese medikamentös kaum noch zu kontrollieren sind. Daher kommt dieser Nebenwirkung während einer Strahlentherapie eine besondere Bedeutung zu. Auffällig war, dass relevante Durchfälle ab Grad 2 bei homozgyoten Trägern des $A$-Varianten-Allels gar nicht auftraten ( $\mathrm{p}=0,0001)$.

Tab. 25 Verteilung der Darmtoxizität in der Gesamtkohorte in Abhängigkeit von rs11856909

\begin{tabular}{lccc}
\hline & Toxizitätsgrad & Gesamtkohorte & \\
\cline { 2 - 4 } & & $G G / \mathrm{G}$ [n] & AA [n] \\
\hline Akute Darmtoxizität & 0 & 74 & 17 \\
& I & 45 & 5 \\
II & 12 & 0 \\
III & 3 & 0 \\
IV & 7 & 0 \\
\hline
\end{tabular}

Auf die Spättoxizität hatte dieser Polymorphismus in den vorliegenden Daten mit der noch vergleichsweise kurzen Nachbeobachtungszeit (Median 4 Jahre) keinen Einfluss.

\subsubsection{TGFBR1-Deletionsvariante (TGFBR1*6A)}

Bei der Deletionsvariante * $6 A$ fehlen im Signalpeptid des TGF $\beta$-Rezeptors 1 drei der neun konsekutiven Alanine (daher Wildtyp als $* 9 A$ bezeichnet). Auf DNA-Ebene entspricht dies einer Deletion von neun Basen. Diese Deletionsvariante wurde, wie in der Einleitung darlegt, in der Literatur häufig als mögliches Tumorsuszeptibilitätsallel diskutiert. Ein Zusammenhang mit Strahlenempfindlichkeit wurde bislang nur in meiner Arbeitsgruppe für in vitro erhobene 
Funktionsparameter beschrieben (Schirmer et al. 2009). In dieser Publikation wurde postuliert, dass bei Vorliegen des TGFBRI*6A-Allels die Funktion der TGF $\beta$-Signalwegs abgeschwächt ist. Diese Hypothese sollte in Bezug auf die klinische Radiotoxizität geprüft werden.

Tab. 26 zeigt die Verteilung von TGFBRI*6A in die Akuttoxizitätsgrade für die Gesamtkohorte von 164 Patienten. Wurde die Akuttoxizität als abhängige ordinale Variable mit fünf Ausprägungen getestet, ergab sich kein statistisch signifikanter Einfluss dieser Deletionsvariante $(\mathrm{p}=0,3)$. Wurde jedoch eine Dichotomisierung in die klinisch bedeutsamen Toxizitätsgrade $<{ }^{\circ} 3$ bzw. $\geq{ }^{\circ} 3$ vorgenommen, waren Träger von TGFBRI*6A in der höhergradigen Toxizitätsgruppe unterrepräsentiert ( $\mathrm{p}=0,03$ nach Kendall's tau). Wurde hier auf die nicht-genetischen Parameter adjustiert, ergab sich ein Odds ratio von ZZ, wobei das nominale Signifikanzniveau von $\mathrm{P}<0,05$ knapp nicht erreicht wurde (Tab. 27).

Ähnlich wie bei der oben beschriebenen SMAD3-Variante war die Assoziation für die dichtomisierte Akuttoxizität am deutlichsten für Haut $(p=0,0004)$ und Darm $(p=0,002)$ ausgeprägt.

Tab. 26 Verteilung der Akuttoxizität in der Gesamtkohorte in Abhängigkeit von TGFBR1*6A

\begin{tabular}{|c|c|c|c|}
\hline & \multirow[t]{2}{*}{ Toxizitätgrad } & \multicolumn{2}{|c|}{ Gesamtkohorte } \\
\hline & & $\begin{array}{c}{ }^{*} 9 A /{ }^{*} 9 A \\
{[n]}\end{array}$ & $\begin{array}{c}{ }^{*} 9 A /^{*} 6 A+{ }^{*} 6 A{ }^{*} 6 A \\
{[n]}\end{array}$ \\
\hline Akuttoxizität & 0 & 3 & 0 \\
\hline & I & 40 & 12 \\
\hline & II & 51 & 20 \\
\hline & III & 24 & 4 \\
\hline & IV & 9 & 0 \\
\hline
\end{tabular}

Tab. 27 Regressionsmodelle zur Adjustierung des Effektes von TGFBR1*6A

\begin{tabular}{|c|c|c|c|c|c|c|}
\hline \multirow[t]{2}{*}{ Modell } & \multicolumn{2}{|c|}{$\frac{\text { Akuttoxizität }^{2}}{\text { ordinal }}$} & \multicolumn{2}{|c|}{$\frac{\text { Akuttoxizität } \geq^{\circ} 2^{3}}{\text { binär logistisch }}$} & \multicolumn{2}{|c|}{$\frac{\text { Akuttoxizität } \geq^{\circ} 3^{3}}{\text { binär logistisch }}$} \\
\hline & OR (95\% KI) & $p$ & OR (95\% KI) & $p$ & OR (95\% KI) & $p$ \\
\hline $\begin{array}{l}\text { Alter }^{1} \\
\text { (alt vs. jung) }\end{array}$ & $2,1(1,2-3,8)$ & 0,01 & $1,0(0,9-1,0)$ & 0,1 & $1,0(0,9-1,0)$ & 0,1 \\
\hline $\begin{array}{l}\text { BMI }^{1} \\
\text { (größer vs. kleiner) }\end{array}$ & $1,4(0,8-2,5)$ & 0,3 & $1,0(0,9-1,1)$ & 1,0 & $1,0(0,9-1,1)$ & 0,9 \\
\hline $\begin{array}{l}\text { Geschlecht } \\
\text { (weiblich vs.männlich) }\end{array}$ & $0,6(0,3-1,1)$ & 0,1 & $1,1(0,5-2,2)$ & 0,8 & $1,9(0,8-4,1)$ & 0,1 \\
\hline $\begin{array}{l}\text { Stadium } \\
\text { (III vs. II) }\end{array}$ & $1,4(1,4-2,6)$ & 0,3 & $0,5(0,2-1,1)$ & 0,1 & $0,8(0,3-1,8)$ & 0,5 \\
\hline $\begin{array}{l}\text { Oxaliplatin } \\
\text { (ja vs. nein) }\end{array}$ & $0,9(1,9-1,7)$ & 0,9 & $0,8(0,4-1,5)$ & 0,4 & $1,3(0,6-2,8)$ & 0,5 \\
\hline $\begin{array}{l}\text { TGFBR } 1{ }^{*} 6 A^{2} \\
{ }^{*} 9 A{ }^{*} 9 A \text { vs. }{ }^{*} 9 A /{ }^{*} 6 A+{ }^{*} 6 A{ }^{*} 6 A\end{array}$ & $0,8(0,4-1,5)$ & 0,4 & $1,1(0,4-2,0)$ & 0,8 & $0,4(0,1-1,1)$ & 0,1 \\
\hline
\end{tabular}

Vorgehensweise analog zu Tab $21 .{ }^{2}$ Für den TGFBRI*6A wurde ein dominanter Effekt für das VariantenAllel zu Grunde gelegt. 
Eine Beziehung zur Spättoxizität fand sich für TGFBR1*6A nicht.

\subsection{Umfassende Analyse der genetischen Variabilität im TGF $\beta$ - Signalweg in Bezug auf die beobachtete Radiotoxizität}

Um einen möglichen Einfluss von Genpolymorphismen im TGF $\beta$-Signalweg auf die Radiotoxizität umfassend darzustellen, wurden - in Ergänzung zu den oben beschriebenen und auf Basis konkreter Hypothesen gestester genetischer Marker - nun 67 weitere Genvarianten in explorativer Weise untersucht. Diese sollten die genetische Variabilität dieses Signalwegs in sechs Genen (TGFBR1, TGFBR2, SMAD2, SMAD3, SMAD4 und SMAD7) repräsentativ abbilden. Die Auswahlkriterien für die zu analysierenden Varianten sind im Methodenteil (siehe Kapitel 3.8) genannt. Dabei wurde auf Assoziationen zunächst im Trainingset von 88 Patienten getestet; entsprechend den hierbei gefundenen statistischen Signifikanzen wurde eine hierarchische Ordnung für die Assoziationsprüfung im 76 Patienten umfassenden Testset erstellt.

\subsubsection{Trainingset}

Im Trainingset wurde jede dieser 67 Genvarianten in explorativer Weise auf eine mögliche Beeinflussung der Akut- und Spättoxizität geprüft, wobei die Toxizitätsparameter als abhängige, ordinal skalierte Variablen mit Ausprägung von Grad 0 bis Grad 4 betrachtet wurden (siehe Tab. 28). Das Hardy-Weinberg-Gleichgewicht war für alle Genloci erfüllt ( $\mathrm{p}>0,05$ nach $\chi^{2}$-Test). Für einen SNP (SMAD3 rs16950556) wurde das Varianten-Allel in den mir vorliegenden Kohorten nicht vorgefunden. Die Positionsangaben in Bezug zum Transkriptionsstart beziehen sich auf die Einträge der Datenbank GenBank (Version GRCh37.p10).

Für jeden SNP wurde die Stärke der Assoziation mittels des Kendall's-tau-Tests berechnet. Dabei wurde jeweils der kleinste p-Wert aus den drei Erbgängen ko-dominant, dominant und rezessiv ermittelt. Die so erhaltenen $\mathrm{p}$-Werte wurden aufsteigend bis $\leq 0,1$ geordnet. Entsprechend dieser Anordnung erfolgte im Testset eine hierarchische Auswertung (Tab. 28). 
Tab. 28 Explorative Testung von 67 Genvarianten in Bezug auf die beobachtete Radiotoxizität

\begin{tabular}{|c|c|c|c|c|c|c|c|c|}
\hline \multirow{2}{*}{ Gen $^{1}$} & \multirow{2}{*}{ SNP } & \multirow{2}{*}{$\begin{array}{l}\text { Genetisches } \\
\text { Element }\end{array}$} & \multirow{2}{*}{$\begin{array}{l}\text { Basenaus- } \\
\text { tausch }\end{array}$} & \multirow{2}{*}{$\begin{array}{c}\mathrm{MAF}^{3} \\
(\%)\end{array}$} & \multicolumn{2}{|c|}{ Akuttoxizität ${ }^{4}$} & \multicolumn{2}{|c|}{ Spättoxizität ${ }^{4}$} \\
\hline & & & & & Modell & $\mathrm{p}$-Wert & Modell & p-Wert \\
\hline TGFB1 & rs6508976 & Intron3 & $A>C$ & 10,2 & $A A / A C / C C$ & 0,61 & $A A / A C / C C$ & 0,32 \\
\hline \multirow[t]{6}{*}{ TGFBRI } & rs10512263 & Intron1 & $T>C$ & 6,2 & $C C$ vs. $T C+T T$ & 0,31 & $C C$ vs. TC+TT & 0,31 \\
\hline & rs 10733710 & Intron 6 & $C>T$ & 18,1 & TT vs. $C T+C C$ & 0,31 & $C C / C T / T T$ & 0,15 \\
\hline & rs10819635 & Upstream -1414 & $A>T$ & 21,0 & $A A / A T / T T$ & 0,55 & TT VS. $A T+A A$ & 0,32 \\
\hline & rs10988716 & Intron1 & $T>C$ & 22,1 & TT VS. $T C+C C$ & 0,60 & $C C$ VS. $T C+T T$ & 0,15 \\
\hline & rs 11568785 & Intron5 & $A>G$ & 10,2 & $A A / A G / G G$ & 0,30 & $A A / A G / G G$ & 0,31 \\
\hline & rs6478974 & Intron1 & $T>A$ & 47,7 & TT vS. TA+AA & 0,59 & $A A$ vS. TA+TT & 0,0007 \\
\hline \multirow[t]{7}{*}{ TGFBR2 } & rs11466531 & 3'UTR & $G>C$ & 2,8 & $G G / G C / C C$ & 0,25 & $G G / G C / C C$ & 0,74 \\
\hline & $\operatorname{rs} 11466536$ & 3'UTR & $C>T$ & 9,7 & $C C / C T / T T$ & 0,35 & $C C / C T / T T$ & 0,25 \\
\hline & rs1551762 & Intron 4 & $T>A$ & 19,3 & $A A$ VS. $T A+T T$ & 0,30 & $A A$ VS. $T A+T T$ & 0,15 \\
\hline & rs3087465 & Upstream - 834 & $C>T$ & 20,5 & $C C / C T / T T$ & 0,01 & TT vs. $C T+C C$ & 0,49 \\
\hline & rs3773650 & Intron 6 & $C>A$ & 23,3 & $C C$ vs. $C A+A A$ & 0,39 & $A A$ VS. $C A+C C$ & 0,16 \\
\hline & rs3773651 & Intron 6 & $T>C$ & 4,5 & $T T / T C / C C$ & 0,12 & $T T / T C / C C$ & 0,09 \\
\hline & rs3773663 & Intron 4 & $G>A$ & 44,9 & $G G / G A / A A$ & 0,23 & $G G / G A / A A$ & 0,37 \\
\hline \multirow[t]{5}{*}{ SMAD2 } & rs 17814648 & Intron 4 & $G>A$ & 4,0 & $G G / G A / A A$ & 0,71 & $G G / G A / A A$ & 0,29 \\
\hline & rs 1787177 & Intron 6 & $T>C$ & 5,7 & $T T / T C / C C$ & 0,23 & $T T / T C / C C$ & 0,47 \\
\hline & rs1792658 & Intron8 & $T>G$ & 27,3 & TT VS. $T G+G G$ & 0,17 & TT VS $T G+G G$ & 0,06 \\
\hline & rs1792666 & 3 'UTR & $A>T$ & 44,3 & $A A$ VS. $A T+T T$ & 0,15 & TT VS. $A T+A A$ & 0,66 \\
\hline & rs8085335 & 3'UTR & $T>C$ & 10,2 & $C C$ vs. $T C+T T$ & 0,31 & $T T / T C / C C$ & 0,21 \\
\hline \multirow[t]{4}{*}{ SMAD3 } & rs1065080 & Exon 3 & $G>A$ & 11,9 & $G G$ vS. $G A+A A$ & 0,63 & $A A$ vS. $G A+A A$ & 0,36 \\
\hline & rs11630297 & Intron3 & $C>G$ & 25,0 & $C C$ VS. $C G+G G$ & 0,01 & $G G$ VS. $C G+C C$ & 0,92 \\
\hline & rs11632964 & Intron1 & $G>A$ & 52,8 & $G G / G A / A A$ & 0,24 & $G G / G A / A A$ & 0,64 \\
\hline & rs11637580 & Intron1 & $C>G$ & 23,3 & $G G$ vS. $C G+C C$ & 0,17 & $C C$ vs. $C G+G G$ & 0,44 \\
\hline
\end{tabular}




\begin{tabular}{|c|c|c|c|c|c|c|c|c|}
\hline \multirow{2}{*}{ Gen $^{1}$} & \multirow{2}{*}{ SNP } & \multirow{2}{*}{$\begin{array}{l}\text { Genetisches } \\
\text { Element }\end{array}$} & \multirow{2}{*}{$\begin{array}{c}\text { Basenaus- } \\
\text { tausch }\end{array}$} & \multirow{2}{*}{$\begin{array}{l}\mathrm{MAF}^{3} \\
\left(\frac{\circ}{0}\right)\end{array}$} & \multicolumn{2}{|c|}{ Akuttoxizität ${ }^{4}$} & \multicolumn{2}{|c|}{ Spättoxizität ${ }^{4}$} \\
\hline & & & & & Modell & p-Wert & Modell & $\mathrm{p}$-Wert \\
\hline & rs12439792 & Intron 3 & $A>T$ & 9,7 & $A A$ VS. $A T+T T$ & 0,27 & $A A / A T / T T$ & 0,11 \\
\hline & rs 12443188 & Intron3 & $A>T$ & 24,4 & TT VS. $A T+T T$ & 0,17 & $A A$ VS. $A T+T T$ & 0,03 \\
\hline & rs 12900401 & 3'UTR & $C>T$ & 4,0 & $C C / C T / T T$ & 0,24 & $C C / C T / T T$ & 0,96 \\
\hline & rs12914140 & Intron3 & $T>C$ & 4,0 & $T T / T C / C C$ & 0,88 & $T T / T C / C C$ & 0,32 \\
\hline & rs1470002 & Intron8 & $G>A$ & 43,8 & $G G$ vs. $G A+A A$ & 0,20 & $G G$ vs. $G A+A A$ & 0,14 \\
\hline & rs1470003 & Intron8 & $G>C$ & 43,8 & $C C$ vs. $G C+G G$ & 0,04 & $G G$ vs. $G C+C C$ & 0,01 \\
\hline & rs16950553 & Intron1 & $C>T$ & 13,6 & $C C / C T / T T$ & 0,13 & TT vs. $C T+C C$ & 0,32 \\
\hline & rs16950556 & Intron1 & $C>G$ & 0,0 & & & & \\
\hline & rs16950559 & Intron1 & $T>A$ & 6,8 & $T T / T A / A A$ & 0,24 & $T T / T A / A A$ & 0,77 \\
\hline & rs16950635 & Exon1 & $G>A$ & 5,1 & $G G$ vs. $G A+A A$ & 0,42 & $G G / G A / A A$ & 0,09 \\
\hline & rs17213990 & Intron1 & $C>T$ & 10,8 & $C C / C T / T T$ & 0,30 & $C C / C T / T T$ & 0,91 \\
\hline & rs17293408 & Intron1 & $C>T$ & 3,4 & $C C / C T / T T$ & 0,85 & $C C / C T / T T$ & 0,18 \\
\hline & rs 17293443 & Intron3 & $T>C$ & 23,9 & TT Vs. $T C+C C$ & 0,17 & TT Vs. $T C+C C$ & 0,11 \\
\hline & rs 17294280 & Intron8 & $T>C$ & 27,3 & TT vs. $T C+C C$ & 0,40 & TT Vs. $T C+C C$ & 0,05 \\
\hline & rs1866320 & Intron8 & $C>A$ & 29,0 & $A A$ vs. $C A+C C$ & 0,40 & $A A$ vs. $C A+C C$ & 0,02 \\
\hline & rs2118613 & Intron1 & $C>G$ & 47,7 & $G G$ vs. $C G+C C$ & 0,18 & $C C / C G / G G$ & 0,12 \\
\hline & rs2289263 & Intron3 & $C>A$ & 44,3 & $C C$ vs. $C A+A A$ & 0,73 & $A A$ VS. $C A+C C$ & 0,03 \\
\hline & $\operatorname{rs} 3743342$ & $3^{\prime} \mathrm{UTR}$ & $C>T$ & 26,1 & $C C$ vs. $C T+T T$ & 0,26 & TT vs. $C T+C C$ & 0,15 \\
\hline & rs3743343 & 3 'UTR & $T>C$ & 22,7 & $T T / T C / C C$ & 0,32 & $T T / T C / C C$ & 0,89 \\
\hline & rs3809572 & Upstream -1262 & $C>T$ & 9,1 & TT vs. $C T+C C$ & 0,31 & $C C / C T / T T$ & 0,06 \\
\hline & rs 4776344 & Intron 5 & $G>A$ & 9,1 & $G G / G A / A A$ & 0,24 & $G G / G A / A A$ & 0,08 \\
\hline & rs4776892 & Intron1 & $T>A$ & 14,8 & $T T / T A / A A$ & 0,44 & $A A$ vs. $T A+T T$ & 0,15 \\
\hline & rs6494629 & Intron1 & $A>G$ & 42,6 & $G G$ vS. $A G+A A$ & 0,62 & $A A / A G / G G$ & 0,17 \\
\hline & rs718663 & Intron1 & $T>C$ & 5,7 & $T T / T C / C C$ & 0,70 & $T T / T C / C C$ & 0,94 \\
\hline
\end{tabular}




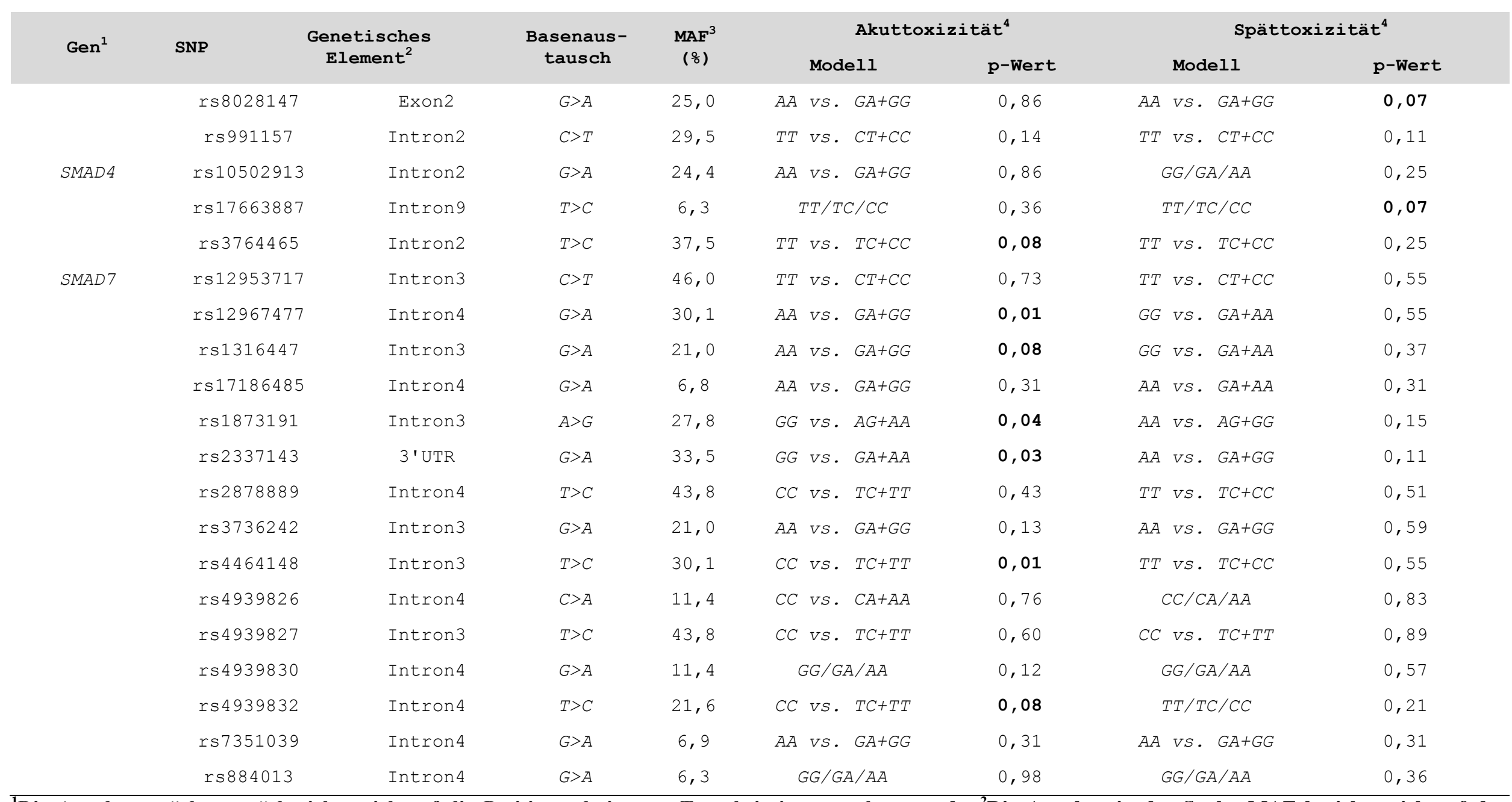

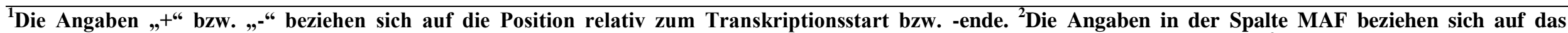

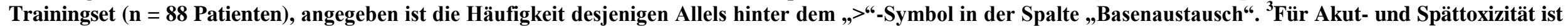

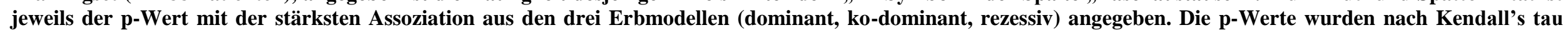
berechnet und bei $\boldsymbol{P} \leq \mathbf{0 , 1}$ durch Fettschrift hervorgehoben. 


\subsubsection{Testset}

Die stärksten Assoziationssignale aus der umfassenden genetischen Charakterisierung des Trainingsets sollten in einem Testset von 76 Patienten überprüft werden. Aus Gründen der Problematik des Multiplen Testens wurde hierbei eine hierarchische Vorgehensweise gewählt. Entsprechend den Ergebnissen des Trainingsets wurden die SNPs mit einem p-Wert $\leq 0,1$ in aufteigender Reihenfolge, beginnend mit der stärksten Assoziation, getestet. Eine Adjustierung auf Multiples Testen wurde mit der Bonferroni-Methode bei jedem Schritt auf die Anzahl der bis dahin analysierten SNPs durchgeführt. Dies bedeutet, dass bei Testung des ersten SNPs (also desjenigen mit der stärksten Assoziation im Trainingset) ein statistisches Signifikanzniveau von $\mathrm{p}=0,05$ gefordert wurde, beim nächstfolgenden SNP von 0,025 bis zu 0,005 für den letzten SNP.

Kriterium für einen statistisch signifikanten Befund war, dass eine Assoziation aus dem Trainingset sich im Testset unter Berücksichtigung des Multiplen Testens mit $\mathrm{p}<0,05$ bestätigen lässt (Tab. 28). Der stärkste Befund zeigte sich für zwei Varianten des SMAD7Gens (rs 12967477, rs4464148); hier war das genannte Signifikanzkriterium erfüllt. Zwischen diesen beiden SNPs besteht ein nahezu komplettes LD; daher wurden diese beiden Varianten unter teststatistischen Aspekten wie eine behandelt. Der Effekt von rs12967477 war auch in der Gesamtkohorte sichtbar, auch nach Adjustierung auf Multiples Testen mit allen 68 untersuchten Genvarianten. Mit zunehmender Toxizität fand sich eine Überrepräsentierung von Patienten mit Homozygotie für das Varianten-Allel. Nach Dichotomisierung der Akuttoxizität mit einem Grenzwert von $\geq 2$ ergab sich für rs12967477 nach Fisher's exaktem Test ein p-Wert von 0,001. Für die klinisch besonders bedeutsamen Akuttoxizitäten $\geq 3$ ergab sich entsprechend ein p-Wert von 0,007. Homozygote Träger des Varianten-Allels hatten im Vergleich $\mathrm{zu}$ den beiden anderen Genotypkonfigurationen bei Berücksichtigung nichtgenetischer Faktoren ein Odds ratio von 6,1 (95 \%-KI 2,0-19,0) für Akuttoxizität $\geq 3$ (Tab. $31)$.

Eine Subgruppenanalyse nach den Einzelorgantoxizitäten erschien in Anbetracht des rezessiven Alleleffektes mit nur wenigen Ereignissen in den einzelnen Organgruppen nicht sinnvoll. 
Tab. 29 SNP-Assoziationen mit Akuttoxizität in den untersuchten Patientenkohorten

\begin{tabular}{|c|c|c|c|}
\hline SNP & $\frac{\text { Trainingset, } \mathrm{n}=88}{\mathrm{p}_{\text {roh }}{ }^{1}}$ & $\frac{\text { Testset, } \mathbf{n = 7 6}}{\mathbf{p}_{a d j}^{2}}$ & $\frac{\text { Gesamtkohorte, } \mathbf{n}=164}{\mathbf{p}_{a d j}{ }^{3}}$ \\
\hline rs2878889 & 0,007 & 0,06 & 0,1 \\
\hline rs12967477 & 0,01 & 0,01 & 0,03 \\
\hline rs4464148 & 0,01 & 0,01 & 0,03 \\
\hline rs11630297 & 0,01 & $>0,5$ & $>0,5$ \\
\hline rs2289263 & 0,03 & $>0,5$ & $>0,5$ \\
\hline rs1470003 & 0,04 & $>0,5$ & $>0,5$ \\
\hline rs1873191 & 0,04 & $>0,5$ & $>0,5$ \\
\hline rs3764465 & 0,08 & $>0,5$ & $>0,5$ \\
\hline rs1316447 & 0,08 & $>0,5$ & $>0,5$ \\
\hline rs4939832 & 0,08 & $>0,5$ & $>0,5$ \\
\hline
\end{tabular}

Die p-Werte wurden mittels Kendall's tau berechnet. ${ }^{1}$ Für das Trainingset sind die p-Werte dieses Tests ( $p_{\text {roh }}$ ) angegeben. ${ }^{2}$ Beim Testset wurde eine hierarchische Auswertung mit Adjustierung auf Multiples Testen nach Bonferroni vorgenommen. ${ }^{3}$ Die Adjustierung für die Gesamtkohorte erfolgte ohne Hierarchie auf alle 68 Genvarianten.

Tab. 30 Verteilung der Akuttoxizität in der Gesamtkohorte in Abhängigkeit von rs12967477

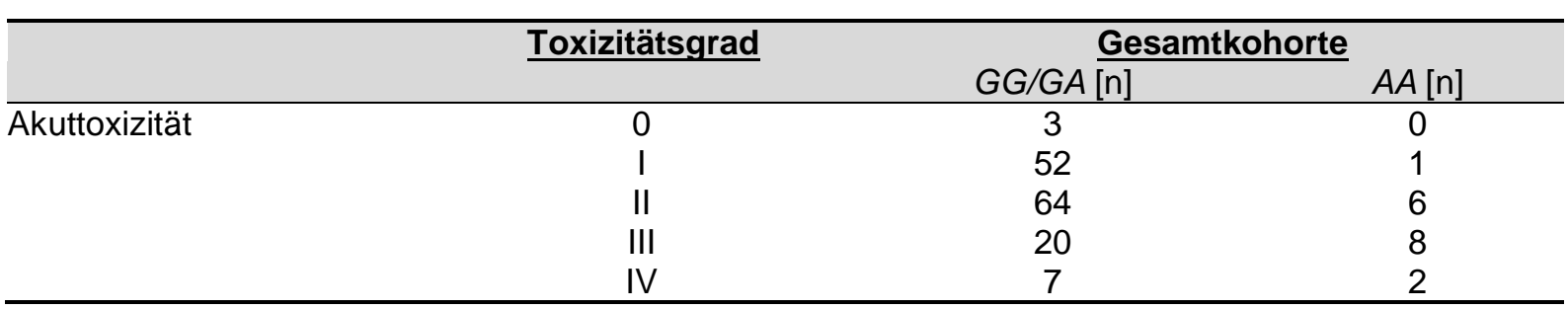

Tab. 31 Regressionsmodelle zur Adjustierung des Effektes von rs12967477

\begin{tabular}{|c|c|c|c|c|c|c|}
\hline \multirow[t]{2}{*}{ Modell } & \multicolumn{2}{|c|}{$\frac{\text { Akuttoxizität }^{2}}{\text { ordinal }}$} & \multicolumn{2}{|c|}{$\frac{\text { Akuttoxizität } \geq^{\circ} 2^{3}}{\text { binär logistisch }}$} & \multicolumn{2}{|c|}{$\frac{\text { Akuttoxizität } \geq^{\circ} 3^{3}}{\text { binär logistisch }}$} \\
\hline & OR (95\% KI) & $p$ & OR $(95 \% \mathrm{KI})$ & p & OR $(95 \% \mathrm{KI})$ & p \\
\hline $\begin{array}{l}\text { Alter }^{1} \\
\text { (alt vs. jung) }\end{array}$ & $1,8(1,0-3,3)$ & 0,05 & $1,0(0,9-1,0)$ & 0,3 & $1,0(0,9-1,0)$ & 0,4 \\
\hline $\begin{array}{l}\text { BMI }^{1} \\
\text { (größer vs. kleiner) }\end{array}$ & $1,3(0,7-2,3)$ & 0,4 & $1,0(0,9-1,1)$ & 0,9 & $1(0,9-1,1)$ & 0,8 \\
\hline $\begin{array}{l}\text { Geschlecht } \\
\text { (weiblich vs.männlich) }\end{array}$ & $0,7(0,4-1,3)$ & 0,3 & $0,9(0,5-1,9)$ & 0,9 & $1,7(0,7-3,8)$ & 0,2 \\
\hline $\begin{array}{l}\text { Stadium } \\
\text { (III vs. II) }\end{array}$ & $1,8(0,9-3,4)$ & 0,1 & $0,5(0,2-1,0)$ & 0,06 & $0,5(0,2-1,3)$ & 0,2 \\
\hline $\begin{array}{l}\text { Oxaliplatin } \\
\text { (ja vs. nein) }\end{array}$ & $0,9(0,5-1,6)$ & 0,7 & $0,8(0,4-1,5)$ & 0,5 & $1,4(0,6-3,1)$ & 0,4 \\
\hline $\begin{array}{l}\text { rs } 12967477^{1} \\
\text { AA vs. GG/GA }\end{array}$ & $5,2(1,9-14,3)$ & 0,001 & $10,4(1,3-82,9)$ & 0,03 & $6,1(2,0-19,0)$ & 0,002 \\
\hline
\end{tabular}

Vorgehensweise analog zu Tab 21. ${ }^{1}$ Für den rs12967477 wurde ein rezessiver Effekt für das VariantenAllel zu Grunde gelegt.

Ein Trend gemäß dem oben genannten Signifikanzkriterium lag für rs2878889 vor. Auch dieser SNP ist im Genbereich von SMAD7 lokalisiert. Hier wurde im Testset ein Bezug auf 
die Akuttoxizität mit $\mathrm{p}=0,06$ (nach Kendall's tau) ermittelt. Im Trainingset hatte dieser SNP das stärkste Signal gezeigt. Jedoch wurde für die Gesamtkohorte nach Adjustierung auf alle 68 Genvarianten das Signifikanzniveau von $\mathrm{p}<0,05$ nicht erreicht.

Tab. 32 Regressionsmodelle zur Adjustierung des Effektes von rs2878889

\begin{tabular}{|c|c|c|c|c|c|c|}
\hline \multirow[t]{2}{*}{ Modell } & \multicolumn{2}{|c|}{$\frac{\text { Akuttoxizität }^{2}}{\text { ordinal }}$} & \multicolumn{2}{|c|}{$\frac{\text { Akuttoxizität } \geq^{\circ} 2^{3}}{\text { binär logistisch }}$} & \multicolumn{2}{|c|}{$\frac{\text { Akuttoxizität } \geq^{\circ} 3^{3}}{\text { binär logistisch }}$} \\
\hline & OR (95\% KI) & $p$ & OR (95\% KI) & p & OR (95\% KI) & p \\
\hline $\begin{array}{l}\text { Alter }{ }^{1} \\
\text { (alt vs. jung) }\end{array}$ & $2,0(1,1-3,6)$ & 0,03 & $1,0(0,9-1,0)$ & 0,1 & $1,0(0,9-1,0)$ & 0,2 \\
\hline $\begin{array}{l}\mathrm{BMI}^{1} \\
\text { (größer vs. kleiner) }\end{array}$ & $1,5(0,8-2,7)$ & 0,2 & $1,0(0,9-1,1)$ & 0,9 & $1,0(0,9-1,1)$ & 0,7 \\
\hline $\begin{array}{l}\text { Geschlecht } \\
\text { (weiblich vs.männlich) }\end{array}$ & $0,7(0,3-1,2)$ & 0,2 & $0,9(0,5-1,9)$ & 0,8 & $1,9(0,8-4,2)$ & 0,1 \\
\hline $\begin{array}{l}\text { Stadium } \\
\text { (III vs. II) }\end{array}$ & $1,5(0,8-3,0)$ & 0,2 & $0,5(0,2-1,1)$ & 0,07 & $0.7(0,3-1,7)$ & 0,4 \\
\hline $\begin{array}{l}\text { Oxaliplatin } \\
\text { (ja vs. nein) }\end{array}$ & $0,9(0,5-1,7)$ & 0,8 & $0,8(0,4-1,5)$ & 0,4 & $1,0(0,5-2,6)$ & 0,7 \\
\hline $\begin{array}{l}\text { rs2878889 } \\
\text { CC vs. TT/TC }\end{array}$ & $3,2(1,5-6,6)$ & 0,002 & $3,1(1,2-8,2)$ & 0,02 & $3,3(1,4-7,8)$ & 0,007 \\
\hline
\end{tabular}

Vorgehensweise analog zu Tab 21. ${ }^{1}$ Für den rs2878889 wurde 2 für das Varianten-Allel zu Grunde gelegt.

Die Auswertung der Spättoxizität erfolgte entsprechend der Akuttoxizität (Tab. 28). In Tabelle Tab. 33 sind die Assoziationen des Trainingsets mit einem p-Wert $\leq 0,1$ dargestellt. Nach Adjustierung auf Multiples Testen mit der Bonferroni-Methode konnte das gesetzte Signifikanzniveau von $\mathrm{p}=0,05$ jedoch für keine der Genvarianten erreicht werden.

Tab. 33 SNP-Assoziationen mit Spättoxizität in den untersuchten Patientenkohorten

\begin{tabular}{lcc}
\hline \multirow{2}{*}{ SNP } & $\frac{\text { Trainingset, } \mathbf{n}=\mathbf{8 8}}{\boldsymbol{P}_{\text {roh }}{ }^{1}}$ & $\frac{\text { Testset, } \mathbf{n}=\mathbf{7 6}}{\boldsymbol{P}_{\text {adj }}{ }^{2}}$ \\
\hline rs6478974 & 0,0007 & $>0,5$ \\
rs1470003 & 0,006 & $>0,5$ \\
rs1866320 & 0,02 & $>0,5$ \\
rs12443188 & 0,03 & $>0,5$ \\
rs17294280 & 0,05 & $>0,5$ \\
rs3809572 & 0,06 & $>0,5$ \\
rs1792658 & 0,06 & $>0,5$ \\
rs17663887 & 0,07 & $>0,5$ \\
rs8028147 & 0,07 & $>0,5$ \\
rs4776344 & 0,08 & $>0,5$ \\
rs16950635 & 0,09 & $>0,5$ \\
rs3773651 & 0,09 & $>0,5$ \\
\hline
\end{tabular}

Die p-Werte wurden mittels Kendall's tau berechnet. ${ }^{1}$ Für das Trainingset sind die p-Werte dieses Tests $\left(p_{r o h}\right)$ angegeben. ${ }^{2}$ Beim Testset wurde unter Verwendung desselben Tests eine hierarchische Auswertung mit Adjustierung auf Multiples Testen nach Bonferroni vorgenommen. 
Auch konnte kein Zusammenhang zwischen dem Auftreten von Akuttoxizitäten und Spättoxizitäten mit der noch vergleichsweise kurzen Nachbeobachtungszeit, im Median vier Jahre, festgestellt werden.

\subsection{Kombinierte Betrachtung von TGF $\beta$-Signalweg- Polymorphismen in Bezug auf die beobachtete Radiotoxizität}

Nach den oben dargestellten Analysen scheinen fünf SNPs (TGFBRI*6A, rs1800471, rs11856909, rs12967477, rs2878889) im Hinblick auf das Risiko, akute Nebenwirkungen einer Strahlentherapie zu erleiden, besonders interessant zu sein. Es stellte sich die Frage nach additiven Effekten bei Vorliegen bestimmter Kombinationen dieser Marker. Dazu wurden zunächst diese fünf Marker in einem schrittweisen binären logistischen Modell auf Beeinflussung einer Akuttoxizität $\geq{ }^{\circ} 2$ untersucht. Als stärkster Prädiktor erwies sich dabei TGFB1 rs1800471, gefolgt von SMAD3 rs11856909 und SMAD7 rs12967477 (siehe Tab. 34). Daher wurde das kombinierte Vorkommen der mutmaßlichen genetischen Risikokonstellationen an diesen drei Positionen analysiert. Allerdings hatten in der Studienkohorte nur zwei Patienten an diesen drei Loci den jeweils für Akuttoxizität prädisponierenden Genotyp; daher kann über das Ausmaß des Risikos für diese MarkerKonstellation mit der vorliegenden Stichprobe keine Aussage getroffen haben. Wurden hier nur die beiden $S M A D$-SNPs betrachtet, fanden sich insgesamt 16 Patienten mit gemeinsamem Auftreten der Risiko-Genotypen für Akuttoxizität $\geq 2$ (d. h. homozygot oder heterozygot für das Wildtyp-Allel bei SMAD3 rs11856909 und homozygotes Varianten-Allel bei SMAD7 rs12967477). Anhand dieser 16 Patienten konnte jedoch kein additives Risiko im Vergleich zur Einzelbetrachtung dieser beiden SNPs ausgemacht werden. 
Tab. 34 Kombinierte Betrachtung der SNP-Effekte auf Akuttoxizität $\geq{ }^{\circ} 2$

\begin{tabular}{|c|c|c|}
\hline & \multicolumn{2}{|c|}{ Akuttoxizität $\geq{ }^{\circ} \mathbf{2}$} \\
\hline & $p$ & OR $(95 \% \mathrm{KI})$ \\
\hline TGFB1 rs 1800471 (GC+CC vs. GG) & 0,01 & $15,0(1,9-120,6)$ \\
\hline SMAD3 rs11856909 (AA vs. GA+GG) & 0,04 & $0,3(0,1-0,9)$ \\
\hline SMAD7 rs12967477 (AA vs. GA+GG) & 0,03 & $9,7(1,2-76,8)$ \\
\hline
\end{tabular}

Es wurde ein binäres logistisches Modell mit schrittweisem Einschluss der fünf SNPs, welche in der Einzelbetrachtung mit Akuttoxizität assoziiert waren, sowie der fünf nicht-genetischen Parameter angewandt. Dies bedeutet, dass aus diesen zehn Variablen zunächst diejenige mit der stärksten Assoziation in das Modell eingeschlossen wurde, wenn ein $p<0,05$ vorlag. Auf Basis dieses Einschlusses wurden für die übrigen Variablen die Assoziationen neu berechnet (konditioniertes Modell). Nachfolgend wurden schrittweise weitere Variablen nach derselben Vorgehensweise eingeschlossen. Die Modellrechnung endete, wenn unter Vorgabe des genannten Signifikanzkriteriums keine weitere Variable mehr eingeschlossen werden konnte. Dies war hier nach drei Schritten der Fall. Für das finale Modell mit den drei eingeschlossen Variablen sind die p-Werte und Odds ratios angegeben. Diese Angaben beziehen sich auf 158 Patienten mit vollständigen Daten.

Ein in analoger Weise zu Tab. 34 für akute Toxizität $\geq^{\circ} 3$ durchgeführtes schrittweises binäres logistisches Modell ergab von den zehn betrachteten Variablen nur für SMAD7 rs12967477 einen statistisch signifikanten Zusammenhang $(p=0,001)$. Das entsprechende Odds ratio für das Risiko bei homozygotem Vorliegen des Varianten-Allels lag bei

$6,3(95 \%$-KI $2,2-18,2)$.

\subsection{TGF $\beta$-Signalweg-Genexpression im Therapieverlauf}

Als nächstes interessierte uns die Wirkung von Bestrahlung auf die Expression von sechs Genen des TGF $\beta$-Signalwegs im Blut. CDKN1A diente als Positivkontrolle für die Strahlenwirkung, CAT wurde als Marker für ROS-Exposition betrachtet. Um etwaige, therapieinduzierte Expressionsänderungen untersuchen $\mathrm{zu}$ können, wurde in periphervenösem Blut unmittelbar vor Therapiebeginn und wenige Tage vor Ende der Bestrahlungsserie in 30 Patienten der Expressionszustand dieser acht Gene analysiert (Abb. $6)$.

Die stärkste Veränderung zeigte sich bei CDKN1A, dessen Expression in Leukozyten des peripheren Blutes sich nach etwa fünf Wochen Bestrahlung (mit je 5 Tagen à 1,8 Gy) gegenüber dem Ausgangswert nahezu verdoppelt hatte. Eine leichte Induktion war auch für $C A T$ zu verzeichnen. Im Gegensatz dazu nahm die Expression der vier untersuchten SMADGene im Therapieverlauf deutlich ab. Am deulichsten war dies für SMAD3 zu sehen. Die Expression von TGFBl selbst und seinem Rezeptor TGFBRl verblieben auf dem Ausgangsniveau. 


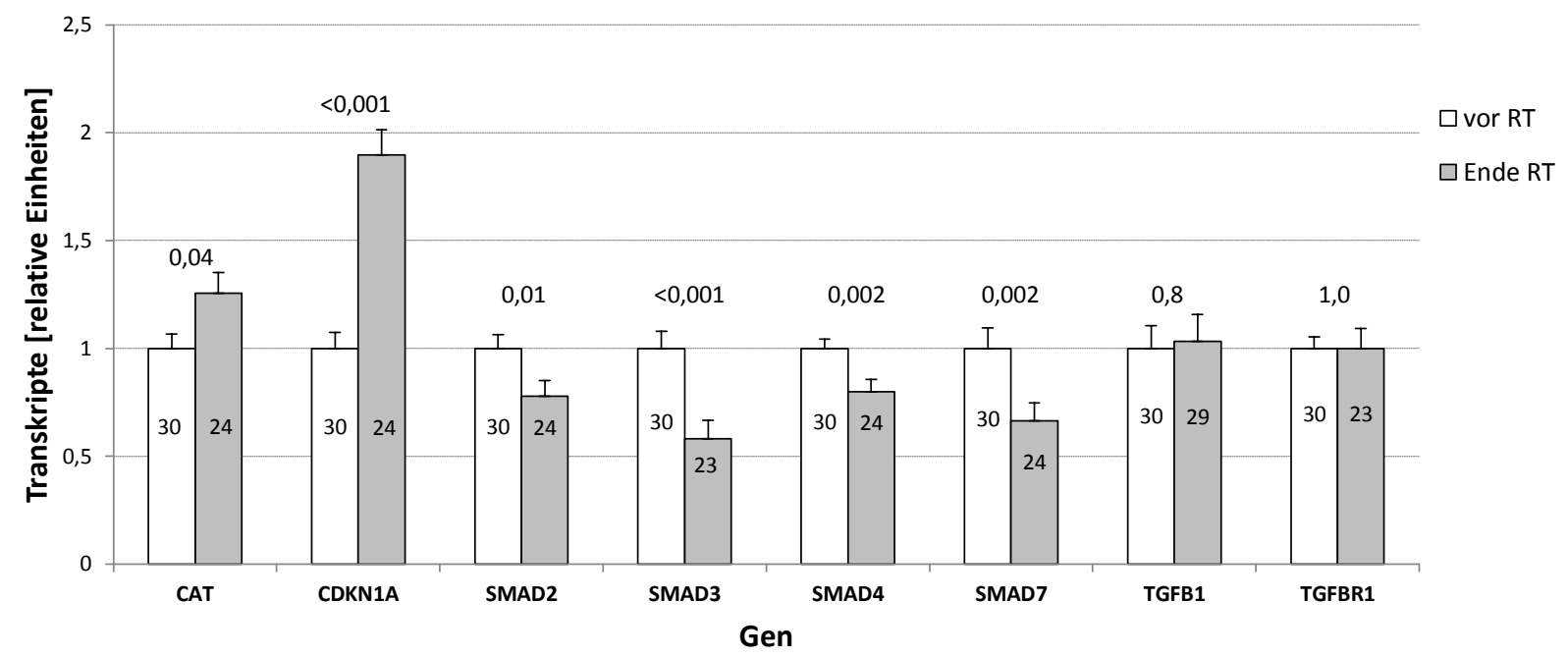

Abb. 6 Expression ausgewählter Kandidatengene im Blut im Verlauf einer Radiochemotherapie. Für diese Analyse wurde bei 30 Patienten unmittelbar vor Therapiebeginn 2,5 ml venöses Blut in eine RNAstabilisierende Lösung (PAX-System) aufgenommen. Zur Evaluierung Therapie-bedingter Effekte wurde eine weitere Probe nach 43-45 Gy kumulativer Dosis abgenommen, wobei hier nicht für alle Patienten eine Analyse möglich war (jeweilige Fallzahlen in grauen Säulen). Die Rohdaten der Expression der acht genannten Zielgene (CTGF wird in Blutzellen nicht transkribiert) wurde auf ein gewichtetes Mittel von GAPDH, HPRT1 und $U B C$ als Referenzgene bezogen. Für jedes Zielgen wurden die so normierten Transkriptzahlen eines Patienten relativ zum Mittelwert der Kohorte von 30 Patienten vor Therapie gesetzt. Da die Säulenhöhe dem Mittelwert der Verteilung entspricht, haben die weißen Säulen daher stets einen Wert von „1“. Die Antennen geben den Standardfehler des Mittelwerts an. Die Zahlen über den Säulen bezeichnen den p-Wert eines zweiseitigen t-Tests zur Prüfung der statistischen Signifikanz zwischen dem Expressionszustand zu Beginn und gegen Ende der Radiochemotherapie.

\subsection{Ex vivo-Simulation der N-RCT in Fibroblasten}

Ausgehend von der klinischen Situation sollte das neoadjuvante Therapie-Protokoll der Patienten in Fibroblasten ex vivo abgebildet werden. Aus Gründen der Zellkultur und der Praktikabilität wurde die Behandlungsphase allerdings auf eine Woche, die Beobachtungsphase auf zwei Wochen begrenzt. Insgesamt wurden 48 Fibroblastenlinien behandelt (Behandlungsprotokoll siehe Kapitel 3.5.5 im Methodenteil). Um Behandlungsinduzierte Effekte auf die Zellviabilität, Bildung von ROS und Änderungen der Expression von Genen des TGF $\beta$-Signalwegs zu zeigen, wurden zu drei Zeitpunkten funktionelle Readouts durchgeführt.

\subsubsection{Expression von Kandidatengenen im Behandlungsverlauf}

Die oben beschriebenen Assoziationen von Genpolymorphismen im TGF $\beta$-Signalweg mit der Akuttoxizität einer N-RCT bestätigen den in der Literatur mehrfach postulierten Zusammenhang dieses Signalwegs mit der Toxizität einer Radiotherapie. Eine naheliegende Hypothese ist eine Beeinflussung der Expression der zugehörigen Gene. Daher sollte die Genexpression auf mRNA-Ebene für sieben zentrale Gene dieses Signalwegs (Ligand TGFB1, Rezeptoren TGFBR1, TGFBR2 und Signaltransduktions-Moleküle SMAD2, SMAD3, 
SMAD4 und SMAD7) quantifiziert werden. Zudem wurde als Positivkontrolle für die Effekte der TGFß1-Behandlung die Expression von CTGF sowie für DNA-Schädigung durch ionisierende Strahlung diejenige von CDKN1A bestimmt. Als Marker einer erhöhten Bildung von ROS wurde das Transkriptionsniveau der ROS-detoxifierenden CAT gemessen. Die Expressionsmessungen erfolgten zu drei Zeitpunkten: an Tag 2 (nach 2x 1,8 Gy), an Tag 5 (nach 5 x 1,8 Gy) und sieben Tage danach (d. h. Tag 12) ohne weitere Bestrahlung (siehe Kapitel Methodenteil 3.5.5).

Der Zeitverlauf für die Effekte der drei durchgeführten Behandlungen auf die Expression der ausgewählten neun Gene ist in den neun Bildern von Abb. 7 veranschaulicht. 


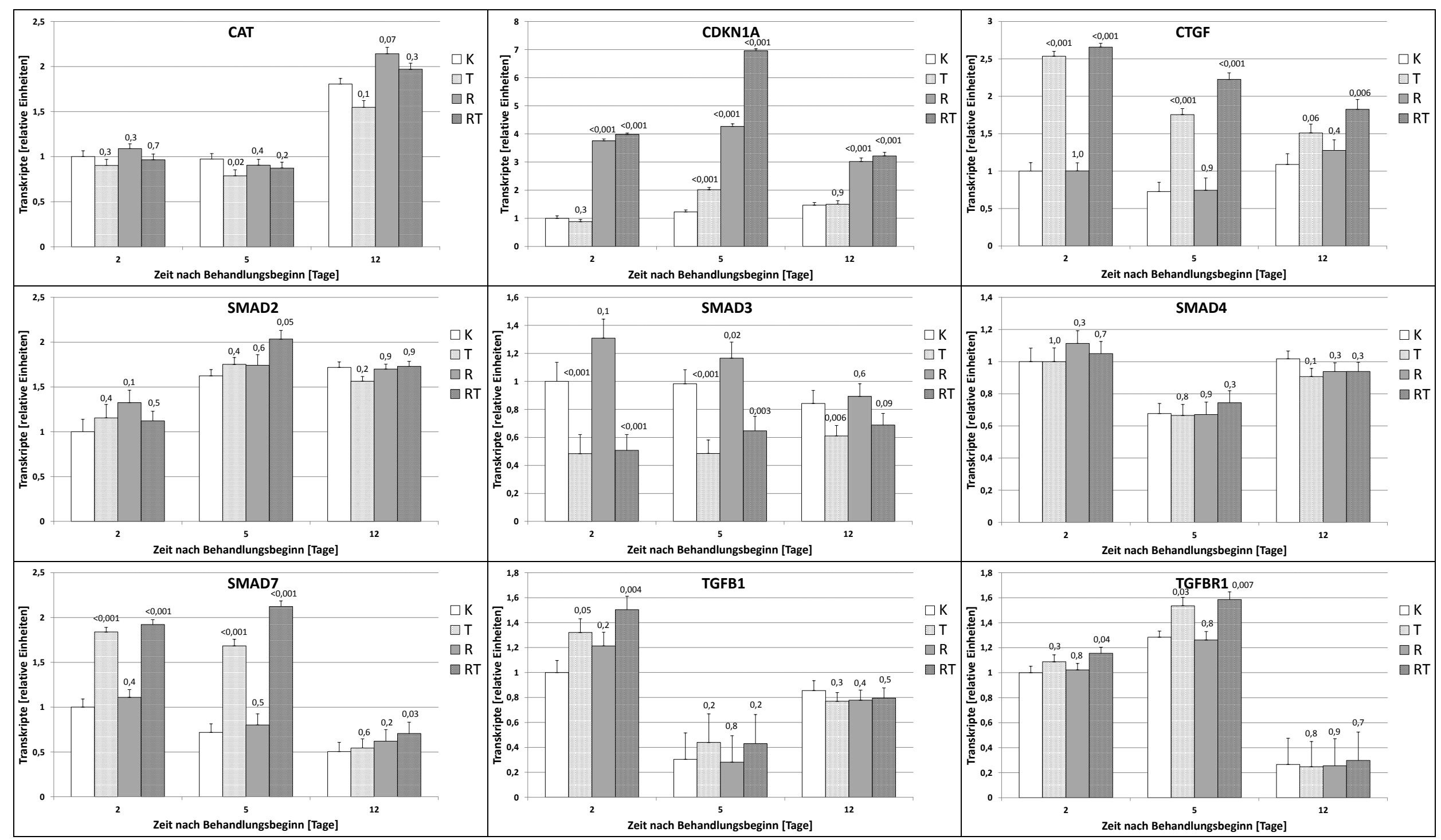

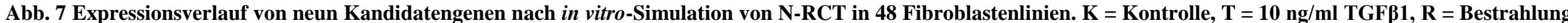
mit je 1,8 Gy an den Tagen 1-5 und einmalige Zugabe von $3 \mu$ M 5-FU vor erster Bestrahlung an Tag 1, RT = Kombination aus $R$ und T. Die auf ein gewichtetes Mittel aus GAPDH und HPRT1 normierten Expressionsdaten wurden auf die Kontrollbedingung an Tag 2 bezogen. Die Säulen geben jeweils den Mittelwert und die Antennen dessen Standardfehler für die 48 Fibroblastenlinien an, die Zahlen über den Säulen die p-Werte eines Zwei-Gruppen-t-Tests für eine Behandlung bezogen auf die Kontrolle des entsprechenden Tages. 
Erwartungsgemäß zeigte sich unter der TGF $\beta 1$-Behandlung bei SMAD3 eine Suppression und bei SMAD7 eine Induktion der Expression. Die zu Beginn der Behandlungsserie erkennbare Autoinduktion von TGFBl durch TGF $\beta 1$ hatte sich bereits nach einigen Tagen noch in Gegenwart dieses Zytokins deutlich abgeschächt und sich anschließend bis Tag 12 vollständig normalisiert. Nach einigen Tagen Exposition gegenüber TGF $\beta 1$ kam es im Vergleich zu einer unbehandelten Kontrolle auch zu einer Induktion von TGFBR1. Während bei SMAD7 und TGFBR1 die TGF $\beta 1$-vermittelte Induktion eine Woche nach Beendigung der Behandlung weitgehend auf das Kontrollniveau zurückgekehrte, war die Suppression von SMAD3 noch nachweisbar, wenngleich weniger ausgeprägt als in Gegenwart von TGF $\beta 1$. Besonders deutlich war eine Induktion durch TGF $\beta 1$ auch für $C T G F$, dessen Expression über den TGF $\beta$ Signalweg stimuliert wird und daher als Positivkontrolle für TGF $\beta 1$-vermittelte Effekte diente. Hier zeigte sich bereits zwei Tage nach Beginn einer TGF $\beta 1$-Behandlung eine massive Induktion. Diese hatte sich auch eine Woche nach Ende dieser Behandlung noch nicht vollständig zurückgebildet. Im Bezug auf die Expression von $C T G F$ fiel auf, dass die TGF $\beta 1-$ bedingte Induktion durch Bestrahlung noch verstärkt wurde, insbesondere zum Ende der 5-tägigen Behandlungsserie und im Anschluss daran. Analog diente als Positivkontrolle der Bestrahlung die Induktion von CDKN1A. Hier zeigte sich, wie erwartet, bereits an Tag 2 eine deutliche Zunahme nach Bestrahlung. Auch diese Effekte nahmen im Verlauf mit der kumulativen Strahlendosis zu und blieben auch eine Woche nach der letzten Bestrahlung gegenüber dem Kontrollniveau stark erhöht. Auffallend war, dass zu Ende des 5-tägigen Behandlungszyklus auch TGF $\beta 1$ die CDKN1A-Expression stimulierte bzw. die Bestrahlungsvermittelte Induktion noch weiter verstärkte; diese Effekte waren eine Woche nach Wegnahme des Zytokins nicht mehr erkennbar. Eine moderat additive Wirkung von TGF $\beta 1$ und Bestrahlung war initial für die Autoinduktion von TGFB1 sowie gegen Ende des Behandlungsprotokolls für die Induktion von SMAD2 und SMAD7 festzustellen. In Bezug auf SMAD3 hingegen verhielten sich die Wirkungen dieser beiden Behandlungsmodalitäten entgegen gesetzt, wohingegen bei SMAD4 keinerlei Effekte auszumachen waren.

Der Expressionsverlauf der CAT als eines ROS-detoxifizierenden Enzyms ließ - abgesehen von einer deutlichen Zunahme auf Kontrollniveau nach einer 12-tägigen Kulturzeit - nur diskrete Behandlungseffekte erkennen: TGF $\beta 1$ hatte hier eine leicht supprimierende, Bestrahlung eine schwach induzierende Wirkung.

In der Abb. 7 wurde die Gentranskription jeweils auf die Kontrolle mit Zellkulturmedium an Tag 2 bezogen. Dies erlaubt auch eine Veranschaulichung des Transkriptionsverlaufs auf Kontrollniveau. Nachteilig daran ist, dass die Veränderungen der spezifischen 
Behandlungsbedingungen gegenüber der Kontrolle an dem jeweils zugehörigen Zeitpunkt nicht direkt ersichtlich sind. In Abb. 8 ist dagegen für die simulierte N-RCT (ohne Zugabe von TGF $\beta 1$ ) die Transkription für sechs TGF $\beta$-Signalweg-Gene in Relation zu den Kontrollen an den entsprechenden Zeitpunkten dargestellt. Aus dieser Darstellung wird deutlich, dass es bereits an Tag 2 nach einer Strahlendosis von kumulativ 3,6 Gy zu einer Induktion der prostimulatorischen SMAD-Gene 2 und 3 sowie des ko-stimulatorischen SMAD4 und des TGFB1-Liganden kam. Bei dem inhibitorischen SMAD7 war dies geringer ausgeprägt, bei dem Rezeptor TGFBRI nicht zu sehen. Im weiteren Verlauf gingen die durch die simulierte $\mathrm{N}-\mathrm{RCT}$ bedingten Induktionen pro-aktivatorischer Komponenten des TGF $\beta$-Signalwegs wieder zurück, während die Transkription von SMAD7 bis zum Ende des Beobachtungszeitraums zunahm.

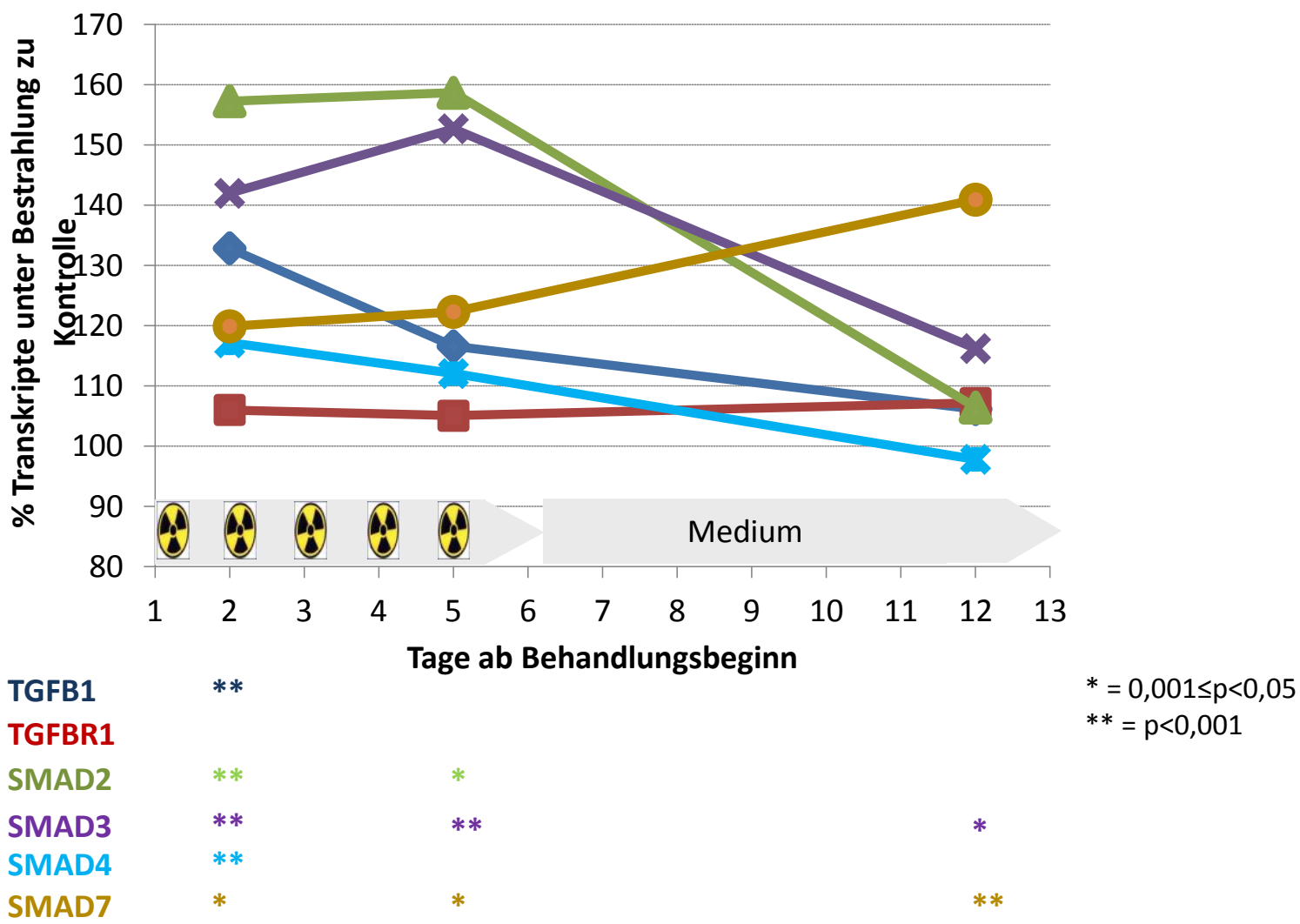

Abb. 8 Zeitverlauf der Gentranskription unter simulierter N-RCT in Fibroblasten. Der Versuchsablauf ist im Methodenteil unter 3.5.5 beschrieben. Die Gentranskription der mit 5-FU und Bestrahlung behandelten Proben wurde für jeden der drei Zeitpunkte auf eine Kontrolle mit Zellkulturmedium bezogen und ist auf der Ordinate der Grafik dargestellt. Im unteren Teil der Abbildung sind für die sechs betrachteten Gene des TGF $\beta$-Signalwegs zu den drei untersuchten Inkubationszeitpunkten (2, 5 und 12 Tage) statistische Veränderungen der simulierten N-RCT gegenüber der Kontrolle gekennzeichnet: * = $\mathbf{0 , 0 0 1} \leq \mathbf{p}<\mathbf{0 , 0 5}$ bzw. $* * \mathbf{p}<\mathbf{0 , 0 0 1}$. Die Normierung der Gentranskription erfolgte über das gewichtete Mittel von GAPDH und HPRT1. 


\subsubsection{Gentranskription in Fibroblasten und klinische Toxizität}

Eine zentrale Frage war, ob die in Fibroblasten erhobenen funktionellen Daten mit den Toxizitätsgraden der Patienten in Verbindung stehen. Sollte dies der Fall sein, könnten derartige Untersuchungen nicht nur einen prädiktiven Wert für die klinische Situation haben, sondern würden sich auch als Modell zur gezielten therapeutischen Intervention eignen.

Dieser Vergleich zwischen in vivo und ex vivo konnte für 40 Patienten bezüglich der Akuttoxizität und für 34 bezüglich der Spättoxizität durchgeführt werden. Dabei wurde jeweils der maximale aufgetretene Toxizitätsgrad betrachtet (siehe Abb. 9).
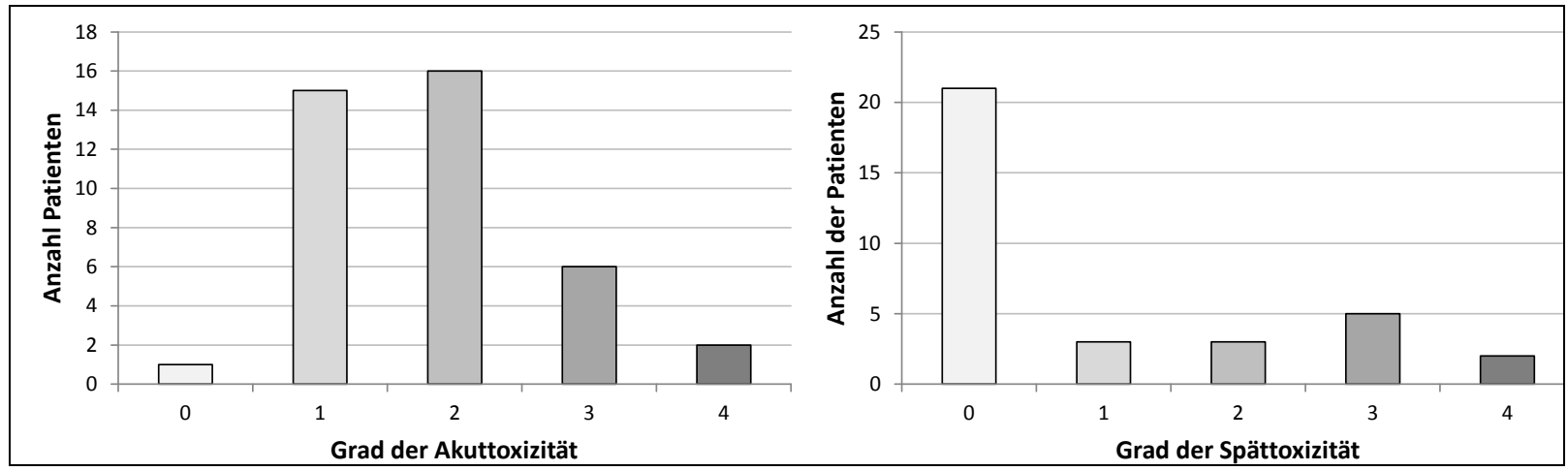

Abb. 9 Verteilung von Akut- und Spättoxizität der Patienten mit ex vivo-Analysen an Fibroblasten. Für den Vergleich mit der Akuttoxizität (links) konnten Messdaten von 40 und für die Spättoxizität (rechts) von 34 Fibroblasten-Linien verwendet werden. Wie in Kapitel 4.2 wurden jeweils die maximalen Akutund Spät-Toxizitätsgrade (aufsteigend von Grad 0 bis 4) aus Proktitis, Zystitis und Dermatitis sowie für die Akuttoxizität zusätzlich Enteritis gewertet.

Die dargestellten Funktionsdaten zu Genexpression (Kap. 4.6), Zellviabilität (Kap. 4.7.2) und ROS (Kap. 4.7.4) wurden mit den Toxizitätsgraden der zugehörigen Patienten verglichen. Aus Gründen der klinischen Relevanz und der beobachteten Häufigkeiten wurden bei der Akuttoxizität die Grade 0 und $1(\Sigma=16)$ sowie 3 und $4(\Sigma=8)$ zusammengefasst, so dass sich zusammen mit Grad $2(\mathrm{n}=16)$ insgesamt drei Gruppen ergaben. Die Spättoxizität wurde in die Grade 0 und $1(\Sigma=24)$ einerseits sowie 2, 3 und $4(\Sigma=10)$ andererseits dichotomisiert.

Bei den Expressionsdaten wurden die durch die drei Behandlungsbedingungen „T“, „R“ und „RT“ im Vergleich zur Kontrolle hervorgerufenen Veränderungen betrachtet, jeweils an den Tagen 2, 5 und 12 der Behandlungsserie (siehe Abb. 10). Insbesondere für die Behandlung „R“ zeigten sich für einige Gene interessante Beziehungen zur Akuttoxizität. Dies betrifft CAT (an Tag 2 und v. a. an Tag 5), CDKN1A (an Tag 12), CTGF (an Tag 12) und SMAD7 (v. a. an Tag 5). Patienten, deren Fiboblasten bereits an Tag 2 eine geringere bzw. fehlende Induktion von CAT aufwiesen, neigten tendenziell stärker zu höhergradiger Akuttoxizität. Dieser Zusammenhang war an Tag 5 (d. h. nach 5 x 1,8 Gy) in der Fibroblastenserie besonders deutlich ausgeprägt, während dieser Tag 12 kaum mehr zu sehen war. 
Demgegenüber zeigte die Expressionsänderung von CDKN1A in Fibroblasten erst an Tag 12 eine Beziehung zur Akuttoxizität. Je geringer die Induktion von CDKN1A nach Bestrahlung im Vergleich zur Kontrolle war, desto höher war das Risiko der Patienten, eine höhergradige Akuttoxizität zu erfahren. Auch bei CTGF zeigte sich ein Bezug v. a. an Tag 12. Eine geringe oder fehlende Transkriptionssteigerung nach Bestrahlung von Fibroblasten war in den entsprechenden Patienten mit höheren Graden von Akuttoxizität behaftet. Letztere erfuhren auch Patienten, deren Fibroblasten an Tag 5 keine oder nur eine geringe SMAD7-Induktion durch Bestrahlung hatten. 

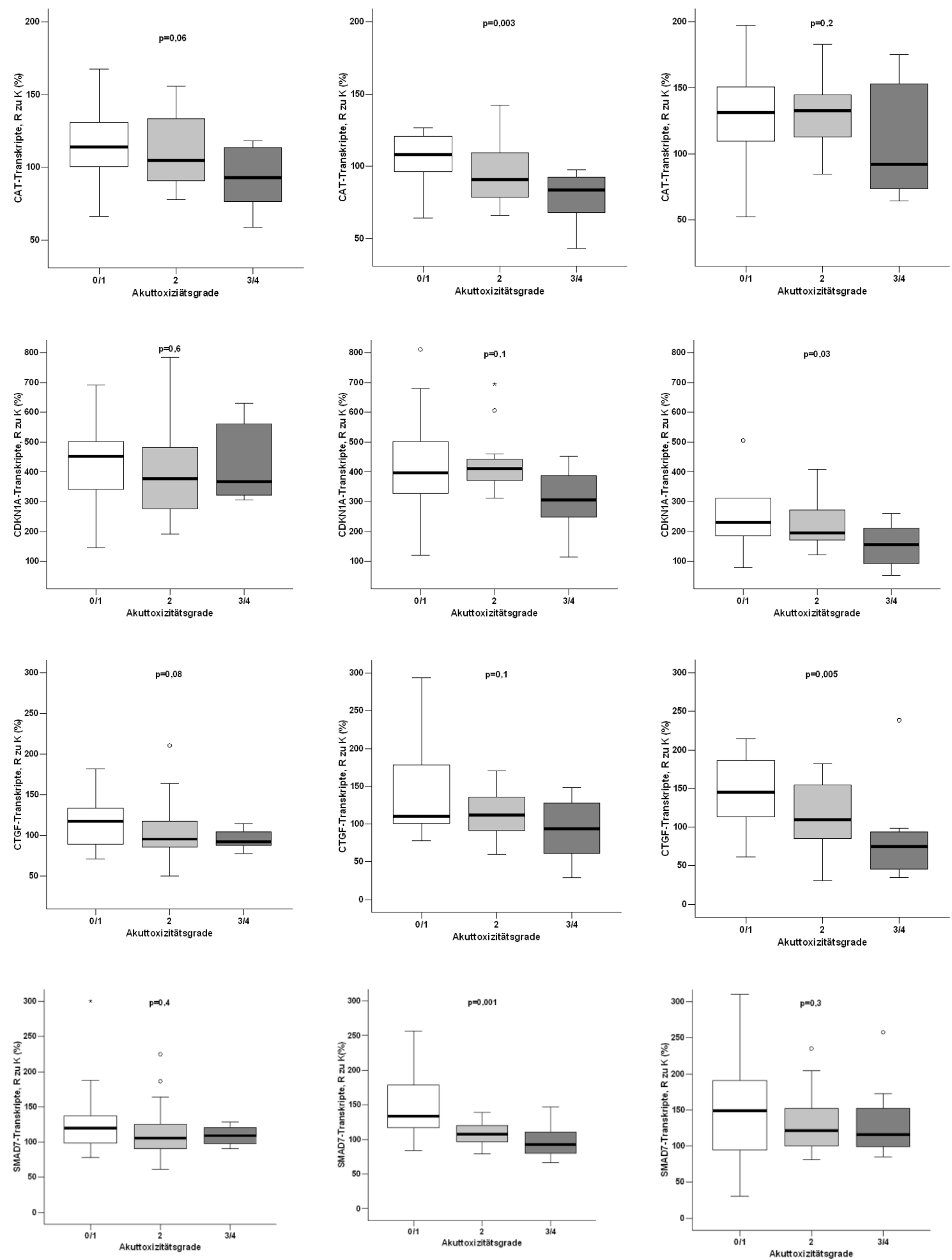

Abb. 10 Akuttoxizität in Relation zur Genexpression in Fibroblasten. Für die vier Gene CAT (Zeile 1), CDKN1A (Zeile 2), CTGF (Zeile 3) und SMAD7 (Zeile 4) ist jeweils für Tag 2 (Spalte 1), Tag 5 (Spalte 2) und Tag 12 (Spalte 3) die durch die Behandlung „R“ (3 $\mu \mathrm{M}$ 5-FU und Bestrahlung) gegenüber einer nur mit Fibroblasten-Zellkulturmedium behandelten Kontrolle veränderten Gentranskription in Abhängigkeit von der bei den zugehörigen Patienten während einer neoadjuvanten Radiochemotherapie aufgetretenen Akuttoxizität dargestellt. Die Genexpressionsdaten waren wie in Fehler! Verweisquelle konnte nicht gefunden werden. auf die Referenzgene GAPDH und HPRT1 normiert. Die statistische Testung erfolgte mit dem Jonckheere-Terpstra-Trend-Test, welcher eine ordinale Anordnung der Toxizitätsgrade annimmt. 
Aus der nachfolgenden Abb. 11 wird deutlich, dass von den Genen des TGF $\beta$-Signalwegs nur SMAD7 unmittelbar zu Ende der Bestrahlungsserie hoch signifikant mit der klinischen Akuttoxizität verknüpft ist.

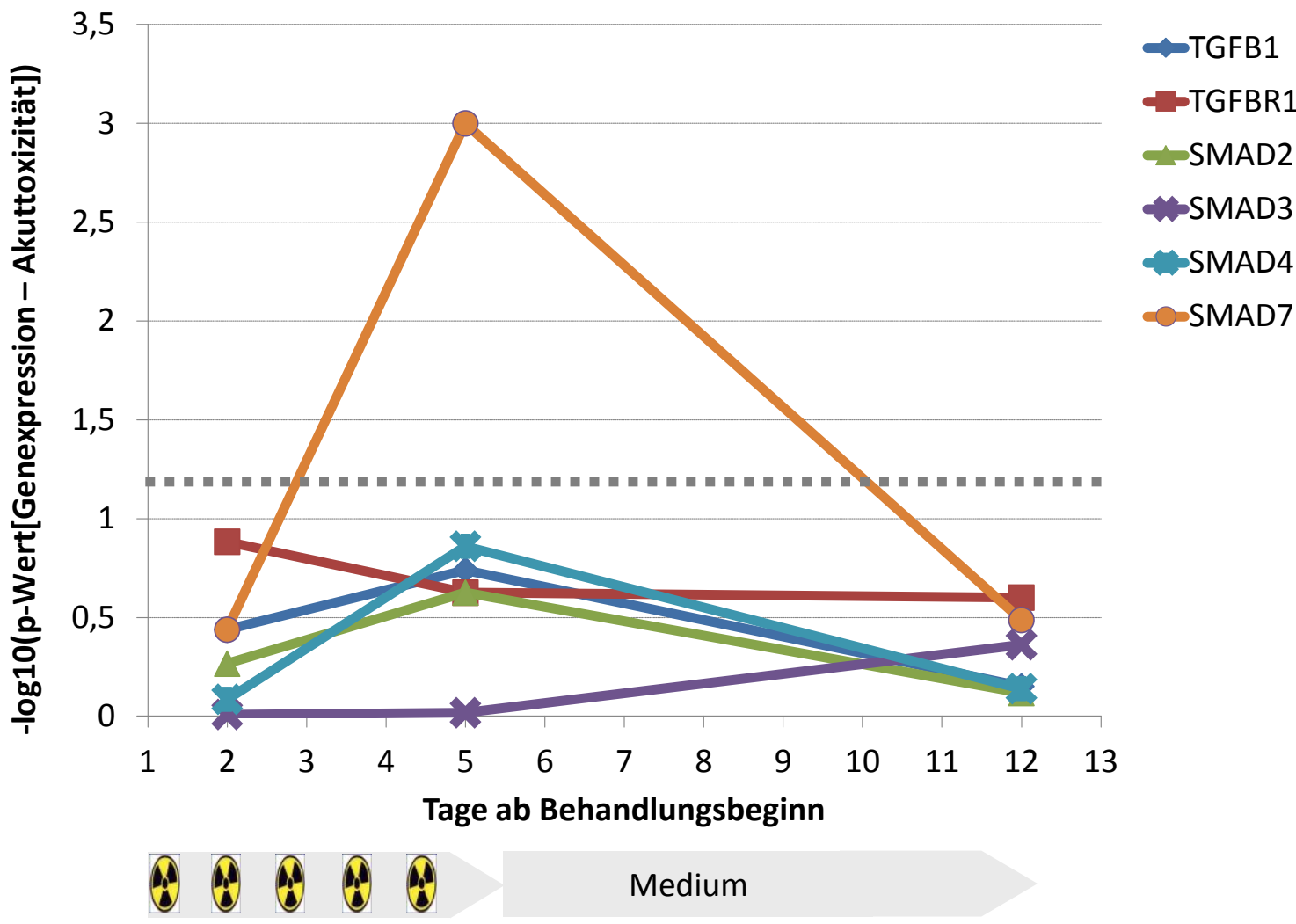

Abb. 11 Assoziation von ex vivo-Gentranskription im Zeitverlauf und klinischer Akuttoxizität. Auf der Ordinate sind die mit dem Jonckheere-Terpstra-Test ermittelten logarithmierten (Basis 10) p-Werte zwischen der Gentranskription in Fibroblasten und der Akuttoxizität (Grad 0 bis 4 nach CTC) der entsprechenden Patienten aufgetragen. Die gestrichelte graue Linie entspricht dem Signifikanzniveau von 0,05. Die Versuchsbedingungen und die Bestimmung der Transkriptionsdaten ist analog zu Abb. 8.

Hinsichtlich der Spättoxizität waren die Zusammenhänge mit der Genexpression in Fibroblasten weniger deutlich. Allenfalls war ein Bezug für die durch TGF $\beta 1$ induzierte Expressionssteigerung des eigenen Gens TGFB1 zu erkennen. Patienten, deren Fibroblasten in der frühen Phase der Experimentenreihe (Tag 2) weniger stark mit einer solchen Autoinduktion reagierten, hatten demnach ein höheres Risiko, eine Spättoxizität von Grad 2 oder höher zu entwickeln. Derselbe Zusammenhang war in den beiden unabhängig voneinander mit TGF $\beta 1$ behandelten Versuchsbedingungen („T“ bzw. „RT“) zu sehen (siehe Abb. 12). Im weiteren Verlauf der Behandlungsserie war dieser Effekt nicht mehr erkennbar. In der Behandlung „T“ war nach Entfernen des TGF $\beta 1$-Liganden durch Waschen an Tag 6 am Ende des Beobachtungszeitraums an Tag 12 eine gegenüber der Kontrolle leicht supprimierte TGFB1-Transkription mit einem tendenziell geringeren Spättoxizitäts-Risiko verbunden. 
Die Funktionsmessungen zu Zellviabilität und ROS in Fibroblasten standen weder mit der Akut- noch der Spättoxizität in Zusammenhang.
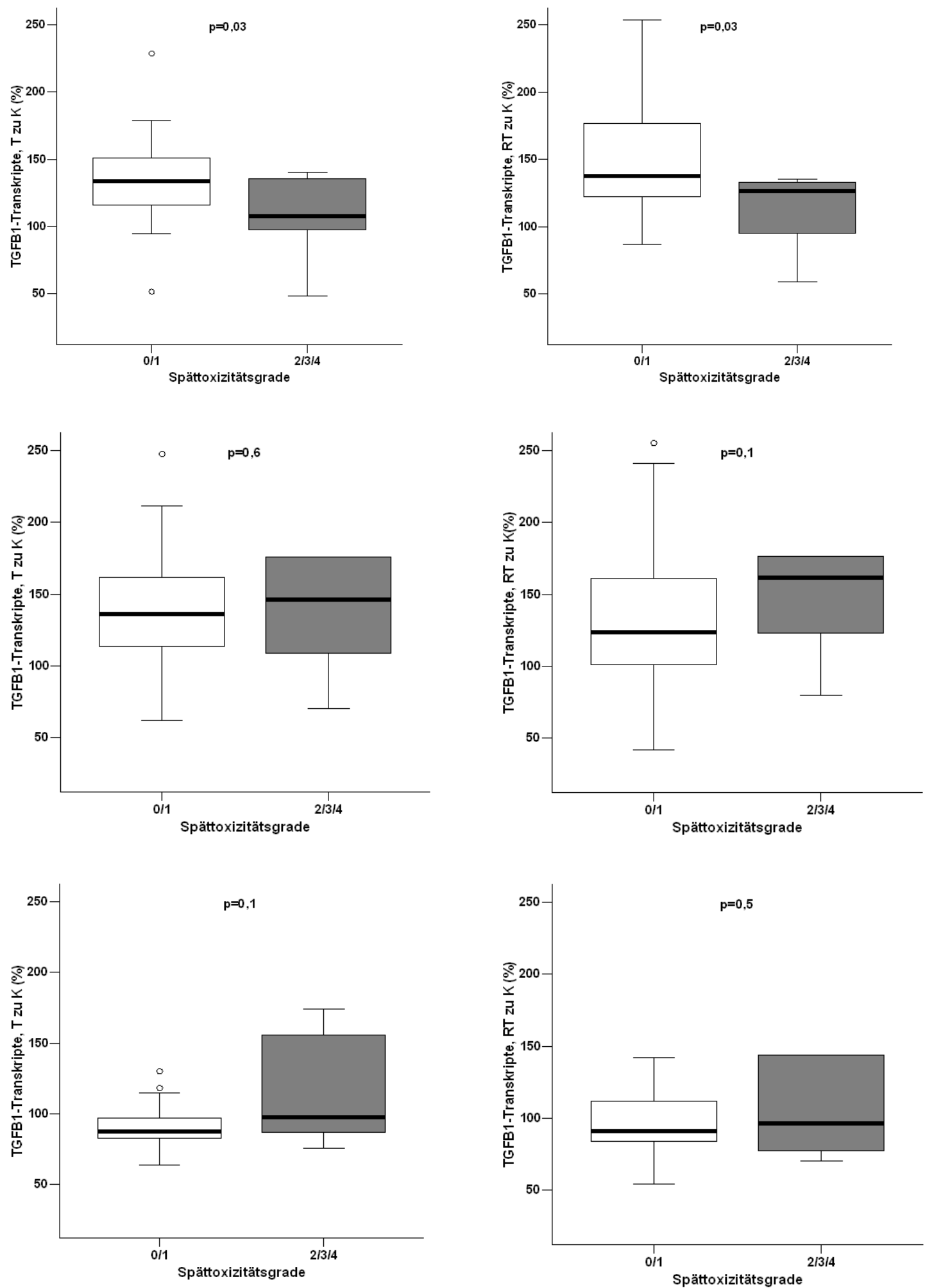

Abb. 12 Spättoxizität in Relation zur Autoinduktion von TGFB1 in Fibroblasten. Die Zeilen entsprechen von oben nach unten den Behandlungstagen 2, 5 und 12. Nebeneinander sind jeweils die Veränderungen der TGFB1-Transkription durch TGFß1 allein (links) bzw. durch TGFß1 in Kombination mit Bestrahlung und $3 \mu \mathrm{M}$ 5-FU (rechts) dargestellt. Statistisch signifikante Unterschiede zwischen den beiden Toxizitätsgruppen 0/1 und 2/3/4 wurden mit dem Mann-Whitney-U-Test geprüft, und die entsprechenden p-Werte sind in den Grafiken eingetragen. 


\subsubsection{Ex vivo-Genexpression und Zellviabilität}

Zur Messung der Viabilität wurde an Tag 5 und Tag 12 jeweils eine Stunde vor Bestrahlung AlamarBlue $^{\circledR}$ als Farbindikator für die Viabilität der Zellen zugegeben.

Hierbei zeigten sich sehr hohe Korrelationen zwischen der Kontrolle ohne spezifische Behandlung und den drei Modalitäten „, $\mathrm{T}^{\prime}$, ,R“, „RT“. Es ergab sich jeweils ein $\mathrm{r}>0,9$ für alle Vergleiche von Behandlung gegenüber der Kontrolle an Tag 5 sowie Tag 12. Zur Auswertung wurde der gepaarte t-Test angewandt, nachdem die Daten der einzelnen Behandlungsgruppen mit Normalverteilung näherungsweise kompatibel waren (KolmogorovSmirnov für alle vier Behandlungsmodalitäten an Tag 5 und Tag $12>0,05$ ). Bei den mit 5-FU behandelten und bestrahlten Proben (,R“) war eine statistisch deutlich signifikante, im Ausmaß aber eher moderate (90\% im Vergleich zur Kontrolle) Reduktion der Viabilität zu beobachten (Abb. 13). Ähnliches galt für die Kombination aus 5-FU, Bestrahlung und TGF $\beta 1$ 1-Behandlung („RT“). Interessant war hier, dass die Viabilität bei „RT“ in Relation zu „R“ an Tag 5 höher und an Tag 12 geringer war. Demgegenüber war die Viabilität der alleinigen TGF $\beta 1$-Behandlung $\left(, \mathrm{T}^{\star 6}\right)$ im Vergleich zur Kontrolle weder an Tag 5 noch an Tag 12 signifikant verändert (Abb. 13).

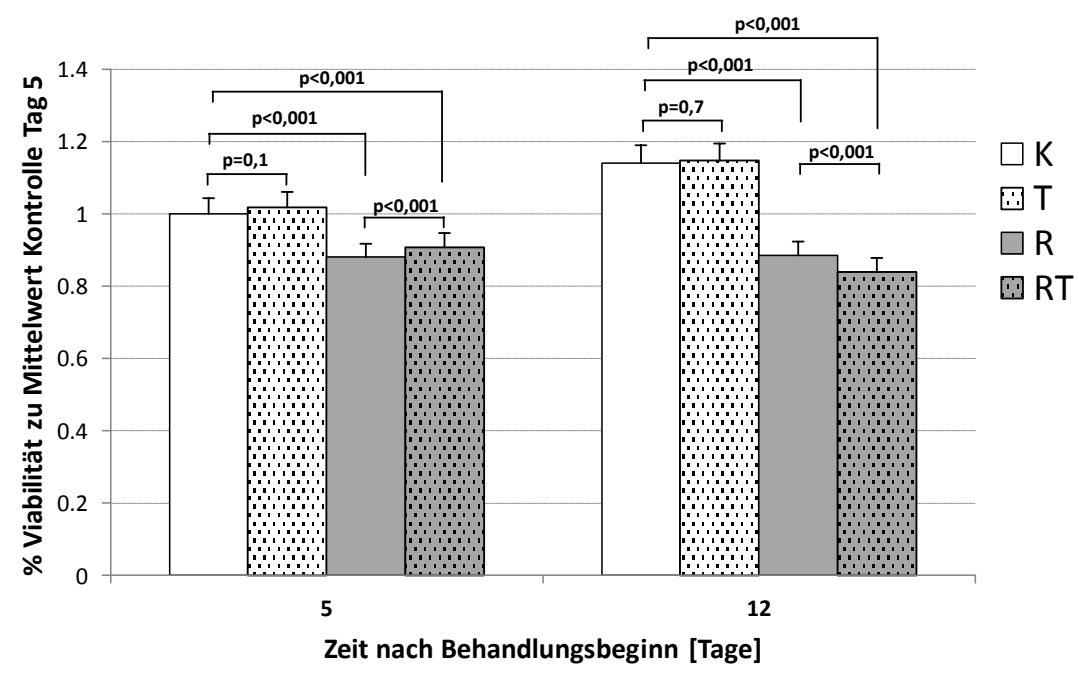

Abb. 13 Einfluss von Bestrahlung und TGF $\beta$ auf die Zellviabilität. Zugabe von Farbindikators an Tag fünf und zwölf jeweils eine Stunde vor der Bestrahlung. Die Messung erfolgte drei Stunden nach Bestrahlung. Die Fluoreszenzwerte sind in \% zum Mittelwert der Kontrolle an Tag 5 dargestellt. Die angegebenen p-Werte beziehen sich jeweils auf den paarweisen $t$-Test der betreffenden Behandlungsmodalität im Vergleich zur Kontrolle desselben Tages.

Als nächstes wurde geprüft, ob ein Zusammenhang zwischen den Viabilitätsdaten und den Expressionsmessungen der neun oben genannten Gene besteht (auf Kapitel 4.3). Dabei zeigte sich auf Kontrollniveau an Tag 5 eine stark negative Korrelation der Viabilität mit der Expression der Gene CAT (Pearson-Korrelationskoeffizient $\mathrm{r}=-0,49, \mathrm{p}<0,001$ ), CDKN1A 
$(\mathrm{r}=-0,61, \mathrm{p}<0,001), C T G F(\mathrm{r}=-0,59, \mathrm{p}<0,001)$ und TGFBRl $(\mathrm{r}=-0,46, \mathrm{p}=0,001)$ sowie eine schwächere zu SMAD7 ( $\mathrm{r}=-0,37, \mathrm{p}=0,01)$. Die paarweise hier verglichenen Datensätze der Viabilität einerseits und der Genexpression andererseits waren mit einer Normalverteilung vereinbar (p-Wert nach Kolmogorov-Smirnov jeweils > 0,05).

An Tag 12 zeigten sich die an Tag 5 beobachteten Zusammenhänge zwischen der basalen Genexpression und der Zellviabilität abgeschwächt; am deutlichsten waren diese noch erkennbar für CDKN1A (r = -0,48, p=0,001), gefolgt von $C A T(\mathrm{r}=-0,30, \mathrm{p}=0,04)$. Bei den anderen zuvor genannten Genen ergaben sich nurmehr statistische Trends für eine negative Korrelation mit der Zellviabilität (p-Werte zwischen 0,05 und 0,1).

Anschließend wurde untersucht, ob spezifische Behandlungs-bedingte Veränderungen auf die Genexpression mit derjenigen auf die Zellviabilität korrelieren. Bei keiner der Behandlungsmodalitäten fand sich zwischen den jeweiligen Kontroll-bereinigten Effekten auf die Expression eines der untersuchten Gene und der Zellviabilität eine statistisch signifikante Korrelation.

\subsubsection{Ex vivo-Genexpression und ROS-Bildung}

Bei Bestrahlung wird initial viel ROS gebildet, welches primär durch die Wechselwirkung der Strahlung mit Wassermolekülen oder sekundär über zelluläre Prozesse gebildet wird. Um die durch Bestrahlung ausgelöste Bildung von ROS und einen möglichen Einfluss durch TGF $\beta 1$ zu zeigen, wurde am zweiten Tag eine Stunde vor der Bestrahlung der Fluoreszenzfarbstoff DCFH-DA zu den Zellkulturen gegeben und drei Stunden nach der Bestrahlung die Signale gemessen. Nach enzymatischer intrazellulärer Deacteylierung entsteht DCFH, welches durch Wasserstoffperoxid $\left(\mathrm{H}_{2} \mathrm{O}_{2}\right)$ zu DCF oxidiert wird, welches dann gemessen wird. Durch den Nachweis von $\mathrm{H}_{2} \mathrm{O}_{2}$, welches durch unterschiedliche Prozesse aus anderen ROS gebildet wird und eine vergleichsweise lange Halbwertszeit hat, lässt sich der oxidative Zellstress insgesamt abschätzen.

Den Erwartungen entsprechend konnte gezeigt werden, dass die Bildung von ROS durch Bestrahlung induziert wird. Durch TGF $\beta 1$ wurde der oxidative Stress leicht erhöht (statistisch nicht signifikant im Vergleich zur Kontrolle, etwas mehr, wenn die zu vergleichenden Proben bestrahlt waren, siehe Abb. 14). 


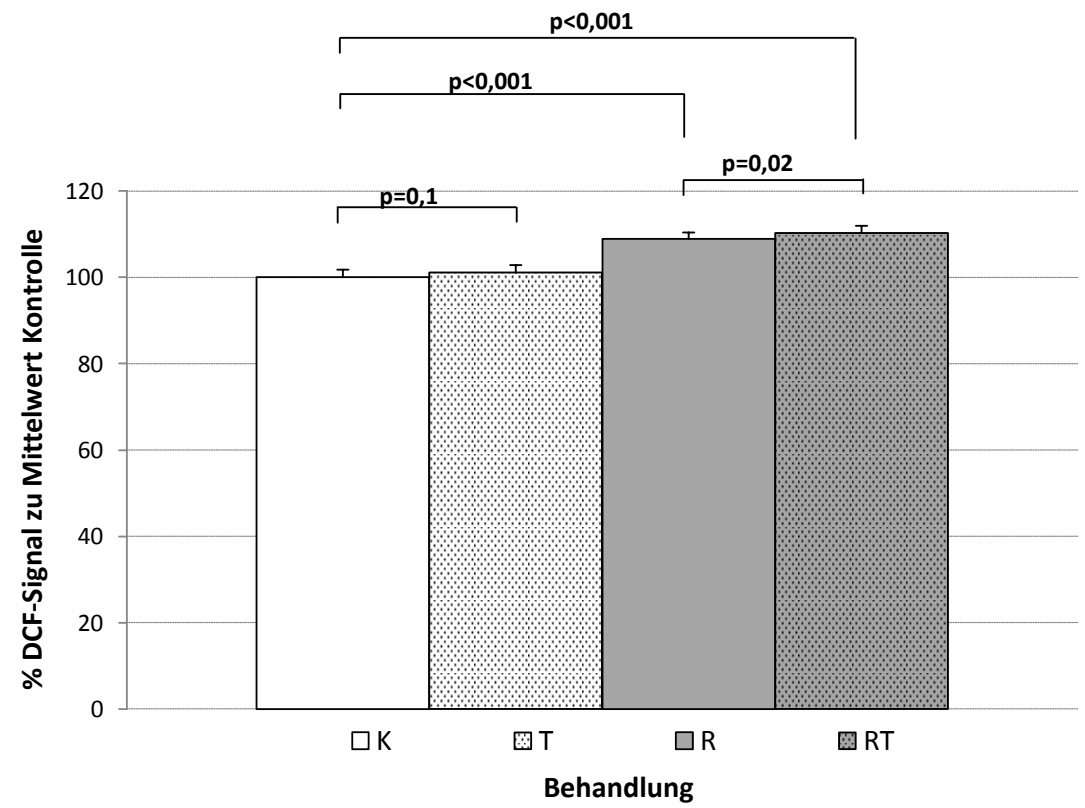

Abb. 14 Einfluss von Bestrahlung und TGF $\beta 1$ auf die ROS-Bildung. Die Zugabe von DCFH-DA erfolgte an Tag 2, eine Stunde vor Bestrahlung, die Messung der Signale drei Stunden nach Bestrahlung. Versuchsbedingungen siehe Abb. 13. Die Fluoreszenzwerte sind in \% zum Mittelwert der Kontrolle dargestellt.

Als nächstes wurde geprüft, ob ein Zusammenhang zwischen der Bildung von ROS und den Expressionsmessungen der neun oben genannten Gene besteht (auf Kapitel 4.3). Dabei zeigte sich auf Kontrollniveau eine stark negative Korrelation zwischen der Bildung von ROS und der Expression der Gene CAT (Pearson-Korrelationskoeffizient $r=-0,47, p=0,001$, Abb. Abb. 15 links), sowie eine schwächer negative Beziehung zu CTGF ( $\mathrm{r}=-0,34, \mathrm{p}=0,02$, Abb. Abb. 15 rechts).
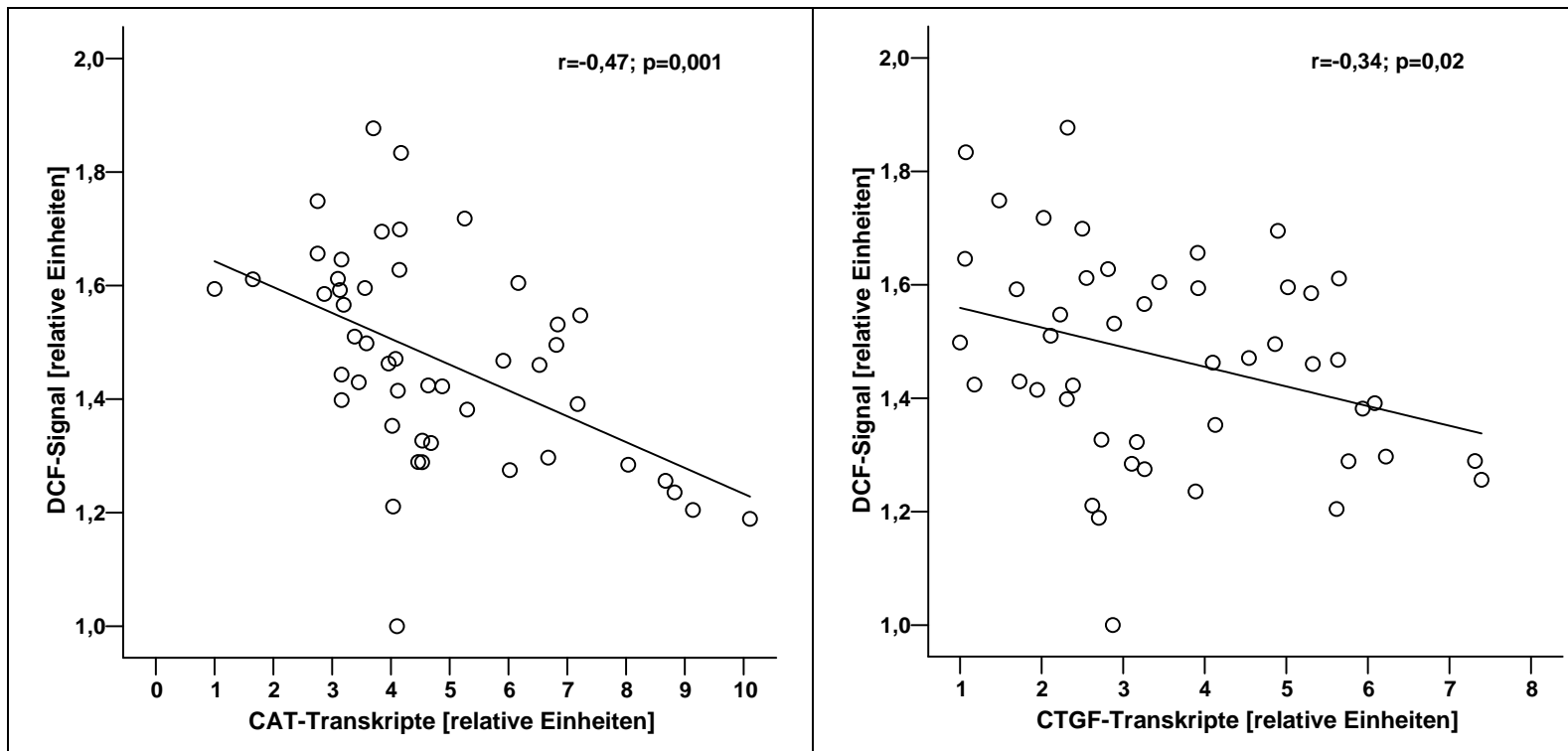

Abb. 15 Korrelation von oxidativem Stress mit der Expression von CAT (links) und CTGF (rechts). Beide Zusammenhänge beziehen sich auf die Kontroll-Bedingung. Der quantitative ROS-Nachweis erfolgte über das aus DCFH-DA gebildete DCF unter der in Abb. 14 genannten Vorgehensweise. Die paarweise hier verglichenen Datensätze der Viabilität einerseits und der Genexpression andererseits waren mit einer Normalverteilung vereinbar (p-Wert nach Kolmogorov-Smirnov jeweils > 0,05), weshalb eine parametrische Testung des Zusammenhangs mit dem Korrelations-Koeffizienten nach Pearson vorgenommen werden konnte.

Anschließend wurde untersucht, ob Behandlungs-bedingte Veränderungen auf die Genexpression mit denjenigen auf die ROS-Bildung korrelieren. Es ergab sich eine 
Korrelation der Effekte der simulierten Radiochemotherapie auf die SMAD7-Expression und ROS Produktion (vgl. hierzu Abb. 16). Eine stärkere Induktion von SMAD7 war mit einem geringeren Anstieg an ROS verbunden. In Kombination mit TGF $\beta 1$ zeigte sich dieser Zusammenhang etwas abgeschwächt (Abb. 16 rechts).
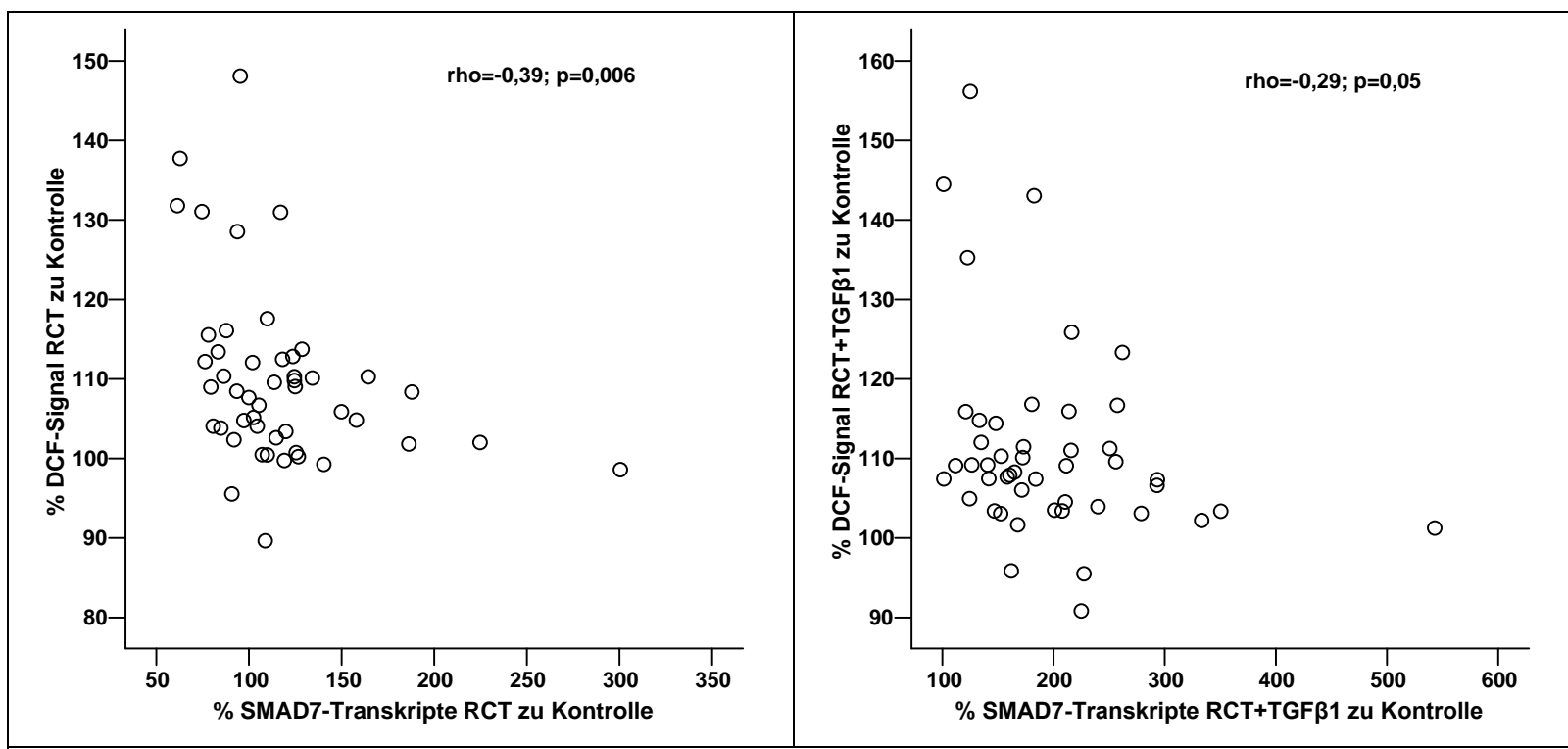

Abb. 16 Bestrahlungs-bedingte Veränderungen der SMAD7-Expression und der ROS-Bildung. Das linke Bild zeigt den Zusammenhang an Behandlungstag 2 ohne, das rechte in Kombination mit $10 \mathrm{ng} / \mathrm{ml}$ TGFß1 (an Tag 1 zugegeben). Für beide Parameter sind für jede Fibroblastenlinie jeweils die prozentualen Veränderungen zur Kontrolle (nur Zellkultur-Medium) dargestellt. Wegen deutlichen Abweichungen von einer Normalverteilung wurde hier eine nicht-parametrische Analyse nach Spearman verwendet, deren Korrelationskoeffizient rho und der zugehörige p-Wert der statistischen Signifikanz angegeben sind. 


\section{Diskussion}

Als klinisch besonders bedeutsame Ergebnisse fanden sich im TGF $\beta$-Signalweg Marker auf DNA- und RNA-Ebene, welche mit der klinischen Akuttoxizität von Patientinnen und Patienten im Rahmen einer N-RCT bei Rektumkarzinom verbunden waren. Bei den genetischen Varianten betrifft dies einen Polymorphismus im Signalpeptid von TGF $\beta 1$, einen intronischen SNP in SMAD3 sowie zwei nahezu in komplettem genetischen LD stehende SMAD7-Genpolymorphismen. In Fibroblasten war eine höhere Induktion der Transkription von SMAD7 und CAT während sowie von CTGF nach ex vivo-simulierter Radiochemotherapie mit einer geringeren klinischen Akuttoxizität verbunden.

\subsection{Arg25Pro-Polymorphismus in TGF $\beta 1$}

Träger der DNA-Variante, die zu einem Austausch von Arg zu Pro an Position 25 des Signalpeptids von TGF $\beta 1$ führt (betrifft ca. $15 \%$ der Behandelten), hatten ein deutlich höheres Risiko für eine Akuttoxizität von mindestens Grad 2 nach CTC, bezogen auf die maximale Ausprägung der vier Organe, Enddarm, sonstiger Darm, Harnblase sowie Haut. Diese Daten fanden Eingang in eine Publikation (Schirmer et al. 2012). Dieser Zusammenhang fand sich jeweils im Trainings- und Testset. Im gesamten Kollektiv war für 108 Personen eine Akuttoxizität $\geq{ }^{\circ} 2$ dokumentiert, wovon 19 mindestens ein Pro25-Allel aufwiesen. Bei den 56 Behandelten mit fehlender oder geringer Akuttoxizität $\left(\leq{ }^{\circ} 1\right)$ gab es nur eine Person, welche das Pro25-Allel trug. In der Gesamtgruppe war dieser Effekt von Pro25 auch nach Adjustierung auf multiples Testen statistisch signifikant. Allerdings ist zu bedenken, dass nur $18 \%$ der Patienten, die an Akuttoxizitäten litten, die Pro25-Variante trugen. Dies deutet darauf hin, dass noch weitere, bislang unbekannte Faktoren zum Auftreten von Akuttoxizität beitragen. Die hohe Inzidenz von Akuttoxizität ist nicht ungewöhnlich, da es sich hierbei um einen kombinierten Wert aus dem Maximum der Toxizität einzelner Organsysteme (compound toxicity value) handelt. Einzelne akute Organtoxizitäten in unseren Kohorten waren vergleichbar mit denen in der European Organization for Research and Treatment of Cancer 22921-Studie (Bosset et al. 2004). Einschränkend ist anzumerken, dass eine Akuttoxizität von ${ }^{\circ} 2$ klinisch in der Regel noch gut zu handhaben ist. Als kritisch werden üblicherweise nur ${ }^{\circ} 3$ und ${ }^{\circ} 4$ angesehen. Bei einer Dichotomisierung der kombinierten Akuttoxizität in < bzw. $\geq^{\circ} 3$ war kein statistisch signifikanter Einfluss von Pro25 zu erkennen. Dies könnte auch der geringen Allelfrequenz dieser Genvariante geschuldet sein. Daher sollte eine Überprüfung an einem unabhängigen, idealerweise deutlich größeren Patientenkollektiv 
erfolgen. Die potenzielle klinische Relevanz wird auch dadurch unterstrichen, dass von den neun Personen mit akut lebensbedrohlicher Toxizität $\left({ }^{\circ} 4\right)$ drei das Pro25-Allel aufwiesen. Nach Fisher's exaktem Test ergab sich in diesem Fall ein p-Wert von 0,08. Dieser Marker könnte ein vielversprechender Kandidat für ein zukünftiges Screening von Patienten vor N-RCT bei Rektumkarzinom sein. Dies ist prospektiv zu prüfen und eine entsprechende Evaluierung scheint auch für andere Radiotherapie-enthaltende Behandlungsregime lohnenswert. Letzteres wurde bereits für das Prostatakarzinom untersucht und dabei ebenfalls ein Risiko für das Pro25-Allel festgestellt (Guhlich 2015).

In der Literatur wurde zuvor noch keine Beziehung zwischen Arg25Pro und akuter Toxizität des N-RCT-Regimes bei Rektumkarzinom beschrieben. Im Vergleich zu den beiden TGFB1SNPs mit wesentlich höherer Allelfrequenz $(-509 C \rightarrow T$, rs1800469 und 869T $\rightarrow C$, rs1800470), welche in meiner Untersuchung keinen Zusammenhang mit Akut- oder Spättoxizität zeigten, gibt es bislang nur wenige Literaturdaten für Arg25Pro. Nach Strahlentherapie waren erektile Dysfunktion häufiger bei genetischen Konstellationen mit Pro25-Trägerstatus (Peters et al. 2008). Allerdings erscheint vorgenannte Studie aus statistischen Gründen sehr fragwürdig, da Kombinationen von Genotypen ohne nennenswertes linkage disequilibrium (Abb. 4) betrachtet und eine Adjustierung auf die Zahl der getesteten Kombinationen unterlassen wurden. In einer Metaanalyse trat kein statistisch signifikanter Effekt von Arg25Pro auf Spättoxizität nach Radiotherapie auf (Zhu et al. 2013), wenngleich die Autoren die Aussagekraft an dieser Stelle mit Verweis auf eine geringe Studien- und Patientenzahl einschränken. In Bezug auf Akuttoxizität ist die Datenlage für Arg25Pro noch geringer. Für schwere Ösophagitis $\geq^{\circ} 3$ nach Lungenbestrahlung fand sich kein Zusammenhang (Guerra et al. 2012). Auch in einer umfassenden Genotypsisierung entzündungsrelevanter Gene fand sich Arg25Pro nicht mit Ösophagitis oder Pneumonitis im Rahmen primärer Radio(chemo)therapie assoziiert (Pu et al. 2014). Eine Erklärung für diese Diskrepanz zu meinem Befund bei Strahlentherapie der Beckenregion könnte sein, dass sich Arg25Pro Kontext-spezifisch auswirkt. Dies gilt nicht nur in anatomischer Hinsicht, sondern auch für die applizierte Radio- wie begleitende Chemotherapie. Es bedarf hier somit weiterer Überprüfung mit vergleichbaren Radio(chemo)regimen.

Unabhängig von Bestrahlung berichten einige Studien über eine Beziehung zwischen chronischen Entzündungsprozessen und Arg25Pro. Auch hier erweist sich die Datenlage sehr uneinheitlich. Eine Reihe von Arbeiten schreibt dem Vorliegen des Pro25-Allels einen ungünstigen Einfluss zu: höhere Prädisposition zu Leberzirrhose bei Hämochromatose (Osterreicher et al. 2005), Atherosklerose unter den Bedingungen einer Hämodialyse (Rao et 
al. 2004), terminale Niereninsuffizienz nach Herztransplantation (van de Wetering et al. 2006), Parodontitis (Huang et al. 2015). Berichte über günstige Effekte von Pro25 betreffen u. a.: Lungenfibrose (El-Gamel et al. 1999), Vaskulopathie bei Empfängern von Herztransplantaten (Densem et al. 2004), geringeres Abstoßungsrisiko nach Organtransplantationen (Ge et al. 2014). Beispielhaft für das Fehlen einer Beeinflussung durch Pro25 seien genannt: Alkohol-assoziierte Leberzirrhose (Osterreicher et al. 2008) und keine erhöhtes Risiko für Niereninsuffizienz nach Herztransplantation bei Kindern (Feingold et al. 2012); im Vergleich zu Erwachsenen, (van de Wetering et al. 2006). Die zitierten Studien stellen eine Auswahl dar und spiegeln die Heterogenität dieses Sachverhaltes wieder. Eine weitaus größere Zahl nicht publizierter Arbeiten ohne Auswirkung von Arg25Pro darf vermutet werden. Sollte es klinisch relevante Effekte dieses Genpolymorphismus geben - und viele der zitierten Untersuchungen beziehen sich auf ansehnliche Patientenzahlen -, so dürften diese Situations- und Kontext-abhängig sein.

Die in der Literatur mehrfach verwendete Einteilung in Hoch-, Mittel- und Niedrig-TGF $\beta 1$ produzierende genetische Konstellationen darf angezweifelt werden. Diese Definition bezieht sich auf Untersuchungen von Zellen weniger Spender und weist dem Pro25 eine verminderte TGFß1-Produktion zu (Awad et al. 1998; Guo et al. 2002). Auch wenn in einer späteren Arbeit erneut über weniger TGF $\beta 1$ im Plasma von Personen mit Pro25 berichtet wurde (Khalil et al. 2005), so fand sich in einer kürzlich veröffentlichten Untersuchung ein solcher Zusammenhang nicht (Kilis-Pstrusinska et al. 2015). Verglichen mit den klinischen Berichten ist die Datenlage für die funktionellen Effekte von Arg25Pro noch weitaus spärlicher. Somit ist aktuell $\mathrm{zu}$ konstatieren, dass die potenziellen molekularen Wirkmechanismen dieser Genvariante noch nicht geklärt sind. Angesichts der Position im Signalpeptid von LAPTGF $\beta 1$ könnte das Pro25-Allel die Transkription, Translation, Sekretion oder Aktivierung von TGF $\beta 1$ modulieren. Einer Dissertation der Arbeitsgruppe zufolge scheint in erster Linie die Sekretion des inaktiven, TGF $\beta 1$-enthaltenden Komplexes durch Pro25 deutlich gesteigert zu sein (Filonenko 2014). Molekulare Grundlage dafür könnte ein verändertes Erkennungsmuster für Signalpeptid-Peptidasen sein, welche nach bioinformatischen Analysen mit der SignalP-Software (Version 3.0; http://www.cbs.dtu.dk/services/SignalP/) im Fall des Pro25-Allels besser abschneiden.

Um die detaillierten molekularen Prozesse im Zusammenhang mit dem Arg25ProPolymorphismus besser zu verstehen, sollten zukünftige Studien auch beurteilen, welche nachgeschalteten Faktoren, die von der TGF $\beta 1$-Expression reguliert werden, relevant für die 
radiogenen Toxizitäten sind. Solche Daten könnten auch wertvoll für die Entwicklung von Medikamenten sein, die gezielt auf den TGF $\beta 1$-Signalweg wirken.

\subsection{SMAD3-SNP rs11856909}

Für den SNP rs11856909 in Intron 1 von SMAD3 war in vorangegangenen Dissertationen in der Arbeitsgruppe eine Beeinflussung der zellulären Radiosensitvität aufgezeigt worden (Janke 2009; Neumann 2012). Daher wurde von mir nun die Hypothese einer Auswirkung auf die klinische Toxizität einer Radiotherapie geprüft. Auf Grund dieser Vorbefunde wurde hier ein statistisches Signifanzniveau von $\mathrm{p}<0,05$ festgelegt. Die $A A$-Genotypkonfiguration, welche in den vorgenannten Dissertationen mit einer erhöhten zellulären Radioresistenz assoziiert war, wirkte sich in meiner Studienkohorte protektiv gegenüber akuter Radiotoxizität aus (Tab. 23 und Tab. 24). Dieser Befund erwies sich mit $p<0,05$ sowohl in der Gesamtkohorte als auch bei getrennter Betrachtung der beiden Studienteile (explorativ und konfirmatorisch) als statistisch signifikant. Auffällig war insbesondere, dass Personen mit diesem $A A$-Genotyp keine akute Enteritis $\geq{ }^{\circ} 2$ nach CTC aufwiesen. Letzteres ist deswegen bedeutsam, da Diarrhöen im Rahmen der neoadjuvanten Radiochemotherapie mitunter so schwer verlaufen können, dass ein Therapieabbruch unumgänglich wird. Auf die Spättoxizität hatte diese Genvariante, zumindest in der betrachteten Nachbeobachtungszeit von im Median vier Jahren, keinen Einfluss.

In der Literatur findet sich zu dem SNP rs11856909 noch kein Eintrag. Über die funktionellen Mechanismen kann deshalb nur spekuliert werden. In Präparationen peripherer mononukleärer Blutzellen von 102 Freiwilligen fand sich in einer früheren Dissertation der Arbeitsgruppe keinerlei Modulation der Gentranskription von SMAD3 durch diesen in Intron 1 dieses Gens gelegenen SNP (Janke 2009). Der fehlende Nachweis auf die Genexpression - zumindest für das untersuchte Zellmodell - gilt auch dann, wenn ein anderer, in hohem LD mit diesem stehender Genpolymorphismus kausativ für die beobachteten funktionellen und klinischen Effekte wäre. Vielleicht ist ein anderes Transkript im Sequenzbereich dieses SNPs kodiert und wird von diesem beeinflusst. Nach aktuellen Datenbankeinträgen (z. B. NCBI, http://www.ncbi.nlm.nih.gov/) scheint dies für die darin annotierten Zellarten nicht der Fall zu sein. Für andere Zelltypen könnte dies durch detaillierte Transkriptom-Analysen geklärt werden. Interessanterweise befindet sich dieser SNP einer Annotierung im UCSC-Browser (https://genome.ucsc.edu/) zufolge im Peak einer Region mit hoher Wahrscheinlichkeit für Acetylierung an Lysin-27 von Histon-H3. Dies gilt als ein Hinweis auf ein Bereich mit regulatorischen Elementen. Es könnte bestimmte Bedingungen, 
z. B. Bestrahlung, geben, unter denen sich dieser Genpolymorphismus - eventuell über eine Histon-Interaktion - funktionell auswirkt. Tatsächlich wurde im Gegensatz zu den Genotypen $G G$ und $G A$ bei der $A A$-Konstellation von rs11856909 keine Induktion von SMAD3 durch Bestrahlung in den Fibroblasten an Tag 5 der Behandlungsserie beobachtet; es fand sich im Gegenteil eine Suppression (siehe Abb. 17). Der letztgenannte Befund ist jedoch angesichts der limitierten Stichprobenzahl zurückhaltend zu bewerten.

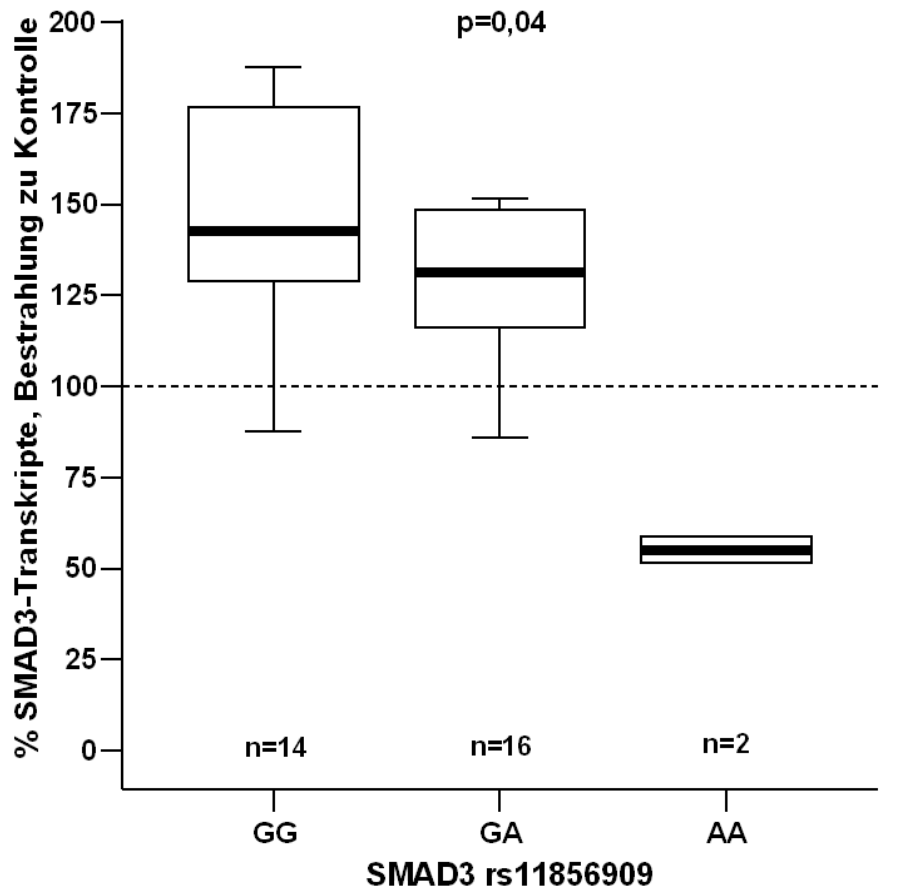

\subsection{SMAD7}

\subsubsection{SMAD7-Genpolymorphismen und Radiotoxizität}

Im Genbereich von SMAD7 zeigten sich zwei SNPs mit der Akuttoxizität verbunden, rs12967477 und rs4464148. Da diese beiden in hohem genetischem LD zueinander stehen und nur für letztere Literaturdaten zum Vergleich vorliegen, diskutiere ich daher nur diesen. Das seltenere Varianten-Allel von rs4464148 (MAF 30,1\% in meiner Stichprobe von Kauskasiern) war dabei mit einem deutlich erhöhten Risiko für hochgradige Akuttoxizität ( $\geq$ Grad 3) verbunden.

Der SNP rs4464148 befindet sich in etwa in der Mitte des großen Introns 3 des SMAD7-Gens (Abb. 18). Mit einigen wenigen anderen SNPs (aufgelistet in Tab. 35) liegt ein hohes LD vor (entsprechend der Grauschattierung der Rauten für jeweils paarweises LD). 


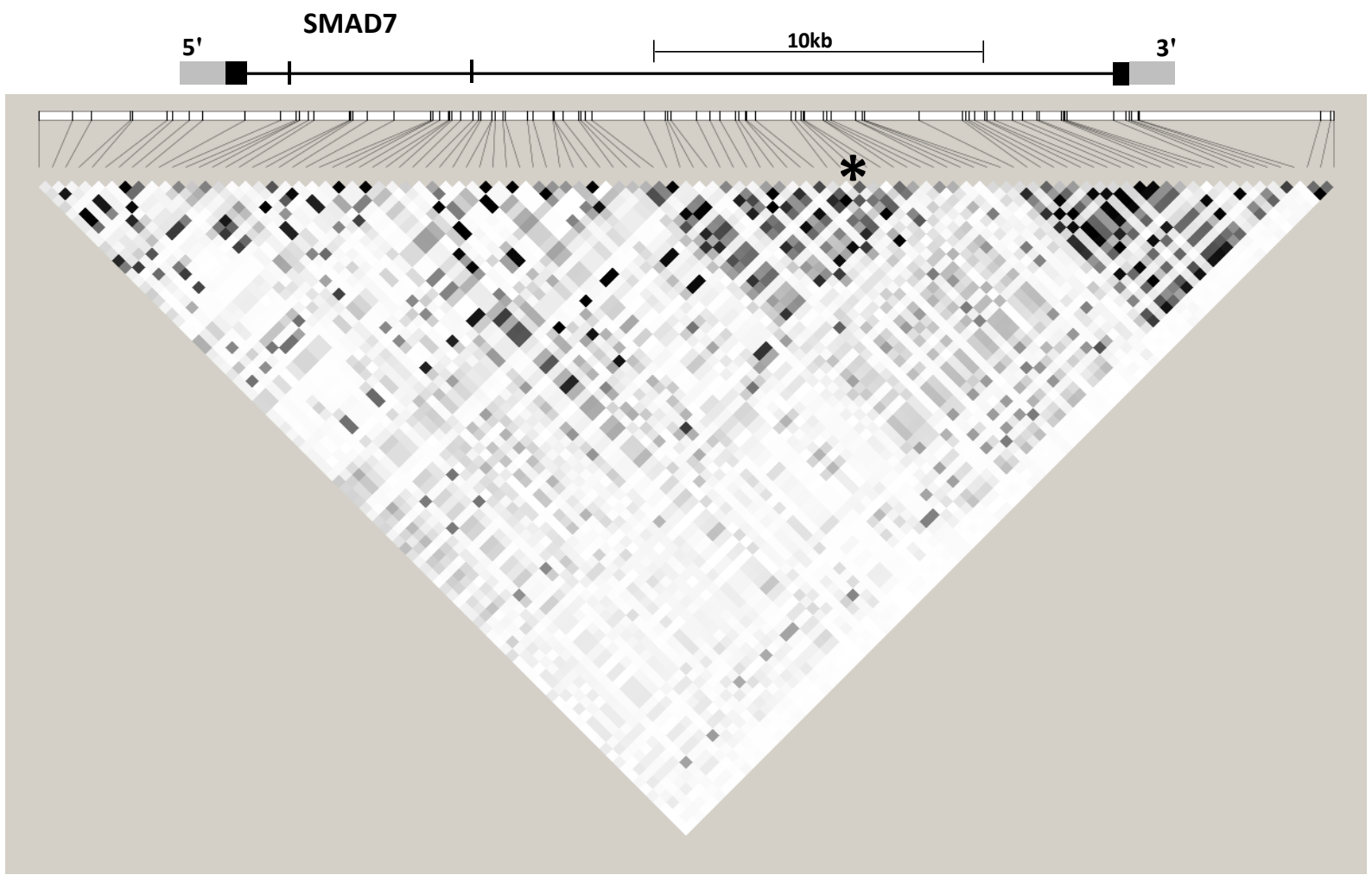

Abb. 18 Genetische Architektur im Bereich des SMAD7-Gens. Dargestellt sind aus der Datenbank 1000 human genomes für die beiden kaukasischen Populationen „CEU“ und „GBR“ alle SNPs mit einer MAF $\geq 0,05$ von $S M A D 7$ einschließlich $5 \mathrm{~kb}$ flankierender Sequenzen. In der schematischen Darstellung oberhalb des LD-Plots sind die UTRs als graue, die Exone als schwarze Rechtecke symbolisiert. Der Stern (*) markiert den mit hochgradiger Akuttoxizität assoziierten SNP rs4464148.

Tab. 35 SNPs in hohem LD mit rs4464148

\begin{tabular}{lcl}
\hline rs-Nummer & LD, $\mathrm{r}^{2}(\%)$ & Distanz zu rs4464148 [bp] \\
\hline rs35715456 & 80 & -6316 \\
rs12967711 & 82 & -3151 \\
rs17186877 & 94 & -1980 \\
rs12967477 & 94 & -1673 \\
rs4939829 & 84 & -1353 \\
rs9946510 & 100 & +805 \\
\hline
\end{tabular}

Aufgelistet sind diejenigen sechs SNPs, welche gemäß den Datenbankeinträgen in 1000 human genomes für die kaukausischen Populationen „CEU“ und „GBR“ mit dem Index-SNP rs4464148 in einem LD mit $\mathbf{r}^{2} \geq 80 \%$ stehen. Betrachtet wurden alle SNPs im Genbereich von $S M A D 7 \pm 5 \mathrm{~kb}$.

Die erste Aufsehen erregende Publikation über eine medizinische Bedeutung von SMAD7Genpolymorphismen förderte in einer genomweiten Assoziationsanalyse (GWAS) einen Bezug zum Risiko, ein kolorektales Karzinom zu entwickeln, zu Tage (Broderick et al. 2007). Das stärkste Signal in einer Patientenkohorte von 940 Individuen mit familiär aufgetretenen kolorektalen Tumoren gegenüber einer gesunden Kontrollgruppe von 965 Personen fand sich dabei für den SMAD7-Polymorphismus rs4939827, wobei über 500.000 ererbte Genvarianten analysiert wurden (jüngst in einer sehr großen Studie mit asiatischen Populationen bestätigt (Zhang et al. 2014) . Der Polymorphismus rs4939827, welcher auch von mir untersucht 
wurde, sich aber nicht auf die radiogene Toxizität auswirkte (Tab. 28), steht in parziellem LD mit rs4464148 ( $\mathrm{D}^{\prime}=0,72 ; \mathrm{r}^{2}=0,23$, entsprechend den Daten aus Abb. 18 unten). Bei diesem nur mäßig ausgeprägten LD ist bei der vorliegenden Stichprobengröße verständlich, warum rs4939827 keinen statistisch signifikanten Bezug zur Akuttoxizität bei Radiotherapie aufwies. Interessanterweise war das $C$-Varianten-Allel von rs4464148, welches bei mir mit einem höheren Risiko für Akuttoxizität verbunden war, in der zitierten GWAS (Broderick et al. 2007) mit einem höheren Risiko für kolorektale Tumore assoziiert, wenngleich dort der Effekt etwas schwächer war als bei rs4939827. In einer unabhängigen Studie wurde für das $C$-Allel von rs4464148 ein Trend zu einem frühzeitigen Auftreten oder familiärer Genese von kolorektalen Karzinomen beschrieben (Curtin et al. 2009). Einer weiteren Untersuchung zufolge könnte dieser Effekt v. a. bei Frauen relevant sein (Thompson et al. 2009).

Die Autoren der genannten GWAS-Studie (Broderick et al. 2007) haben kurze Zeit später eine detailliertere Sequenzierung der assoziierten Genloci durchgeführt. Dabei wurde als kausative Genvariante der heute mit rs58920878 bezeichnete Genpolymorphismus postuliert, welcher mutmaßlich die Bindung von Transkriptionsfaktoren beeinflusst und somit die SMAD7-Expression modulierten könnte (Pittman et al. 2009). Der SNP rs58920878 steht mit dem in meiner Analyse enthaltenen rs12953717 in nahezu komplettem $\operatorname{LD}\left(\mathrm{r}^{2}=0,98\right)$. Letzterer war in meiner Studie weder mit der Akut- noch Spättoxizität verbunden (Tab. 28). Somit scheint der von mir erhobene Befund bezüglich rs4464148 unabhängig von rs12953717 oder rs58920878 zu sein. Dies wurde auch durch weitere Studien bestätigt, in welchen rs12953717, nicht aber rs4464148, mit dem Risiko für kolorektalen Krebs assoziiert waren (Li et al. 2011; Slattery et al. 2010). Möglicherweise liegt in SMAD7 mehr als ein Genbereich mit funktioneller und medizinischer Bedeutung vor.

Das Postulat zweier funktioneller Loci in SMAD7 wird durch eine weitere Studie bestätigt, welche für diese beiden polymorphen Stellen eine differenzielle Beeinflussung der Prognose von Darmkrebs nach vorangegangener NSAID-Einnahme beschrieben hat (Passarelli et al. 2011). Dabei ging das seltenere Allel des SNPs rs4939827 $\left(r^{2}=0,58\right.$ mit dem als kausativ postulierten rs58920878) mit einem kürzeren, das seltenere Allel von rs4464148, mit einem längeren Überleben einher. Diesen Literaturdaten zufolge könnte die Einnahme von NSAID mit der Intention einer Darmkrebsprophylaxe für die Subgruppe von Personen mit CCGenotyp an der Position rs4939827 (betrifft etwa 19\% bei Kaukasiern) kritisch zu erwägen sein. Die Beobachtung eines Zusammenhangs zwischen SMAD7-Genpolymorphismen und der Überlebenszeit bei Darmkrebs nach vorangegangener NSAID-Einnahme weist auf eine mögliche Interaktion zwischen SMAD7 und entzündlichen Prozessen hin. 
Über eine längere Überlebenszeit für das seltenere Allel von rs4464148 wurde auch nach adjuvanter 5-FU-basierter Chemotherapie berichtet (Dai et al. 2012), wenngleich dieser Befund nur nominal statistisch signifikant war. Ob tatsächlich die Überlebenszeit bei kolorektalen Karzinomen durch SMAD7-Genpolymorphismen beeinflusst wird, ist aber noch strittig (Hoskins et al. 2012). Weitere Untersuchungen hierzu sind nötig und erfordern auch die Berücksichtigung der jeweils applizierten Behandlungsregime.

\subsubsection{SMAD7-Genexpression und Radiotoxizität}

Bei der ex vivo-Therapiesimulation in Fibroblasten zeigte sich die statistisch stärkste Assoziation mit der klinischen Akuttoxizität für die SMAD7-Transkription an Tag 5 bei Behandlung „R“ (5-FU und Bestrahlung), verglichen mit der nur mit Zellkulturmedium behandelte Kontrolle (siehe Abb. 10 und Abb. 11). In Fibroblasten der Patientensubgruppe mit der geringsten Akuttoxizität war dabei die deutlichste Steigerung der SMAD7Transkription festzustellen. Nach einer weiteren Woche ohne spezifische Behandlung lag weitgehend unabhängig von der Ausprägung der klinischen Akuttoxizität eine mittlere Induktion von SMAD7 um 40\% vor (siehe Abb. 8). Möglicherweise sind Personen mit einer verzögerten Transkriptionssteigerung von SMAD7 in Bindegewebszellen für höhergradige Akuttoxitzitäten im Rahmen einer Radiotherapie gefährdet.

Im Tiermodell führte eine Blockade des TGF $\beta$-Signalwegs zu weniger Strahlen-bedingten Nebenwirkungen. Mechanistisch ging dies mit einer Induktion der Transkription des inhibitorischen SMAD7 einher (Xavier et al. 2004). In einer anderen Studie fand sich nach Bestrahlung von Nierengewebe der Maus neben einer Aktivierung des TGF $\beta$-Signalwegs auch eine Transkriptionserhöhung von SMAD7 (19267544). Auch bei den protektiven Effekten gegenüber unerwünschten radiogenen Wirkungen durch Neutralisierung von TGF $\beta$ scheint eine Induktion der SMAD7-Transkription beteiligt zu sein (Schultze-Mosgau et al. 2004). Vor kurzem konnte die zentrale Rolle von SMAD7 für die akute Strahlenreaktion eindrucksvoll demonstriert werden (Han et al. 2013): Transgene Mäuse mit einer SMAD7Expression im Mundhöhlenepithel erwiesen sich resistent gegenüber Bestrahlungs-induzierter Entzündung. Auch die topische Anwendung des entsprechenden Smad7-Proteins wirkte sich protektiv aus. Diese Befunde könnten einen Meilenstein für die Beherrschung schwerer Akuttoxizitäten einer Radiotherapie darstellen.

Die Bewertung von Radiosensitivität über ex vivo bestimmte Expressionsprofile wurde bereits in anderem Zusammenhang beschrieben. Mittels neun Kandidatengenen in Fibroblasten vor und nach ex vivo-Bestrahlung wurde in Bezug auf das subkutane Fibroserisiko nach Bestrahlung im HNO-Bereich eine Subgruppe von besonders radioresistenten Personen 
postuliert (Andreassen et al. 2013). Vergleichbare Untersuchungen für eine Radio- bzw. kombinierte Radiochemotherapie bei Rektumkarzinom sind mir bislang nicht bekannt.

\subsection{3 rs4464148 und SMAD7-Genexpression in Fibroblasten}

Nachdem ein Bezug der klinischen Akuttoxizität sowohl mit dem SNP rs4464148 als auch mit der SMAD7-Expression in Fibroblasten beobachtet wurde, stellte sich die Frage, ob der SNP rs4464148 mit der Behandlungs-bedingten Veränderung der SMAD7-Transkription in Fibroblasten in Zusammenhang steht. Dies war in der Tat der Fall: Das Vorliegen des $C$ Varianten-Allels von rs4464148, welches mit einem deutlichen erhöhten Risiko für Akuttoxizität verbunden war (siehe Kapitel 4.4 im Ergebnisteil), wirkte sich auf die Strahlenbedingte SMAD7-Induktion aus: Diese war beim TT-Genotyp am stärksten ausgeprägt und nahm mit der Zahl der $C$-Allele ab (siehe nachstehende Abb. 19). Auch wenn dieser Zusammenhang auf Grund der relativ kleinen Stichprobenzahl vorsichtig interpretiert werden sollte, könnte dieser SNP bzw. einer mit diesem in hohem LD stehender (Tab. 35) ursächlich für die Beziehung zwischen der SMAD7-Expression in Fibroblasten und der Akuttoxitzität sein. Auf diese Weise bekräftigen die Ergebnisse der Analysen in den Fibroblasten den Befund der Genotypisierungsserie.

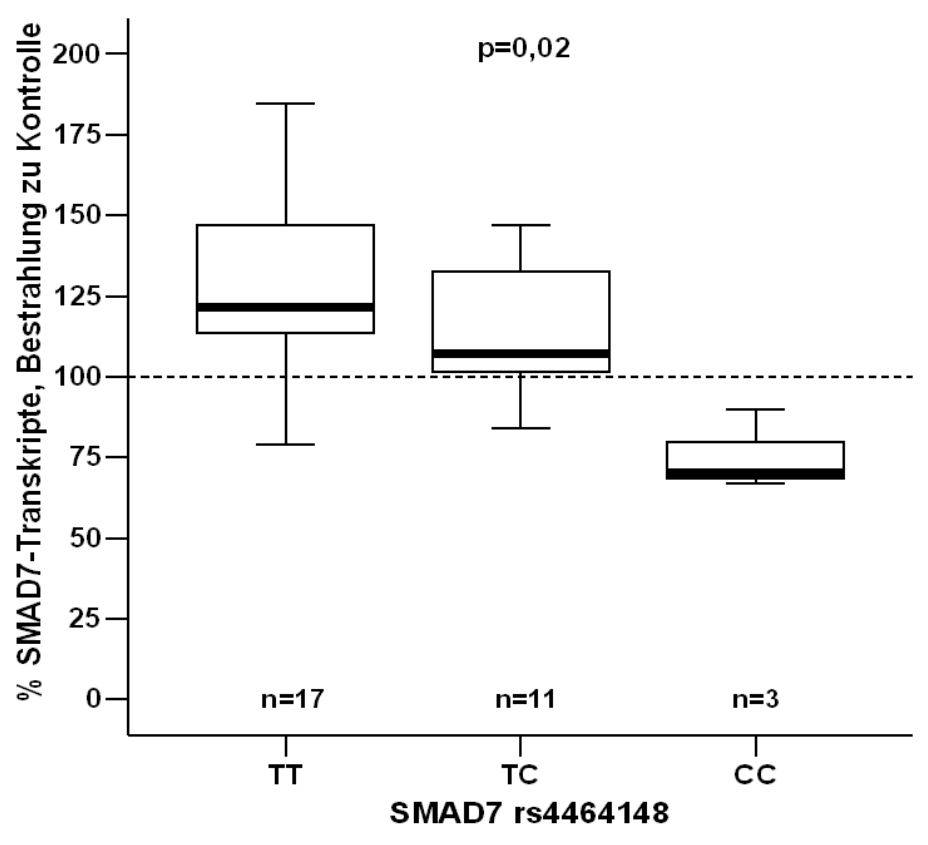

Abb. 19 Durch Bestrahlung veränderte SMAD7-Transkription in Abhängigkeit von rs4464148. Die dargestellten Daten beziehen sich auf den Tag 5 der Behandlungsserie in Fibroblasten; somit waren 5 x 1,8 Gy vor der Zellernte appliziert worden. Die Normierung der Daten, die Darstellungsweise dieses Boxplots und die statistische Prüfung sind analog zu Abb. 17.

\subsubsection{Arbeitshypothese zu SMAD7 rs4464148}

Die zu prüfende Arbeitshypothese könnte lauten: Das seltenere Allel von rs4464148 bedingt eventuell auf Grund einer geringeren SMAD7-Induktion nach Bestrahlung - eine höhere Entzündungsneigung und geht somit mit einer erhöhten Akuttoxizität einher. Diese 
Entzündung könnte sich jedoch positiv auf die therapeutische Elimination der Tumorzellen auswirken. Starke radiogene Akutnebenwirkungen werden typischerweise mit einem besseren Ansprechen in Verbindung gebracht (Hennies et al. 2014; Wolff et al. 2010b; Wolff et al. 2013; Wolff et al. 2011a; Wolff et al. 2010a; Wolff et al. 2011b). Eventuell neigen Frauen stärker zu derartigen Entzündungsprozessen (Wolff et al. 2011c). Dies könnte eine Erklärung sein, warum der oben genannte Einfluss von SMAD7-Genpolymorphismen auf das Darmkrebsrisiko (Thompson et al. 2009) und die Effekte von anti-entzündlichen NSAIDs (Passarelli et al. 2011) möglicherweise bei Frauen stärker hervortreten. Beim LynchSyndrom, einer autosomal-dominanten Erberkrankung mit 80\% Penetranz zu kolorektalen Karzinomen, besteht offenbar kein Zusammenhang mit SMAD7-Genpolymorphismen (Talseth-Palmer et al. 2011).

\subsection{Kritische Betrachtung}

Dem Problem, durch eine große Zahl statistischer Tests entsprechend viele falsch positive Befunde zu erhalten, wurde durch die Aufteilung der Studienkohorte in ein Trainings- und Testset und ein damit verbundenes hierarchisches Vorgehen bei der Assoziationstestung begegnet. Dies bedingte notwendigerweise geringere Fallzahlen an Patienten in den beiden Teilkohorten. Dadurch erhöht sich die Wahrscheinlichkeit, dass sich Heterogenitäten in der auf subjektiver ärztlicher Einschätzung beruhenden klinischen Toxizitätsdokumentation stärker auswirken und die erhobenen Ergebnisse beeinflust haben könnten. Diese Dokumentation erstreckte sich über einen Zeitraum von mehreren Jahren mit wechselndem ärztlichem Personal. Unter diesem Gesichtspunkt war es ein Vorteil der Studie, dass sie an einem einzigen Studienort durchgeführt wurde. Eine allgemeine Anleitung zur Dokumentation war allen Beteiligen zugänglich, und weitestgehende Homogenität in der Durchführung der Radiochemotherapie kann angenommen werden.

Die Genotypisierung beschränkte sich auf ausgewählte Gene im TGFB-Signalweg. Eine Aussage über eine mögliche Bedeutung von Genpolymorphismen in anderen Genen dieses Signalwegs ist damit nicht möglich. Auch wenn bei den analysierten Genen die gesamte genetische Variabilität mit einer Mindestallelfrequenz von $5 \%$ erfasst wurde, so blieb doch eine große Zahl potenziell interessanter polymorpher Stellen mit einer geringeren Allelfrequenz unberücksichtigt.

Von klinischer Relevanz sind vor allem die schweren Toxizitätsgrade 3 und 4. Diese treten glücklicherweise vergleichsweise selten auf, stellen aber eine ernste Bedrohung für die betroffenen Personen dar. Für den mit 6,7 \% Allelfrequenz seltenen Arg25Pro- 
Polymorphismus im TGFB1-Gen wurde eine Assoziation mit klinischer Akuttoxizität $\geq^{\circ} 2$ beobachtet. Das Fehlen einer entsprechenden Assoziation mit Toxizitätsgraden $\geq^{0} 3$ ist angesichts der Kombination aus geringer Häufigkeit von Geno- und Phänotyp nicht erstaunlich. Zur Klärung, ob diese Genvariante auch mit den schweren Ausprägungen der Akuttoxizität verbunden ist, bedarf es eines weit größeren Stichprobenumfangs. Für die beiden anderen wesentlichen Befunde aus den Genotyp-Phänotyp-Analysen, den SNPs SMAD3-rs11856909 und SMAD7-rs4464148, waren bei einem deutlich häufigeren Vorkommens des jeweiligen Varianten-Allels Assoziation mit Akuttoxizitätsgraden $\geq 2$ und $\geq 3$ nachweisbar. Dies unterstreicht die mögliche klinische Relevanz dieser Ergebnisse.

Wenngleich die ex vivo-Simulation einer neodjuvanten Radiochemotherapie in Fibroblasten vielversprechende Zusammenhänge mit der klinischen Akuttoxizität aufzeigte, müssen diese Daten in Anbetracht von insgesamt 40 behandelten und auswertbaren Zelllinien als explorativ betrachtet werden. Interessant ist jedoch, dass der zuvor in der klinischen Assoziationsstudie identifizierte SMAD7-Genpolymorphismus auch mit dem Ausmaß der ex vivo-Induktion von SMAD7 nach Bestrahlung verbunden war. Dies stellt einen mechanistischen Ansatzpunkt zur Klärung der klinischen Beobachtung dar, der weitere Forschungsanstrengungen verdient.

\subsection{Ausblick}

Hinsichtlich der Perspektive einer Anwendung der Ergebnisse meiner Dissertation in der strahlentherapeutischen Behandlung sind weitere Untersuchungen, klinisch wie laborexperimentell, erforderlich.

Die beschriebenen Assoziationen sollten prospektiv in vergleichbaren Studienkollektiven überprüft werden. Prädiktive Biomarker für das Risiko schwerer radiogener Toxizitäten wären für die klinische Situation sehr wertvoll. Könnten besonders empfindliche Patienten im Vorfeld durch genetische Analysen erkannt werden, ließen sich therapiebedingte Schäden gegebenenfalls vermeiden (Diskussion von TherapiealteRNAtiven) oder zumindest mindern (intensive klinische Kontrolle und frühzeitig Einleitung supportiver Maßnahmen).

Mittels weiterführender funktioneller Analysen sollten die zu Grunde liegenden biologischen Mechanismen besser verstanden werden. Dies wäre im Hinblick auf eine mögliche zukünftige Beeinflussbarkeit dieser Prozesse sehr bedeutsam. Zu prüfende Hypothesen können auf Basis meiner Befunde bereits jetzt formuliert werden.

Die vorliegende Studie ist die erste, die eine klare Beziehung zwischen dem Arg25ProPolymorphismus und der Akuttoxizität einer neoadjuvanten Radiochemotherapie bei 
Rektumkarzionom demonstriert. Inwiefern das auch für andere Indikationen und Modalitäten einer Radio(chemo)therapie gilt, bleibt zu klären. Bei dieser Genvariante ist angesichts der Lokalisation in der Nähe der Spaltstelle im Signalpeptid eine qualitative - oder wahrscheinliche - quantitative Veränderung der Aktivität der Signalpeptidase denkbar. Diese könnte Auswirkungen auf die subzelluläre Dirigierung des TGF $\beta 1-$ Vorläuferproteins und den sezernierten TGF $\beta 1$-Anteil haben. Weiterführende Untersuchungen sollten auch beurteilen, welche der TGF $\beta 1$-Expression nachgeschalteten Faktoren vom Arg25Pro-Polymorphismus beeinflusst werden.

Der SMAD3-Polymorphismus rs11856909 ist im großen Intron 1 dieses Gen gelegen und es besteht ein hohes LD mit einer Reihe weiterer Genvarianten. Mögliche mechanistische Szenarien könnten z. B. eine unteschiedliche Bindung von Transkriptionsfaktoren, eine Beeinflussung von Splicing-Prozessen durch Veränderung der räumlichen Konfiguration der Verläufer-RNA oder eine differenzielle Modulation der Transkription nicht-kodierender RNA sein. Bei derartigen funktionellen Analysen wären ggf. auch die Genpolymorphismen in hohem LD mit rs11856909 zu berücksichtigen.

Der beobachtete Zusammenhang zwischen klinischer Akuttoxizität und verminderter SMAD7Induktion nach Bestrahlung ex vivo reiht sich in neuere Literaturberichte ein, denen zufolge SMAD7 eine protektive Wirkung gegenüber radiogenen Nebenwirkungen haben kann. Wenn es gelänge, die SMAD7-Expression unter Radiotherapie zu steigern, könnte ggf. die Toxizität verringert werden. Möglicherweise gibt es unter der Vielzahl der verfügbaren Medikamente die ein oder andere Substanz mit einer solchen Begleitwirkung. Dies könnte in einem ersten Schritt durch ein entsprechendes in vitro-Screening exploriert werden. Interessant wäre die Verabreichung eines derartigen Adjuanz während einer Radiotherapie insbesondere für Personen, welche - etwa bedingt durch ihre genetische Konstitution - unter Bestrahlung keine bzw. eine verzögerte SMAD7-Induktion aufweisen. Einen aussichtsreicheren Biomarker zur Identifikation solcher Personen stellt der in meiner Arbeit beschriebene SMAD7Polymorphismus rs 4464148 dar. 


\section{Zusammenfassung}

In Deutschland erkranken jährlich etwa 20.000 Personen neu an einem Rektumkarzinom. Nach aktuellem Standard wird bei Rektumkarzinomen im unteren und mittleren Drittel eine neoadjuvante Radiochemotherapie durchgeführt. Hierdurch wird eine exzellente lokale Kontrolle erreicht. Bei einigen Behandelten treten jedoch erhebliche Nebenwirkungen auf, wobei in meiner Dissertation der Fokus auf den in den bestrahlten Arealen beobachteten Akut- und Spättoxizitäten lag. Robuste Prädiktoren für das Risiko, derartige Nebenwirkungen zu erleiden, gibt es für diese klinische Situation bislang nicht. Als ein wichtiger Faktor für radiogene Toxizität wird der TGFB-Signalweg erachtet. Es wird vermutet, dass Variationen in Genen dieses Signalwegs wesentlich zur individuell variablen Strahlenempfindlichkeit beitragen. Ziel meiner Dissertation war die Identifizierung von Biomarkern, ererbten Keimbahn-Polymorphismen und Gentranskriptionsänderungen in sieben zentralen Genen dieses Signalwegs in Bezug auf akute und chronische Toxizitäten einer neoadjuvanten Radiochemotherapie bei Rektumkarzinom.

Die klinische Kohorte bestand aus 164 Personen, aufgeteilt in einen Trainingssatz von 88 und einen Testsatz von 76. Alle wiesen ein Rektumkarzinom mit einem Stadium von UICC II oder III auf. Akute (bis 90 Tage nach Radiochemotherapie) bzw. chronische Toxizitäten wurden als Proktitis, Enteritis, Zystitis und Dermatitis aus der klinischen Dokumentation entsprechend der Ausprägungsgrade 0-4 entnommen. An DNA aus peripherem Blut dieser Personen wurden insgesamt 74 Keimbahn-Polymorphismen analysiert. Diese repräsentieren die genetische Variabilität mit mindestens $5 \%$ Häufigkeit in der Allgemeinbevölkerung in den sieben Genen TGFB1, TGFBR1, TGFBR2, SMAD2, SMAD3, SMAD4 und SMAD7. Im Rahmen einer 12-tägigen Simulation der neoadjuvanten Radiochemotherapie (N-RCT) wurden an 48 von Patienten gewonnenen Fibroblastenlinien die Behandlungs-bedingten Effekte auf die Gentranskription der zuvor genannten sieben Gene quantifiziert.

Bei den Assoziationsanalysen mit den klinischen Daten konnten drei Marker identifiziert werden, welche das Risiko für eine mindestens mäßig ausgeprägte radiogene Akuttoxizität $\geq^{\circ} 2$ reproduzierbar und nach Adjustierung auf Alter, Geschlecht, Body-Mass-Index, Krankheitsstadium und Art der begleitenden Chemotherapie beeinflussten: Das Prolin-Allel von Arg25Pro im Signalpeptid von TGF $\beta 1$ sowie zwei intronische SNPs in SMAD3 (rs11856909) und SMAD7 (rs12967477). Hinsichtlich der klinisch besonders bedeutsamen schweren oder lebensbedrohlichen Akutreaktionen ( ${ }^{\circ} 3$ und $\left.{ }^{\circ} 4\right)$ fand sich ein Zusammenhang insbesondere mit dem genannten SMAD7-SNP (Odds ratio für Homozygotie des selteneren 
Allels gegenüber den anderen beiden Genotypkonfigurationen 6,3; $95 \%$-Konfidenzintervall 2,2-18,2; $P=0,001)$. Das Risiko für eine Spättoxizität hingegen war für keinen der untersuchten Genpolymorphismen statistisch signifikant verändert.

Bei der ex vivo simulierten $\mathrm{N}-\mathrm{RCT}$ in Fibroblasten fiel während der fünftägigen Bestrahlungsphase eine Induktion insbesondere des stimulatorischen SMAD2 und SMAD3 auf. Während der anschließenden Beobachtung über eine Woche normalisierten sich diese wieder weitgehend. Die Transkription des inhibitorischen SMAD7 begann während der Bestrahlung und nahm anschließend weiter zu. Je geringer die Induktion von SMAD7 am Ende der ex vivo-Bestrahlung war, desto stärker waren die Akuttoxizitäten der entsprechenden Patienten ausgeprägt.

Die Ergebnisse dieser Dissertation legen einen Einfluss genetischer und transkriptioneller Faktoren des TGF $\beta$-Signalwegs für die radiogene Akuttoxizität bei der N-RCT von Patienten mit Rektumkarzinom nahe. Besondere Bedeutung könnte dabei dem inhibitorischen SMAD7 zukommen; ein Zusammenhang mit der klinischen Akutreaktion zeigte sich hierbei sowohl für einen Keimbahn-Polymorphismus als auch für die Transkription unter ex vivoBestrahlung. Tatsächlich waren diese beiden Faktoren miteinander verknüpft, d. h. die Induktion von SMAD7 unter Bestrahlung war vom genannten SMAD7-SNP abhängig. Damit konnte durch funktionelle Untersuchungen eine zuvor beobachtete klinische Assoziation mit einem Genotyp bekräftigt werden. Dies lässt eine prospektive Studie vielversprechend erscheinen. In dieser wäre der Nutzen einer prätherapeutischen Genotypisierung der beschriebenen SMAD7-Genvariante, neben den beiden in TGF $\beta 1$ und SMAD3, zur Abschätzung der $\mathrm{zu}$ erwartenden Akuttoxizität $\mathrm{zu}$ prüfen. Weiterführende molekulargenetische Untersuchungen, z. B. mittels gezielter Manipulation der Transkription von SMAD7 bzw. dessen Monitoring unter Bestrahlung, könnten zur mechanistischen Klärung beitragen und eine Basis für zukünftige Interventionen bereitstellen. 


\section{Literaturverzeichnis}

Andreassen CN, Alsner J, Overgaard J, Herskind C, Haviland J, Owen R, Homewood J, Bliss J, Yarnold J (2005): TGFB1 polymorphisms are associated with risk of late normal tissue complications in the breast after radiotherapy for early breast cancer. Radiother Oncol $\underline{75}, 18$ 21

Andreassen CN, Alsner J, Overgaard M, Sorensen FB, Overgaard J (2006): Risk of radiationinduced subcutaneous fibrosis in relation to single nucleotide polymorphisms in TGFB1, SOD2, XRCC1, XRCC3, APEX and ATM--a study based on DNA from formalin fixed paraffin embedded tissue samples. Int J Radiat Biol $\underline{82}$, 577-86

Andreassen CN, Overgaard J, Alsner J (2013): Independent prospective validation of a predictive test for risk of radiation induced fibrosis based on the gene expression pattern in fibroblasts irradiated in vitro. Radiother Oncol $\underline{108}$, 469-72

Anscher MS, Thrasher B, Zgonjanin L, Rabbani ZN, Corbley MJ, Fu K, Sun L, Lee WC, Ling LE, Vujaskovic Z (2008): Small molecular inhibitor of transforming growth factor-beta protects against development of radiation-induced lung injury. Int $\mathbf{J}$ Radiat Oncol Biol Phys $\underline{71}, 829-37$

Aschele C, Friso ML, Pucciarelli S, Lonardi S, Sartor L, Fabris G, Urso ED, Del Bianco P, Sotti G, Lise M, Monfardini S (2005): A phase I-II study of weekly oxaliplatin, 5-fluorouracil continuous infusion and preoperative radiotherapy in locally advanced rectal cancer. Ann Oncol $\underline{16}, 1140-6$

Attisano L, Wrana JL (2002): Signal transduction by the TGF-beta superfamily. Science 296, $1646-7$

Awad MR, El-Gamel A, Hasleton P, Turner DM, Sinnott PJ, Hutchinson IV (1998): Genotypic variation in the transforming growth factor-betal gene: association with transforming growth factor-beta1 production, fibrotic lung disease, and graft fibrosis after lung transplantation. Transplantation $\underline{66}, 1014-20$

Barber JB, Burrill W, Spreadborough AR, Levine E, Warren C, Kiltie AE, Roberts SA, Scott D (2000): Relationship between in vitro chromosomal radiosensitivity of peripheral blood lymphocytes and the expression of normal tissue damage following radiotherapy for breast cancer. Radiother Oncol 포, 179-86

Barcellos-Hoff MH (1993): Radiation-induced transforming growth factor beta and subsequent extracellular matrix reorganization in murine mammary gland. Cancer Res $\underline{53}$, $3880-6$

Barcellos-Hoff MH, Dix TA (1996): Redox-mediated activation of latent transforming growth factor-beta 1. Mol Endocrinol 10, 1077-83

Barcellos-Hoff MH, Derynck R, Tsang ML, Weatherbee JA (1994): Transforming growth factor-beta activation in irradiated murine mammary gland. J Clin Invest $\underline{93}, 892-9$ 
BaRNArd JA, Beauchamp RD, Coffey RJ, Moses HL (1989): Regulation of intestinal epithelial cell growth by transforming growth factor type beta. Proc Natl Acad Sci U S A $\underline{86}$, 1578-82

Barnett GC, Elliott RM, Alsner J, Andreassen CN, Abdelhay O, Burnet NG, Chang-Claude J, Coles CE, Gutierrez-Enriquez S, Fuentes-Raspall MJ, Alonso-Munoz MC, Kerns S, Raabe A, Symonds RP, Seibold P, Talbot CJ, Wenz F, Wilkinson J, Yarnold J, Dunning AM, Rosenstein BS, West CM, Bentzen SM (2012): Individual patient data meta-analysis shows no association between the SNP rs1800469 in TGFB and late radiotherapy toxicity. Radiother Oncol 105, 289-95

Begg AC, Russell NS, Knaken H, Lebesque JV (1993): Lack of correlation of human fibroblast radiosensitivity in vitro with early skin reactions in patients undergoing radiotherapy. Int J Radiat Biol $\underline{64}$, 393-405

Blobe GC, Schiemann WP, Lodish HF (2000): Role of transforming growth factor beta in human disease. N Engl J Med $\underline{342}$, 1350-8

Border WA, Noble NA (1994): Transforming growth factor beta in tissue fibrosis. N Engl J Med 331, 1286-92

Borgmann K, Hoeller U, Nowack S, Bernhard M, Roper B, Brackrock S, Petersen C, Szymczak S, Ziegler A, Feyer P, et al. (2008): Individual radiosensitivity measured with lymphocytes may predict the risk of acute reaction after radiotherapy. Int J Radiat Oncol Biol Phys $\underline{71}, 256-64$

Bosset JF, Calais G, Daban A, Berger C, Radosevic-Jelic L, Maingon P, Bardet E, Pierart M, Briffaux A (2004): Preoperative chemoradiotherapy versus preoperative radiotherapy in rectal cancer patients: assessment of acute toxicity and treatment compliance. Report of the 22921 randomised trial conducted by the EORTC Radiotherapy Group. Eur J Cancer 40, 219-24

Bourton EC, Plowman PN, Zahir SA, Senguloglu GU, Serrai H, Bottley G, Parris CN (2012): Multispectral imaging flow cytometry reveals distinct frequencies of gamma-H2AX foci induction in DNA double strand break repair defective human cell lines. Cytometry A $\underline{81}$, $130-7$

Brock WA, Tucker SL, Geara FB, Turesson I, Wike J, Nyman J, Peters LJ (1995): Fibroblast radiosensitivity versus acute and late normal skin responses in patients treated for breast cancer. Int J Radiat Oncol Biol Phys $\underline{32}$, 1371-9

Brockmoller J, Tzvetkov MV (2008): Pharmacogenetics: data, concepts and tools to improve drug discovery and drug treatment. Eur J Clin Pharmacol 64, 133-57

Broderick P, Carvajal-Carmona L, Pittman AM, Webb E, Howarth K, Rowan A, Lubbe S, Spain S, Sullivan K, Fielding S, et al.(2007): A genome-wide association study shows that common alleles of SMAD7 influence colorectal cancer risk. Nat Genet 39, 1315-7

Calcagno AM, Chewning KJ, Wu CP, Ambudkar SV (2006): Plasma membrane calcium ATPase (PMCA4): a housekeeper for RT-PCR relative quantification of polytopic membrane proteins. BMC Mol Biol ㄱ, 29 
Chujo S, Shirasaki F, Kawara S, Inagaki Y, Kinbara T, Inaoki M, Takigawa M, Takehara K (2005): Connective tissue growth factor causes persistent proalpha2(I) collagen gene expression induced by transforming growth factor-beta in a mouse fibrosis model. $\mathrm{J}$ Cell Physiol 203, 447-56

Crawford SE, Stellmach V, Murphy-Ullrich JE, Ribeiro SM, Lawler J, Hynes RO, Boivin GP, Bouck N (1998): Thrombospondin-1 is a major activator of TGF-beta1 in vivo. Cell 93, 115970

Cunha SI, Pietras K (2011): ALK1 as an emerging target for antiangiogenic therapy of cancer. Blood 117, 6999-7006

Curtin K, Lin WY, George R, Katory M, Shorto J, Cannon-Albright LA, Bishop DT, Cox A, Camp NJ (2009): Meta association of colorectal cancer confirms risk alleles at 8q24 and 18q21. Cancer Epidemiol Biomarkers Prev 18, 616-21

Dai J, Gu J, Huang M, Eng C, Kopetz ES, Ellis LM, Hawk E, Wu X (2012): GWASidentified colorectal cancer susceptibility loci associated with clinical outcomes. Carcinogenesis $\underline{33}, 1327-31$

Damaraju S, Murray D, Dufour J, Carandang D, Myrehaug S, Fallone G, Field C, Greiner R, Hanson J, Cass CE, Parliament M (2006): Association of DNA repair and steroid metabolism gene polymorphisms with clinical late toxicity in patients treated with conformal radiotherapy for prostate cancer. Clin Cancer Res $\underline{12}$, 2545-54

De Jaeger K, Seppenwoolde Y, Kampinga HH, Boersma LJ, Belderbos JS, Lebesque JV (2004): Significance of plasma transforming growth factor-beta levels in radiotherapy for non-small-cell lung cancer. Int J Radiat Oncol Biol Phys $\underline{58}$, 1378-87

De Langhe S, De Ruyck K, Ost P, Fonteyne V, Werbrouck J, De Meerleer G, De Neve W, Thierens H (2013): Acute radiation-induced nocturia in prostate cancer patients is associated with pretreatment symptoms, radical prostatectomy, and genetic markers in the TGFbeta1 gene. Int J Radiat Oncol Biol Phys $\underline{85}$, 393-9

De Ruyck K, Van Eijkeren M, Claes K, Bacher K, Vral A, De Neve W, Thierens H (2006): TGFbeta1 polymorphisms and late clinical radiosensitivity in patients treated for gynecologic tumors. Int J Radiat Oncol Biol Phys $\underline{65}$, 1240-8

Densem CG, Hutchinson IV, Yonan N, Brooks NH (2004): Donor and recipient-transforming growth factor-beta 1 polymorphism and cardiac transplant-related coronary artery disease. Transpl Immunol $\underline{13}, 211-7$

Dent P, Yacoub A, Contessa J, Caron R, Amorino G, Valerie K, Hagan MP, Grant S, Schmidt-Ullrich R (2003): Stress and radiation-induced activation of multiple intracellular signaling pathways. Radiat Res $\underline{159}$, 283-300

Derynck R, Zhang YE (2003): Smad-dependent and Smad-independent pathways in TGFbeta family signalling. Nature $\underline{425}, 577-84$

Djuzenova CS, Muhl B, Fehn M, Oppitz U, Muller B, Flentje M (2006): Radiosensitivity in breast cancer assessed by the Comet and micronucleus assays. Br J Cancer 94, 1194-203 
Duncan MR, Frazier KS, Abramson S, Williams S, Klapper H, Huang X, Grotendorst GR (1999): Connective tissue growth factor mediates transforming growth factor beta-induced collagen synthesis: down-regulation by cAMP FASEB J $\underline{13}, 1774-86$

El-Gamel A, Awad MR, Hasleton PS, Yonan NA, Hutchinson JA, Campbell CS, Rahman AH, Deiraniya AK, Sinnott PJ, Hutchinson IV (1999): Transforming growth factor-beta (TGF-beta1) genotype and lung allograft fibrosis. J Heart Lung Transplant $\underline{18}$, 517-23

Feingold B, Brooks MM, Zeevi A, Ohmann EL, Burckart GJ, Ferrell RE, Chinnock R, Canter C, Addonizio L, Bernstein D, et al. (2012): Renal function and genetic polymorphisms in pediatric heart transplant recipients. J Heart Lung Transplant 31, 1003-8

Filonenko K: Molecular mechanisms of the TGF $\beta 1$ Arg25Pro polymorphism related to acute radiotherapy-induced toxicity. Med. Diss. Göttingen 2014

Flanders KC (2004): Smad3 as a mediator of the fibrotic response. Int J Exp Pathol 모, 47-64

Fleckenstein K, Zgonjanin L, Chen L, Rabbani Z, Jackson IL, Thrasher B, Kirkpatrick J, Foster WM, Vujaskovic Z (2007): Temporal onset of hypoxia and oxidative stress after pulmonary irradiation. Int J Radiat Oncol Biol Phys $\underline{68}$, 196-204

Gambichler T, Skrygan M, Tomi NS, Breuksch S, Altmeyer P, Kreuter A (2007): Significant downregulation of transforming growth factor-beta signal transducers in human skin following ultraviolet-A1 irradiation. Br J Dermatol $\underline{156}, 951-6$

Ge YZ, Wu R, Lu TZ, Jia RP, Li MH, Gao XF, Jiang XM, Zhu XB, Li LP, et al. (2014): Combined effects of TGFB1 +869 T/C and +915 G/C polymorphisms on acute rejection risk in solid organ transplant recipients: a systematic review and meta-analysis. PLoS One $\underline{9}$, e93938

Geara FB, Peters LJ, Ang KK, Wike JL, Brock WA (1993): Prospective comparison of in vitro normal cell radiosensitivity and normal tissue reactions in radiotherapy patients. Int $\mathbf{J}$ Radiat Oncol Biol Phys 27, 1173-9

Grainger DJ, Heathcote K, Chiano M, Snieder H, Kemp PR, Metcalfe JC, Carter ND, Spector TD (1999): Genetic control of the circulating concentration of transforming growth factor type beta1. Hum Mol Genet $\underline{8}, 93-7$

Guerra JL, Gomez D, Wei Q, Liu Z, Wang LE, Yuan X, Zhuang Y, Komaki R, Liao Z (2012): Association between single nucleotide polymorphisms of the transforming growth factor beta1 gene and the risk of severe radiation esophagitis in patients with lung cancer. Radiother Oncol 105, 299-304

Guhlich M: Genetische Determinanten in der Genese und Strahlentherapie des Prostatakarzinoms. Med Diss. Göttingen 2015

Guo Z, Binswanger U, Knoflach A (2002): Role of codon 10 and codon 25 polymorphisms on TGF-beta 1 gene expression and protein synthesis in stable renal allograft recipients. Transplant Proc 34, 2904-6 
Han G, Bian L, Li F, Cotrim A, Wang D, Lu J, Deng Y, Bird G, Sowers A, Mitchell JB, Gutkind JS, Zhao R, Raben D, ten Dijke P, Refaeli Y, Zhang Q, Wang XJ (2013): Preventive and therapeutic effects of Smad7 on radiation-induced oral mucositis. Nat Med 19, 421-8

Hayashi H, Abdollah S, Qiu Y, Cai J, Xu YY, Grinnell BW, Richardson MA, Topper JN, Gimbrone MA, Jr., et al. (1997): The MAD-related protein Smad7 associates with the TGFbeta receptor and functions as an antagonist of TGFbeta signaling. Cell $\underline{89}, 1165-73$

Haydont V, Riser BL, Aigueperse J, Vozenin-Brotons MC (2008): Specific signals involved in the long-term maintenance of radiation-induced fibrogenic differentiation: a role for CCN2 and low concentration of TGF-beta1. Am J Physiol Cell Physiol 294, C1332-41

Hennies S, Hermann RM, Gaedcke J, Grade M, Hess CF, Christiansen H, Wolff HA (2014): Increasing toxicity during neoadjuvant radiochemotherapy as positive prognostic factor for patients with esophageal carcinoma. Dis Esophagus 27, 146-51

Hoffmann A: Individuelle Strahlenreaktion in humanen Lymphozyten: Genexpressionsänderungen, Zytotoxizität und Modulation durch Zytokine. Med. Diss. Göttingen 2008

Hoskins JM, Ong PS, Keku TO, Galanko JA, Martin CF, Coleman CA, Wolfe M, Sandler RS, McLeod HL (2012): Association of eleven common, low-penetrance colorectal cancer susceptibility genetic variants at six risk loci with clinical outcome. PLoS One $\underline{7}$, e41954

http://www.krebsdaten.de; Zugriff am 15.06.2014

Huang J, Ding C, Chen X, He R, Chen N (2015): Association of TGF-beta1 -509C/T, $+869 \mathrm{~T} / \mathrm{C}$, and $+915 \mathrm{G} / \mathrm{C}$ polymorphisms with periodontitis susceptibility. Oral Dis $\underline{21}, 443-50$

Imaizumi N, Monnier Y, Hegi M, Mirimanoff RO, Ruegg C (2010): Radiotherapy suppresses angiogenesis in mice through TGF-betaRI/ALK5-dependent inhibition of endothelial cell sprouting. PLoS One $\underline{5}$, e11084

Itoh S, Itoh F, Goumans MJ, Ten Dijke P (2000): Signaling of transforming growth factorbeta family members through Smad proteins. Eur J Biochem 267, 6954-67

Janke JH: Bedeutung genetischer Variabilität im TGFB-Signalweg für Gentranskription, Proteinbildung und Zellvitalität: Untersuchungen zur Wirkung therapeutischer Strahlendosis und des TGFß1-Liganden. Med Diss. Göttingen 2009

Jobling MF, Mott JD, Finnegan MT, Jurukovski V, Erickson AC, Walian PJ, Taylor SE, Ledbetter S, Lawrence CM, Rifkin DB, Barcellos-Hoff MH (2006): Isoform-specific activation of latent transforming growth factor beta (LTGF-beta) by reactive oxygen species. Radiat Res $\underline{166}, 839-48$

Jones LA, Scott D, Cowan R, Roberts SA (1995): Abnormal radiosensitivity of lymphocytes from breast cancer patients with excessive normal tissue damage after radiotherapy: chromosome aberrations after low dose-rate irradiation. Int J Radiat Biol $\underline{67}, 519-28$

Karlsson G, Liu Y, Larsson J, Goumans MJ, Lee JS, Thorgeirsson SS, Ringner M, Karlsson S (2005): Gene expression profiling demonstrates that TGF-beta1 signals exclusively through 
receptor complexes involving Alk5 and identifies targets of TGF-beta signaling. Physiol Genomics $\underline{21}, 396-403$

Khalil MS, El Nahas AM, Blakemore AI (2005): Transforming growth factor-beta1 SNPs: genetic and phenotypic correlations in progressive kidney insufficiency Nephron. Exp Nephrol 101, e31-41

Kilis-Pstrusinska K, Mastalerz-Migas A, Zwolinska D, Grzeszczak W, Zachwieja K, Zachwieja J, Madziarska K, Hyla Klekot L (2015): The rs1800471 Polymorphism of TGFB1 Gene, Serum TGF-Beta1 Level and Chronic Kidney Disease Progression. Adv Exp Med Biol $\underline{833}, 37-46$

Kopp JB, Factor VM, Mozes M, Nagy P, Sanderson N, Bottinger EP, Klotman PE, Thorgeirsson SS (1996): Transgenic mice with increased plasma levels of TGF-beta 1 develop progressive renal disease. Lab Invest $\underline{74}$, 991-1003

Kruse JJ, Floot BG, te Poele JA, Russell NS, Stewart FA (2009): Radiation-induced activation of TGF-beta signaling pathways in relation to vascular damage in mouse kidneys. Radiat Res $\underline{171}, 188-97$

Li X, Yang XX, Hu NY, Sun JZ, Li FX, Li M (2011): A risk-associated single nucleotide polymorphism of SMAD7 is common to colorectal, gastric, and lung cancers in a Han Chinese population. Mol Biol Rep $\underline{38}$, 5093-7

Lopez E, Guerrero R, Nunez MI, del Moral R, Villalobos M, Martinez-Galan J, Valenzuela MT, Munoz-Gamez JA, Oliver FJ, Martin-Oliva D, Ruiz de Almodovar JM (2005): Early and late skin reactions to radiotherapy for breast cancer and their correlation with radiationinduced DNA damage in lymphocytes. Breast Cancer Res $\underline{7}$, R690-8

Lou JL, Chen ZJ, Wei J, He JL, Jin LF, Chen SJ, Zheng W, Xu SJ (2008): Response of lymphocytes to radiation in untreated breast cancer patients as detected with three different genetic assays. Biomed Environ Sci 21, 499-508

Machiels JP, Duck L, Honhon B, Coster B, Coche JC, Scalliet P, Humblet Y, Aydin S, Kerger J, Remouchamps V, et al. (2005): Phase II study of preoperative oxaliplatin, capecitabine and exteRNAl beam radiotherapy in patients with rectal cancer: the RadiOxCape study. Ann Oncol $\underline{16}, 1898-905$

Martin M, Lefaix JL, Pinton P, Crechet F, Daburon F (1993): Temporal modulation of TGFbeta 1 and beta-actin gene expression in pig skin and muscular fibrosis after ionizing radiation. Radiat Res $\underline{134}$, 63-70

Martin M, Vozenin MC, Gault N, Crechet F, Pfarr CM, Lefaix JL (1997): Coactivation of AP-1 activity and TGF-beta1 gene expression in the stress response of normal skin cells to ionizing radiation. Oncogene $\underline{15}, 981-9$

Massague J (1990): The transforming growth factor-beta family. Annu Rev Cell Biol $\underline{6}$, 597641

Martin M, Lefaix J, Delanian S (2000): TGF-beta1 and radiation fibrosis: a master switch and a specific therapeutic target?. Int J Radiat Oncol Biol Phys 47, 277-90 
Massague J (1998): TGF-beta signal transduction. Annu Rev Biochem 67, 753-91

Massague J (2000): How cells read TGF-beta signals. Nat Rev Mol Cell Biol 1, 169-78

Milliat F, Sabourin JC, Tarlet G, Holler V, Deutsch E, Buard V, Tamarat R, Atfi A, Benderitter M, Francois A (2008): Essential role of plasminogen activator inhibitor type-1 in radiation enteropathy. Am J Pathol 172, 691-701

Miyazono K, Kusanagi K, Inoue H (2001): Divergence and convergence of TGF-beta/BMP signaling. J Cell Physiol 187, 265-76

Moustakas A, Souchelnytskyi S, Heldin CH (2001): Smad regulation in TGF-beta signal transduction. J Cell Sci 114, 4359-69

Mumbrekar KD, FeRNAndes DJ, Goutham HV, Sharan K, Vadhiraja BM, Satyamoorthy K, Bola Sadashiva SR (2014): Influence of double-strand break repair on radiation therapyinduced acute skin reactions in breast cancer patients. Int J Radiat Oncol Biol Phys $\underline{88}, 671-6$

Munger JS, Harpel JG, Gleizes PE, Mazzieri R, Nunes I, Rifkin DB (1997): Latent transforming growth factor-beta: structural features and mechanisms of activation. Kidney Int $\underline{51}, 1376-82$

Nagtegaal ID, Gosens MJ, Marijnen CA, Rutten HJ, van de Velde CJ, van Krieken JH (2007): Combinations of tumor and treatment parameters are more discriminative for prognosis than the present TNM system in rectal cancer. J Clin Oncol 25, 1647-50

Nakao A, Afrakhte M, Moren A, Nakayama T, Christian JL, Heuchel R, Itoh S, Kawabata M, Heldin NE, Heldin CH, ten Dijke P (1997): Identification of Smad7, a TGFbeta-inducible antagonist of TGF-beta signalling. Nature $\underline{389}, 631-5$

Neumann M: Genetisch bedingte Variabilität der Expression von Genen des TGF $\beta$ Signalwegs und deren Bedeutung für die Zellvitalität: Untersuchungen in T-Lymphozyten, immortalisierten B-Lymphozyten und Fibroblasten. Med. Diss. Göttingen 2012

Niu N, Qin Y, Fridley BL, Hou J, Kalari KR, Zhu M, Wu TY, Jenkins GD, Batzler A, Wang L (2010): Radiation pharmacogenomics: a genome-wide association approach to identify radiation response biomarkers using human lymphoblastoid cell lines. Genome Res $\underline{20}, 1482-$ 92

Novakova-Jiresova A, Van Gameren MM, Coppes RP, Kampinga HH, Groen HJ (2004): Transforming growth factor-beta plasma dynamics and post-irradiation lung injury in lung cancer patients. Radiother Oncol 71, 183-9

Oppitz U, Baier K, Wulf J, Schakowski R, Flentje M (2001): The in vitro colony assay: a predictor of clinical outcome. Int J Radiat Biol 77, 105-10

Oppitz U, Schulte S, Stopper H, Baier K, Muller M, Wulf J, Schakowski R, Flentje M (2002): In vitro radiosensitivity measured in lymphocytes and fibroblasts by colony formation and comet assay: comparison with clinical acute reactions to radiotherapy in breast cancer patients. Int J Radiat Biol 푸, 611-6 
Osterreicher CH, Datz C, Stickel F, Hellerbrand C, Penz M, Hofer H, Wrba F, Penner E, Schuppan D, Ferenci P (2005): TGF-betal codon 25 gene polymorphism is associated with cirrhosis in patients with hereditary hemochromatosis. Cytokine $\underline{31}, 142-8$

Osterreicher CH, Halangk J, Berg T, Patsenker E, Homann N, Hellerbrand C, Seitz HK, Eurich D, Stickel F (2008): Evaluation of the transforming growth factor betal codon 25 (Arg-->Pro) polymorphism in alcoholic liver disease. Cytokine $\underline{42}, 18-23$

Ozsahin M, Crompton NE, Gourgou S, Kramar A, Li L, Shi Y, Sozzi WJ, Zouhair A, Mirimanoff RO, Azria D (2005): CD4 and CD8 T-lymphocyte apoptosis can predict radiation-induced late toxicity: a prospective study in 399 patients. Clin Cancer Res $\underline{11}$, 742633

Park SK, Kim J, Seomun Y, Choi J, Kim DH, Han IO, Lee EH, Chung SK, Joo CK (2001): Hydrogen peroxide is a novel inducer of connective tissue growth factor. Biochem Biophys Res Commun 284, 966-71

Passarelli MN, Coghill AE, Hutter CM, Zheng Y, Makar KW, Potter JD, Newcomb PA (2011): Common colorectal cancer risk variants in SMAD7 are associated with survival among prediagnostic nonsteroidal anti-inflammatory drug users: a population-based study of postmenopausal women. Genes Chromosomes Cancer 50, 875-86

Peters CA, Stock RG, Cesaretti JA, Atencio DP, Peters S, Burri RJ, Stone NN, Ostrer H, Rosenstein BS (2008): TGFB1 single nucleotide polymorphisms are associated with adverse quality of life in prostate cancer patients treated with radiotherapy. Int $\mathrm{J}$ Radiat Oncol Biol Phys $\underline{70}, 752-9$

Pittman AM, Naranjo S, Webb E, Broderick P, Lips EH, van Wezel T, Morreau H, Sullivan $\mathrm{K}$, Fielding S, Twiss P, et al. (2009): The colorectal cancer risk at $18 \mathrm{q} 21$ is caused by a novel variant altering SMAD7 expression. Genome Res $\underline{19}$, 987-93

$\mathrm{Pu}$ X, Wang L, Chang JY, Hildebrandt MA, Ye Y, Lu C, Skinner HD, Niu N, Jenkins GD, Komaki R, Minna JD, et al. (2014): Inflammation-related genetic variants predict toxicity following definitive radiotherapy for lung cancer. Clin Pharmacol Ther $\underline{96}$, 609-15

Randall K, Coggle JE (1995): Expression of transforming growth factor-beta 1 in mouse skin during the acute phase of radiation damage. Int J Radiat Biol $\underline{68}, 301-9$

Randall K, Coggle JE (1996): Long-term expression of transforming growth factor TGF beta 1 in mouse skin after localized beta-irradiation. Int J Radiat Biol $\underline{70}$, 351-60

Rao M, Guo D, Jaber BL, Tighiouart H, Pereira BJ, Balakrishnan VS (2004): Transforming growth factor-beta 1 gene polymorphisms and cardiovascular disease in hemodialysis patients. Kidney Int $\underline{66}, 419-27$

Reuther S, Szymczak S, Raabe A, Borgmann K, Ziegler A, Petersen C, Dikomey E, Hoeller U (2015): Association between SNPs in defined functional pathways and risk of early or late toxicity as well as individual radiosensitivity. Strahlenther Onkol 191, 59-66

Rieger KE, Hong WJ, Tusher VG, Tang J, Tibshirani R, Chu G (2004): Toxicity from radiation therapy associated with abnormal transcriptional responses to DNA damage. Proc Natl Acad Sci U S A $\underline{101}, 6635-40$ 
Roberts AB, Piek E, Bottinger EP, Ashcroft G, Mitchell JB, Flanders KC (2001): Is Smad3 a major player in signal transduction pathways leading to fibrogenesis?. Chest $\underline{120}$, 43S-47S

Rodel C, Sauer R (2007): Integration of novel agents into combined-modality treatment for rectal cancer patients. Strahlenther Onkol 183, 227-35

Rudat V, Dietz A, Nollert J, Conradt C, Weber KJ, Flentje M, Wannenmacher M (1999): Acute and late toxicity, tumour control and intrinsic radiosensitivity of primary fibroblasts in vitro of patients with advanced head and neck cancer after concomitant boost radiochemotherapy. Radiother Oncol 53, 233-45

Sanderson N, Factor V, Nagy P, Kopp J, Kondaiah P, Wakefield L, Roberts AB, Sporn MB, Thorgeirsson SS (1995): Hepatic expression of mature transforming growth factor beta 1 in transgenic mice results in multiple tissue lesions. Proc Natl Acad Sci U S A 92, 2572-6

Sanoff HK, Morris W, Mitcheltree AL, Wilson S, Lund JL (2015): Lack of Support and Information Regarding Long-Term Negative Effects in Survivors of Rectal Cancer. Clin J Oncol Nurs $\underline{19}$, 444-8

Sauer R, Becker H, Hohenberger W, Rodel C, Wittekind C, Fietkau R, Martus P, Tschmelitsch J, Hager E, Hess CF, et al. (2004): Preoperative versus postoperative chemoradiotherapy for rectal cancer. N Engl J Med 351, 1731-40

Sauer R, Liersch T, Merkel S, Fietkau R, Hohenberger W, Hess C, Becker H, Raab HR, Villanueva MT, Witzigmann H, et al. (2012): Preoperative versus postoperative chemoradiotherapy for locally advanced rectal cancer: results of the German CAO/ARO/AIO94 randomized phase III trial after a median follow-up of 11 years. J Clin Oncol $\underline{30}$, 1926-33

Scharpfenecker M, Kruse JJ, Sprong D, Russell NS, Ten Dijke P, Stewart FA (2009): Ionizing radiation shifts the PAI-1/ID-1 balance and activates notch signaling in endothelial cells. Int J Radiat Oncol Biol Phys $\underline{73}, 506-13$

Schirmer MA, Hoffmann AO, Campean R, Janke JH, Zidek LM, Hoffmann M, Kruse M, Sehrt D, Tzvetkov MV, Rave-Frank M, Brockmoller J (2009): Bioinformatic and functional analysis of TGFBR1 polymorphisms. Pharmacogenet Genomics 19, 249-59

Schirmer MA, Brockmoller J, Rave-Frank M, Virsik P, Wilken B, Kuhnle E, Campean R, Hoffmann AO, Muller K, Goetze RG, Neumann M, et al. (2011): A putatively functional haplotype in the gene encoding transforming growth factor beta-1 as a potential biomarker for radiosensitivity. Int J Radiat Oncol Biol Phys $\underline{79}$, 866-74

Schirmer MA, Mergler CP, Rave-Frank M, Herrmann MK, Hennies S, Gaedcke J, Conradi LC, Jo P, Beissbarth T, Hess CF, et al. (2012): Acute toxicity of radiochemotherapy in rectal cancer patients: a risk particularly for carriers of the TGFB1 Pro25 variant. Int J Radiat Oncol Biol Phys $\underline{83}, 149-57$

Schultze-Mosgau S, Blaese MA, Grabenbauer G, Wehrhan F, Kopp J, Amann K, Rodemann HP, Rodel F (2004): Smad-3 and Smad-7 expression following anti-transforming growth factor beta 1 (TGFbeta1)-treatment in irradiated rat tissue. Radiother Oncol $\underline{70}$, 249-59 
Sebag-Montefiore D, Stephens RJ, Steele R, Monson J, Grieve R, Khanna S, Quirke P, Couture J, de Metz C, Myint AS, et al. (2009): Preoperative radiotherapy versus selective postoperative chemoradiotherapy in patients with rectal cancer (MRC CR07 and NCIC-CTG C016): a multicentre, randomised trial. Lancet $\underline{373}, 811-20$

Slattery ML, Herrick J, Curtin K, Samowitz W, Wolff RK, Caan BJ, Duggan D, Potter JD, Peters U (2010): Increased risk of colon cancer associated with a genetic polymorphism of SMAD7. Cancer Res 70, 1479-85

Talseth-Palmer BA, Brenne IS, Ashton KA, Evans TJ, McPhillips M, Groombridge C, Suchy J, Kurzawski G, Spigelman A, Lubinski J, Scott RJ (2011): Colorectal cancer susceptibility loci on chromosome 8q23.3 and 11q23.1 as modifiers for disease expression in Lynch syndrome J Med Genet $\underline{48}, 279-84$

ten Dijke P, Hill CS (2004): New insights into TGF-beta-Smad signalling. Trends Biochem Sci $\underline{29}, 265-73$

Thompson CL, Plummer SJ, Acheson LS, Tucker TC, Casey G, Li L (2009): Association of common genetic variants in SMAD7 and risk of colon cancer. Carcinogenesis $\underline{30}, 982-6$

Twardella D, Popanda O, Helmbold I, Ebbeler R, Benner A, von Fournier D, Haase W, Sautter-Bihl ML, Wenz F, Schmezer P, Chang-Claude J (2003): Personal characteristics, therapy modalities and individual DNA repair capacity as predictive factors of acute skin toxicity in an unselected cohort of breast cancer patients receiving radiotherapy. Radiother Oncol $\underline{69}, 145-53$

van de Wetering J, Weimar CH, Balk AH, RooDNAt JI, Holweg CT, Baan CC, van Domburg RT, Weimar W (2006): The impact of transforming growth factor-betal gene polymorphism on end-stage renal failure after heart transplantation. Transplantation $\underline{82}, 1744-8$

Wang J, Zheng H, Sung CC, Richter KK, Hauer-Jensen M (1998): Cellular sources of transforming growth factor-beta isoforms in early and chronic radiation enteropathy. Am $\mathrm{J}$ Pathol $\underline{153}, 1531-40$

Widel M, Jedrus S, Lukaszczyk B, Raczek-Zwierzycka K, Swierniak A (2003): Radiationinduced micronucleus frequency in peripheral blood lymphocytes is correlated with normal tissue damage in patients with cervical carcinoma undergoing radiotherapy. Radiat Res $\underline{159}$, $713-21$

Wolff HA, Gaedcke J, Jung K, Hermann RM, Rothe H, Schirmer M, Liersch T, Herrmann MK, Hennies S, Rave-Frank M, et al. (2010a): High-grade acute organ toxicity during preoperative radiochemotherapy as positive predictor for complete histopathologic tumor regression in multimodal treatment of locally advanced rectal cancer. Strahlenther Onkol $\underline{186}$, $30-5$

Wolff HA, Bosch J, Jung K, Overbeck T, Hennies S, Matthias C, Hess CF, Roedel RM, Christiansen H (2010b): High-grade acute organ toxicity as positive prognostic factor in primary radio(chemo)therapy for locally advanced, inoperable head and neck cancer. Strahlenther Onkol 186, 262-8 
Wolff HA, Daldrup B, Jung K, Overbeck T, Hennies S, Matthias C, Hess CF, Roedel RM, Christiansen H (2011a): High-grade acute organ toxicity as positive prognostic factor in adjuvant radiation and chemotherapy for locally advanced head and neck cancer. Radiology 258, $864-71$

Wolff HA, Raus I, Jung K, Schuler P, Herrmann MK, Hennies S, Vorwerk H, Hille A, Hess $\mathrm{CF}$, Christiansen $\mathrm{H}$ (2011b): High-grade acute organ toxicity as a positive prognostic factor in primary radiochemotherapy for anal carcinoma. Int J Radiat Oncol Biol Phys $\underline{79}$, 1467-78

Wolff HA, Conradi LC, Schirmer M, Beissbarth T, Sprenger T, Rave-Frank M, Hennies S, Hess CF, Becker H, Christiansen H, Liersch T (2011c): Gender-specific acute organ toxicity during intensified preoperative radiochemotherapy for rectal cancer. Oncologist $\underline{16}, 621-31$

Wolff HA, Conradi LC, Beissbarth T, Leha A, Hohenberger W, Merkel S, Fietkau R, Raab HR, Tschmelitsch J, Hess CF, et al. (2013): Gender affects acute organ toxicity during radiochemotherapy for rectal cancer: long-term results of the German CAO/ARO/AIO-94 phase III trial. Radiother Oncol $\underline{108}, 48-54$

Xavier S, Piek E, Fujii M, Javelaud D, Mauviel A, Flanders KC, Samuni AM, Felici A, Reiss M, Yarkoni S, et al. (2004): Amelioration of radiation-induced fibrosis: inhibition of transforming growth factor-beta signaling by halofuginone. J Biol Chem $\underline{279}$, 15167-76

Yu L, Border WA, Huang Y, Noble NA (2003): TGF-beta isoforms in renal fibrogenesis. Kidney Int $\underline{64}, 844-56$

Zhang B, Jia WH, Matsuda K, Kweon SS, Matsuo K, Xiang YB, Shin A, Jee SH, Kim DH, Cai Q, et al. (2014): Large-scale genetic study in East Asians identifies six new loci associated with colorectal cancer risk. Nat Genet $\underline{46}, 533-42$

Zhang L, Yang M, Bi N, Ji W, Wu C, Tan W, Zhao L, Yu D, Lin D, Wang L (2010): Association of TGF-beta1 and XPD polymorphisms with severe acute radiation-induced esophageal toxicity in locally advanced lung cancer patients treated with radiotherapy. Radiother Oncol 97, 19-25

Zhao L, Sheldon K, Chen M, Yin MS, Hayman JA, Kalemkerian GP, Arenberg D, Lyons SE, Curtis JL, Davis M, et al. (2008): The predictive role of plasma TGF-beta1 during radiation therapy for radiation-induced lung toxicity deserves further study in patients with non-small cell lung cancer. Lung Cancer $\underline{59}, 232-9$

Zhu ML, Wang M, Shi TY, Li QX, Xi P, Xia KQ, Zheng L, Wei QY (2013): No association between TGFB1 polymorphisms and late radiotherapy toxicity: a meta-analysis. PLoS One $\underline{8}$, e76964

Zidek LM: Populationshäufigkeit und funktionelle Bedeutung angeborener Polymorphismen in den Genen des Transforming Growth Factor- $\beta 1$ (TGFB1) und dessen Rezeptoren. Diplomarbeit, Klinisch-pharmakolog. Diplomarbeit Göttingen 2005 


\section{Danksagung}

Ohne die Unterstützung und Hilfe von universitärer und familiärer Seite wäre mir die Ausarbeitung meiner Dissertation nicht möglich gewesen. Deshalb möchte ich an dieser Stelle allen danken, die mir bei der Bewältigung dieser Aufgabe zur Seite standen.

Mein Dank gilt Herrn Prof. Dr. med. J. Brockmöller, dem Leiter der Abteilung für Klinische Pharmakologie der Universität Göttingen, für die Überlassung des Themas und die Möglichkeit wissenschaftlichen Arbeitens in seiner Abteilung, ohne die diese Arbeit gar nicht möglich gewesen wäre.

Ganz herzlich möchte ich mich auch bei Herrn PD. Dr. med. Markus Schirmer bedanken, der mit seiner Bereitschaft zur ÜbeRNAhme der Betreuung und vielen wertvollen Anregungen und Tipps wesentlich zur Fertigstellung dieser Arbeit beigetragen hat. Seine beständige Diskussions- und Hilfsbereitschaft haben mir ebenso geholfen wie sein Zeitaufwand für das Korrekturlesen.

Der gesamten Arbeitsgruppe der Klinischen Pharmakologie danke ich für die Beratung und Hilfestellung bei der experimentellen Durchführung und die kooperative und immer freundschaftliche Arbeitsatmosphäre.

Nicht zuletzt darf ich mich auch bei der Abteilung für Strahlentherapie, hier insbesondere bei Frau Rave-Fränk, Frau Hoffmeister, Frau Karsten-Krapp und Frau Bitter, für ihre Unterstützung bei der experimentellen Arbeit, z. B. bei der Probengewinnung, Archivierung und Bestrahlung bedanken. Ihre Hilfestellung und freundliche Zusammenarbeit haben mir sehr geholfen. 


\section{Lebenslauf}

Ich wurde am 11.01.1984 als dritte Tochter der Eheleute Brunhilde Mergler (geb. Henrich) und Dipl. Phys.- Ing. Robert Mergler in Bad Soden geboren.

Von 1990 bis 1994 besuchte ich die Grundschule Westerbach in Eschborn. Danach wechselte ich auf das Gymnasium der St. Angela-Schule in Königstein i.Ts., wo ich 2003 das Abitur ablegte.

Im Herbst 2003 begann ich ein Physikstudium an der Technischen Universität in Darmstadt. Ein Jahr später entschied ich mich für ein Studium der Medizin und begann im Herbst 2004 das Studium der Zahnmedizin an der Goethe-Universität Frankfurt a. M.

Im Herbst 2006 wechselte ich zum Studium der Humanmedizin an die Georg-August Universität Göttingen. Im Jahr 2008 bestand ich erfolgreich das Physikum. Im Sommersemester 2010 begann ich meine Dissertation in der klinischen Forschergruppe KFO 179, gefördert durch ein Vollzeitstipendium der Universität Göttingen im Rahmen von „Gö4med“ während des Wintersemesters 2010/11 und ein studienbegleitendes Stipendium im Sommersemester 2011.

Von Februar 2012 bis Januar 2013 war ich als PJ-Studentin in den Abteilungen Innere Medizin, Radiologie und Strahlentherapie der Universität Göttingen, in der Inneren Medizin im Kantonsspital Altdorf in der Schweiz, in der Chirurgie des Kantonsspitals Aarberg in der Schweiz sowie in der Chirurgie im Universitätsklinikum Fort-de-France auf der Karibikinsel Martinique tätig.

Das Medizinstudium schloss ich im Juni 2013 mit dem Staatsexamen an der Georg-AugustUniversität Göttingen erfolgreich ab und erhielt meine Approbation als Ärztin.

Seit Dezember 2013 arbeitete ich - neben der Erstellung meiner Dissertationsschrift zunächst als Assistenzärztin für Radiologie im Universitätsklinikum Freiburg, ab September 2014 als Assistenzärztin der Inneren Medizin am St. Elisabethen-Krankenhaus Frankfurt und seit Juli 2015 als Assistenzärztin für Psychiatrie in der Asklepios-Klinik in Langen.

Inzwischen verheiratet, brachte ich im Mai 2016 eine Tochter zur Welt. 